PAULA NAOMI MUNIZ DOS SANTOS

\title{
AVALIAÇÃO DO COMPORTAMENTO DO TRÁFEGO EM VIAS COM VEÍCULOS AUTÔNOMOS E CONVENCIONAIS TRANSITANDO SIMULTANEAMENTE.
}

SÃO PAULO 


\title{
Avaliação do comportamento do tráfego em vias com veículos autônomos e convencionais transitando simultaneamente.
}

\author{
Dissertação apresentada à Escola \\ Politécnica da Universidade de São \\ Paulo, como requisito parcial para a \\ obtenção do título de Mestre em Ciências \\ Área de Concentração: Engenharia de \\ Sistemas Logísticos \\ Orientador: Prof. Livre-Docente João \\ Batista Camargo Junior
}

SÃO PAULO 
Autorizo a reprodução e divulgação total ou parcial deste trabalho, por qualquer meio convencional ou eletrônico, para fins de estudo e pesquisa, desde que citada a fonte.

Este exemplar foi revisado e corrigido em relação à versão original, sob responsabilidade única do autor e com a anuência de seu orientador.

São Paulo, de de

Assinatura do autor:

Assinatura do orientador:

\section{Catalogação-na-publicação}

dos Santos, Paula Naomi Muniz

Avaliação do comportamento do tráfego em vias com veículos autônomos e convencionais transitando simultaneamente / P. N. M. dos Santos -- versão corr. -- São Paulo, 2019.

$107 \mathrm{p}$.

Dissertação (Mestrado) - Escola Politécnica da Universidade de São Paulo. Departamento de Engenharia de Transportes.

1.Veiculos Autonomos 2.Simulacao I.Universidade de São Paulo. Escola Politécnica. Departamento de Engenharia de Transportes II.t. 


\section{AGRADECIMENTOS}

Agradeço aos meus familiares por sempre estarem ao meu lado e serem exemplos de pessoas que quero seguir. Também agradeço aos amigos que foram compreensíveis quando recusei todos os convites para me dedicar a este trabalho. Aos colegas do escritório, agradeço por me pouparem de trabalhar em alguns finais de semana para investir meu tempo nesta pesquisa.

E agradeço especialmente ao meu orientador Professor Livre-Docente João Batista, que em todas as vezes que eu desanimei e pensei em desistir (não foram poucas) conseguiu me encorajar e me fazer enxergar o caminho certo a seguir. Ao Lúcio Vismari, um agradecimento por todas as discussões que sempre agregaram muito valor à pesquisa. 


\section{RESUMO}

DOS SANTOS, P. N. M. Avaliação do comportamento do tráfego em vias com veículos autônomos e convencionais trafegando simultaneamente. 2019. $109 \mathrm{f}$. Tese (Mestrado) - Escola Politécnica, Universidade de São Paulo, São Paulo, 2019.

Apesar da expressiva quantidade de trabalhos relacionados aos veículos autônomos, poucos são aqueles encontrados sobre a coexistência de veículos autônomos e convencionais no sistema viário. O comportamento dos veículos autônomos é abordado majoritariamente visando analisar a tecnologia envolvida para a comunicação entre os veículos ou a segurança destes dispositivos. Desta forma, o objetivo da pesquisa é avaliar o impacto, do ponto de vista logístico, no comportamento do tráfego em vias com veículos convencionais e autônomos simultaneamente.

Através de simulação computacional utilizando ferramentas tradicionais e de código aberto, este trabalho analisa, como a inclusão crescente de veículos autônomos em algumas vias da malha viária da cidade de São Paulo afeta o comportamento dinâmico dos veículos. Cenários de tráfego foram modelados e considerados neste estudo, e sobre eles se concluiu, que a simples inserção de veículos autônomos no sistema não reflete na melhoria uniforme do tráfego, ou seja, algumas rotas, dependendo da sua extensão, volume de veículos e número de semáforos podem sofrer melhorias pouco representativas com relação à velocidade média, tempo de espera em fila e tempo médio de viagem.

Palavras-chave: veículos autônomos, simulação de tráfego viário. 


\begin{abstract}
DOS SANTOS, P. N. M. Evaluating of the behavior of the traffic in routes with autonomous and conventional vehicles traveling simultaneously. 2019. 109 p. Tese (Mestrado) - Escola Politécnica, Universidade de São Paulo, São Paulo, 2019.
\end{abstract}

Despite the abundance of research related to autonomous vehicles, few papers are found on the coexistence of autonomous and conventional. The behavior of the autonomous vehicles is often approached to analyze aspects such as the technology involved for the communication between the vehicles or the safety of these devices. This research has the objective of evaluating the impact, from the logistic point of view, of the traffic behavior in routes with conventional and autonomous vehicles simultaneously.

Through computer simulation using traditional and open source tools, this paper analyzes the dynamic behavior of vehicles, as the growing inclusion of autonomous vehicles in some of the streets of the city of São Paulo. Traffic scenarios were modeled and considered in this study, and it was concluded that the simple insertion of autonomous vehicles into the system does not reflect the uniform improvement of traffic, ie some routes, depending on their extension, traffic volume and number of traffic lights may undergo minor improvements in relation to the average speed, waiting time in queue and average travel time.

Key words: autonomous vehicles, traffic simulation 


\section{SUMÁRIO}

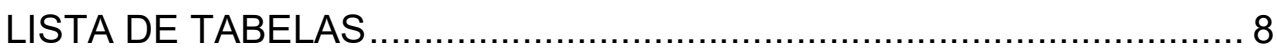

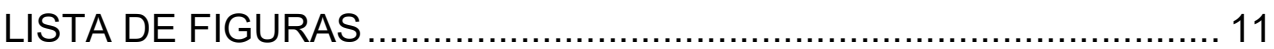

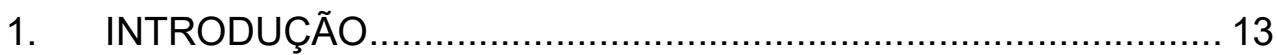

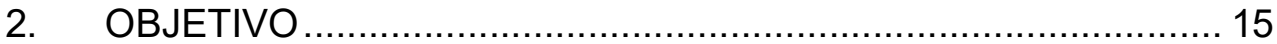

3. ESTADO DA ARTE ........................................................... 15

3.1 Possíveis vantagens dos veículos autônomos ......................... 18

3.2 Resiliência da malha logística ............................................ 23

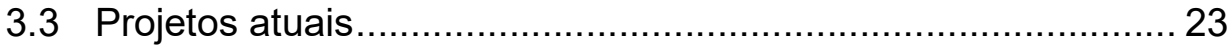

3.4 Adaptação da engenharia de tráfego nas cidades ................... 25

3.5 Simulação: definições e conceitos ....................................... 27

3.6 Modelos de simulação de tráfego de veículos........................ 29

3.7 Ambientes de simulação de tráfego .................................. 32

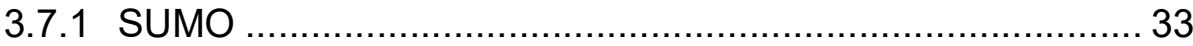

4. PROPOSTA DE MÉTODO DE AVALIAÇÃO DO IMPACTO DA INTRODUÇÃO DE VEÍCULOS AUTÔNOMOS ................................... 35

5. MODELO INICIAL DE ESTUDO ......................................... 40

5.1 Características dos veículos.......................................... 43

5.2 Cenários estudados ...................................................... 44

5.3 Resultados do modelo ...................................................... 46

5.3.1 Distâncias totais percorridas ....................................... 47 
5.3.2 Velocidade Média.

5.3.3 Tempo total dos veículos em filas

5.4 Avaliação dos resultados obtidos através do modelo inicial de estudo. 49

6. MODELO DE APROXIMAÇÃO DA REALIDADE ........................56

6.1 Características dos veículos.................................................... 70

6.2 Características dos cenários ................................................ 72

6.3 Resultados iniciais e calibração do modelo.............................. 72

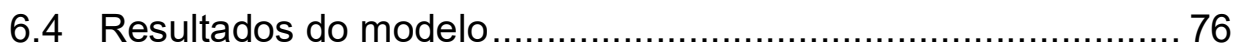

6.4.1 Velocidade Média......................................................... 76

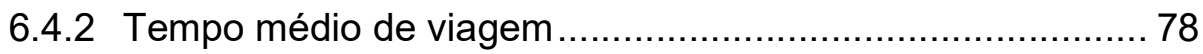

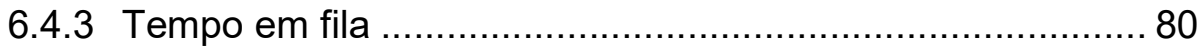

7. AVALIAÇÃo dos RESUltados do MODELO DE

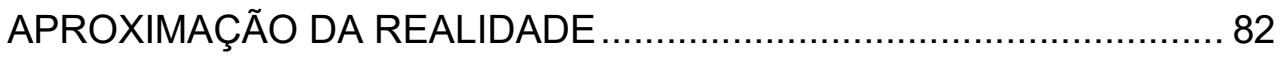

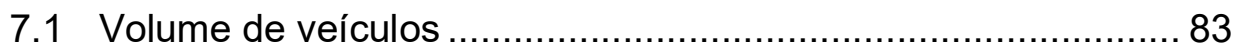

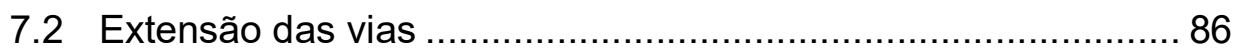

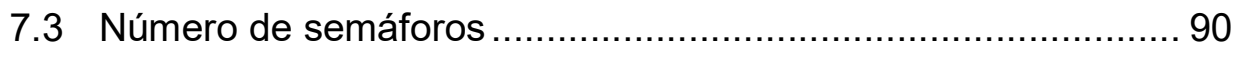

7.4 Análise detalhada entre os veículos do cenário Parcial ............ 94

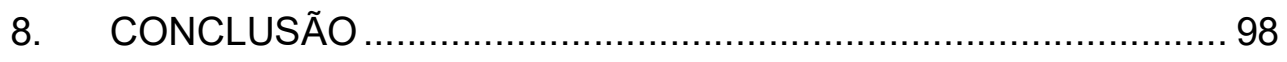

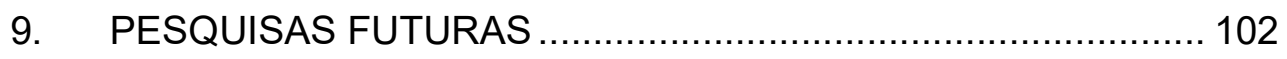

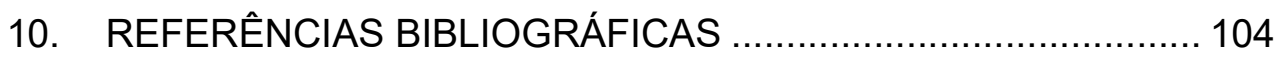




\section{LISTA DE TABELAS}

Tabela 1 - Níveis de automação de veículos ..................................... 16

Tabela 2 - Nomenclatura dos veículos .............................................. 42

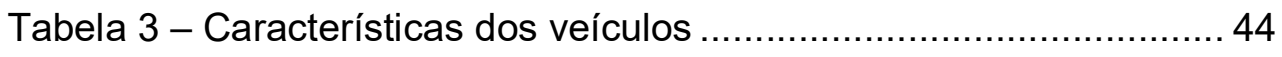

Tabela 4 - Caracterização dos cenários................................................... 46

Tabela 5 - Distância total percorrida [km] ......................................... 47

Tabela 6 - Velocidade média dos veículos $[\mathrm{km} / \mathrm{h}]$................................ 48

Tabela 7 - Tempo total de espera em fila [s] .......................................... 49

Tabela 8 - Melhores desempenhos por veículo .................................... 51

Tabela 9 - Piores desempenhos por veículo........................................... 52

Tabela 10 - Cenário com melhores desempenhos ................................ 54

Tabela 11 - Cenários com piores desempenhos ....................................5 55

Tabela 12 - Classificação geral dos cenários .......................................... 55

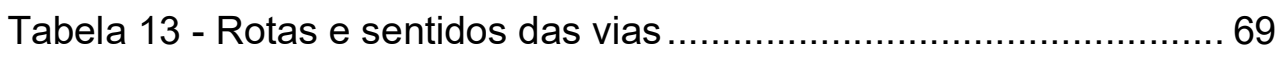

Tabela 14 - Número de veículos por rota.............................................. 71

Tabela 15 - Características fixas dos veículos...................................... 71

Tabela 16 - Parâmetros $\sigma$ e t dos veículos ............................................. 72

Tabela 17 - Cenários simulados ........................................................... 72

Tabela 18 - Número de veículos por cenário nos Sentidos 01 de cada via

Tabela 19 - Número de veículos por cenário nos Sentidos 02 de cada via

Tabela 20 - Ajuste do número de veículos por tipo e rota para Sentido

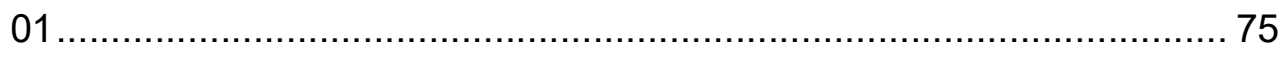


Tabela 21 - Ajuste do número de veículos por tipo e rota para Sentido 02. 76

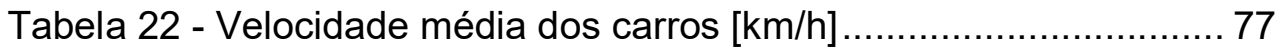

Tabela 23 - Velocidade média caminhões $[\mathrm{km} / \mathrm{h}]$............................78

Tabela 24 - Tempo médio de viagem dos carros por via [s] ...............79

Tabela 25 - Tempo médio de viagem dos caminhões por via [s] ..........8 80

Tabela 26 - Tempo médio dos carros em fila [s] ............................ 81

Tabela 27 - Tempo médio dos caminhões em fila [s] ......................... 82

Tabela 28 - Classificação das rotas por volume de veículos ................ 84

Tabela 29 - Comparação percentual das diferenças de velocidade média

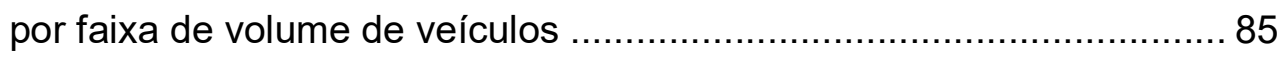

Tabela 30 - Comparação percentual das diferenças de tempo médio de viagem por faixa de volume de veículos ..................................... 85

Tabela 31 - Comparação percentual das diferenças de tempo médio em fila por faixa de volume de veículos ............................................ 86

Tabela 32 - Classificação das rotas por faixa de quilometragem.......... 87 Tabela 33 - Comparação percentual das diferenças de velocidade média

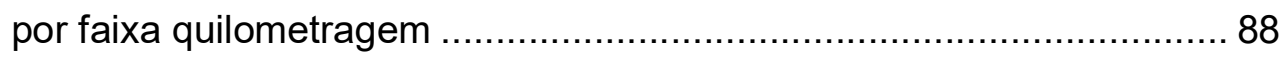

Tabela 34 - Comparação percentual das diferenças de tempo médio de

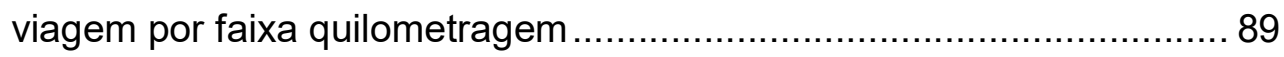
Tabela 35 - Diferença percentual do tempo médio em fila por faixa de

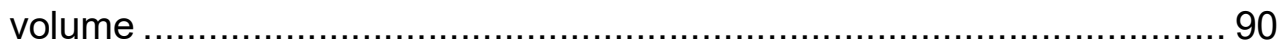

Tabela 36 - Classificação das rotas por número de semáforos ............. 91 Tabela 37 - Comparação percentual das diferenças de velocidade média por faixa de número de semáforos ........................................ 92 
Tabela 38 - Comparação percentual das diferenças de tempo médio de viagem por faixa de número de semáforos .................................. 93 Tabela 39 - Comparação percentual das diferenças de tempo médio em fila por faixa de número de semáforos ........................................ 93 Tabela 40 - Aumento da velocidade média no Sentido 1 de cada via ...95 Tabela 41 - Aumento da velocidade média no Sentido 2 de cada via ... 96 Tabela 42 - Redução do tempo médio de viagem no Sentido 1 de cada

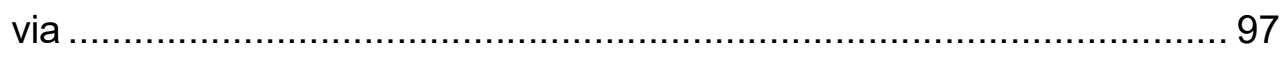
Tabela 43 - Redução do tempo médio de viagem no Sentido 2 de cada

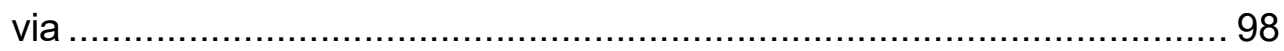




\section{LISTA DE FIGURAS}

Figura 1 - Tipos de conexão nas cidades .......................................... 18

Figura 2 - Formulação de um estudo de simulação e modelagem ....... 37

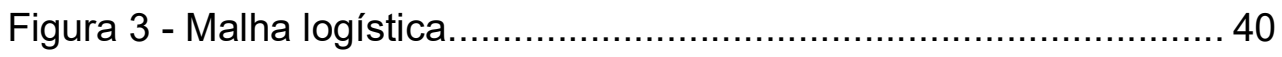

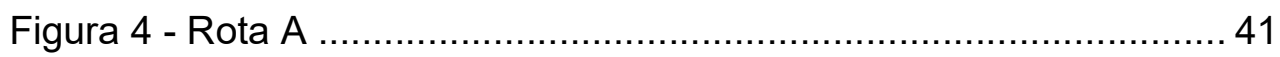

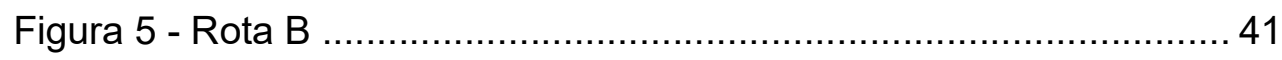

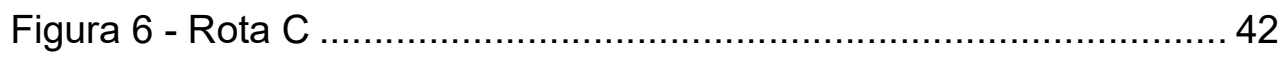

Figura 7 - Configuração das vias com todos os veículos....................... 43

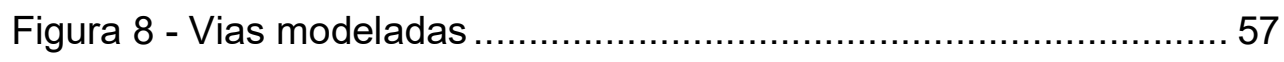

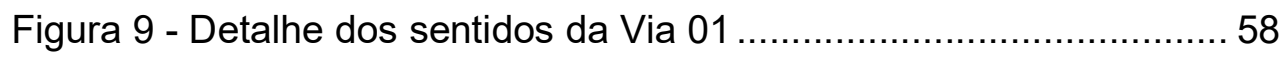

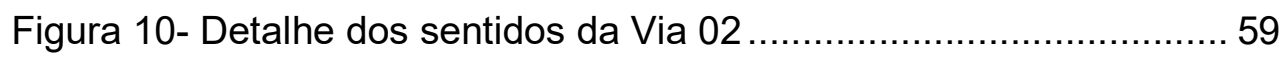

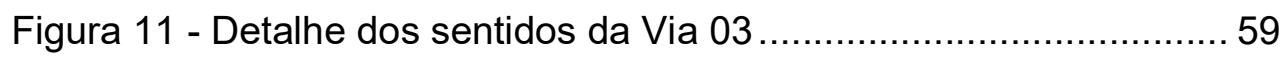

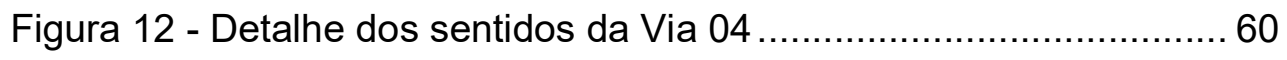

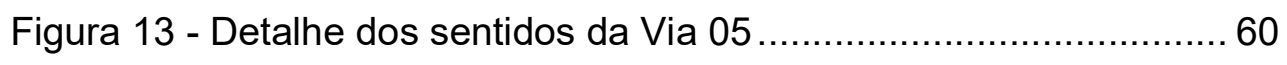

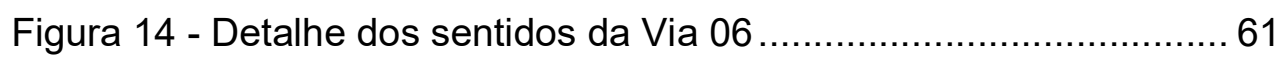

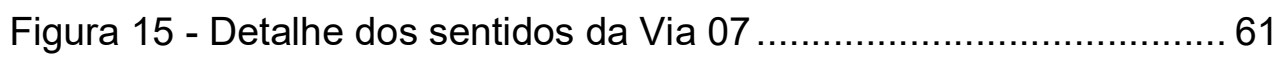

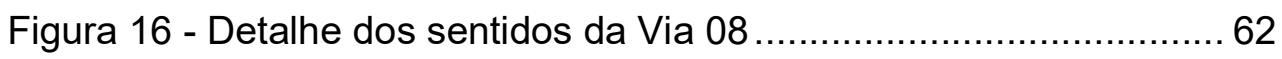

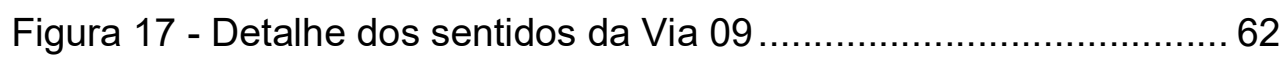

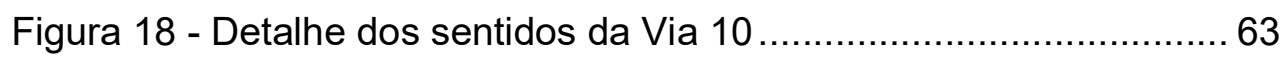

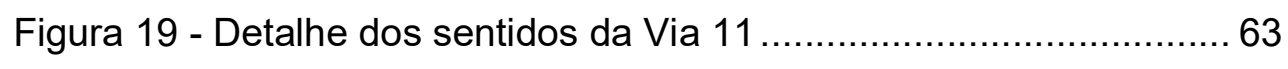

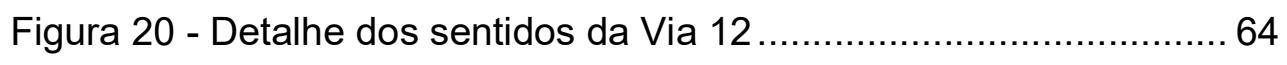

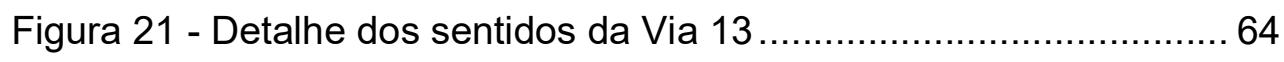

Figura 22 - Detalhe dos sentidos da Via 14 ……………...................... 65

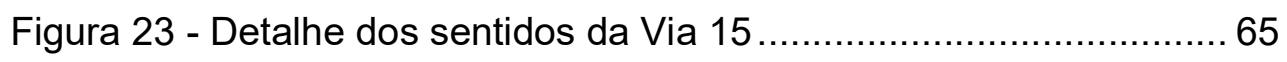

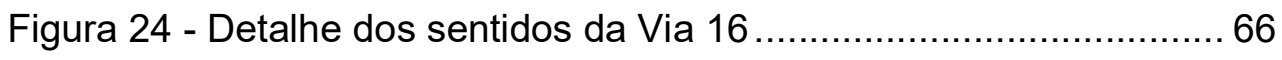




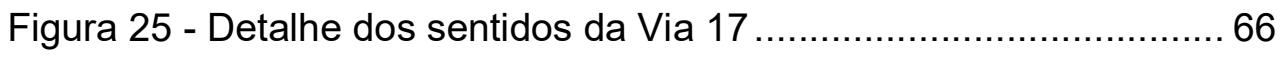

Figura 26 - Detalhe dos sentidos da Via 18 ....................................... 67

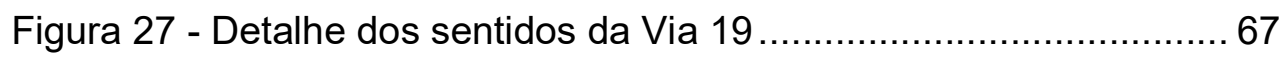

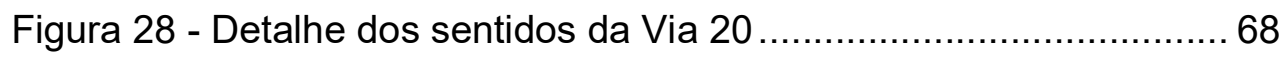

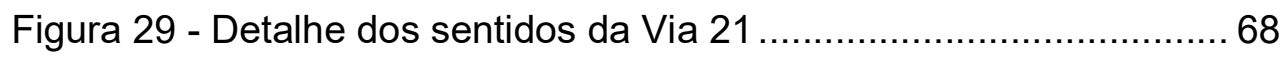

Figura 30 - Número de rotas por faixa de volume de veículos............... 83

Figura 31 - Número de rotas por faixa de quilometragem..................... 87

Figura 32 - Número de rotas por número de semáforos ........................ 91 


\section{INTRODUÇÃO}

Os seres humanos quase sempre imaginam cidades futuristas como um cenário onde os meios de transporte seriam inteligentes, não sendo necessário controle humano algum para que os veículos trafegassem em perfeita harmonia.

Inúmeras são as pesquisas sobre os carros autônomos atualmente. Diversos autores, como Schoettle e Sivak (2015), Azmat (2015), McGehee et al (2016), Surden e Williams (2016), acreditam que no futuro todos os veículos terão características autônomas, ou seja, serão aptos a trafegarem nas vias sem a interferência do controle humano. Os primeiros protótipos de veículos denominados autônomos já estão em testes em ambientes controlados.

Apesar da abundância de pesquisas relacionadas aos veículos autônomos, poucas são aquelas encontradas sobre a coexistência de veículos autônomos e convencionais. O comportamento dos veículos autônomos é abordado muitas vezes visando analisar aspectos como a tecnologia envolvida para a comunicação entre os veículos ou a segurança destes dispositivos. São poucos os trabalhos com objetivos de avaliar o desempenho logístico resultante da inserção gradual de veículos autônomos na malha viária atual com tráfego de veículos convencionais.

No capítulo 2 desta pesquisa é apresentado o objetivo a ser alcançado.

No capítulo 3 deste trabalho apresenta-se a revisão bibliográfica sobre veículos autônomos e simulação de sistemas. 
No capítulo 4 é apresentado o método proposto para avaliação do impacto da inserção dos veículos autônomos nos sistemas modelados, que consiste em 4 etapas: planejamento, modelagem, experimentação e conclusão.

Assim, primeiramente criou-se uma malha logística fictícia utilizada para verificação dos parâmetros definidos para a diferenciação das características dos veículos autônomos e convencionais. Este cenário fictício e a análise dos resultados dos cenários simulados nesta malha está apresentada, juntamente com a caracterização deste modelo, no capítulo 5 .

Como forma a aproximar os resultados a uma situação análoga à realidade, no capítulo 6 define-se um novo modelo de simulação. Neste novo ambiente, foram modeladas algumas das principais vias da região metropolitana da cidade de São Paulo. Os dados de volume de tráfego são baseados no Relatório de Mobilidade no Sistema Viário Principal (CET, 2017). Fez-se necessário uma calibração dos números de veículos em cada rota do modelo para que fosse possível realizar a comparação dos resultados de todos os cenários.

A avaliação dos resultados obtidos neste cenário é apresentada e discutida no capítulo 7. São comparados os resultados de velocidade média, tempo médio em fila e tempo médio de viagem sob as perspectivas de volume de veículos, extensão de vias e número de semáforos.

No capítulo 8 são discutidas as conclusões obtidas através das análises e comparações dos resultados dos cenários. 
Por fim, o capítulo 9 aborda temas pertinentes e que não foram possíveis tratar neste trabalho, apresentando sugestões para a continuidade da pesquisa.

\section{OBJETIVO}

A pesquisa tem como objetivo avaliar o impacto, do ponto de vista logístico, da introdução gradual de veículos autônomos no sistema viário em conjunto com os veículos convencionais.

Através de simulação computacional, a pesquisa analisa, do ponto de vista logístico, como a inclusão crescente de veículos autônomos no sistema viário convencional afeta o comportamento dinâmico do tráfego como um todo, incluindo os veículos convencionais. São considerados, para efeito de comparação, fatores como, tempo de viagem de cada veículo, distância percorrida, velocidade média e tempo médio em fila,

\section{ESTADO DA ARTE}

Surden e Williams (2016) definem que o conceito de equipamento autônomo pode ser aplicado aos sistemas controlados por computadores, que fazem escolhas decisivas sobre suas próprias ações, com pouca ou nenhuma interação humana. O exemplo mais simples de um sistema móvel autônomo são os aspiradores de pó automáticos. Estes aparelhos são pequenos equipamentos com rodas que são capazes de limpar ambientes evitando 
obstáculos cobrindo grandes áreas, sem a necessidade de instruções e direcionamento.

Assim, de acordo com Petterson e Karlsson (2015), veículos autônomos são aqueles que não necessitam de um condutor. Estes veículos possuem a capacidade de navegar, decidir, prever e agir de forma inteligente em situações habituais e críticas.

Para Azmat (2015), existem três fatores que determinam se um carro pode ou não ser considerado um veículo autônomo: navegabilidade inteligente, hardwares (câmeras e sensores) e inteligência artificial, para comunicação com um centro de controle e comando.

A Sociedade de Engenheiros Automotivos (SAE 2017) classifica os veículos autônomos em 6 diferentes categorias, de acordo com o nível de automação que possui, como mostra a Tabela 1:

Tabela 1 - Níveis de automação de veículos

\begin{tabular}{|c|c|}
\hline $\begin{array}{c}\text { Nível de } \\
\text { Automação }\end{array}$ & Descrição \\
\hline 0 & $\begin{array}{l}\text { O veículo não possui qualquer autonomia. O condutor do veículo é } \\
\text { o único responsável por todas as ações e decisões. }\end{array}$ \\
\hline 1 & $\begin{array}{l}\text { A automação está presente em apenas uma ou duas funções do } \\
\text { veículo, e este emite alertas e informações ao condutor. }\end{array}$ \\
\hline 2 & $\begin{array}{l}\text { O veículo possui algumas funções autônomas, mas o condutor } \\
\text { precisa estar atento a todas suas ações e as vias ao seu redor. }\end{array}$ \\
\hline 3 & $\begin{array}{c}\text { O veículo é conduzido pelo usuário mas não é necessária a } \\
\text { completa atenção às vias. O condutor toma o controle apenas em } \\
\text { situações de emergência, mas com um intervalo de tempo } \\
\text { suficiente para esta transição de controle. }\end{array}$ \\
\hline 4 & $\begin{array}{c}\text { O veículo é projetado para possuir autonomia para trafegar nas } \\
\text { cidades em condições favoráveis. O motorista pode ter a opção de } \\
\text { controlar o veículo manualmente. }\end{array}$ \\
\hline 5 & $\begin{array}{l}\text { O veículo é projetado para possuir total autonomia para trafegar nas } \\
\text { cidades mesmo em condições críticas. O usuário deverá apenas } \\
\text { informar o local de destino e não precisará tomar o controle do } \\
\text { veículo em nenhuma situação, a não ser que seja de seu desejo. }\end{array}$ \\
\hline
\end{tabular}


Os veículos e as cidades formarão juntos um ambiente cooperativo. Para isso, as cidades, consideradas aqui como a Infraestrutura (vias, radares, semáforos), e veículos possuirão três tipos de comunicação: Veículo com a cidade (V2I, Vehicle-2-Infrastructure), Veículo com Veículo (V2V, Vehicle-2-Vehicle) e Cidade com a Cidade (I2I, Infrastructure-2-Infrastructure).

A comunicação V2I permitirá, por exemplo, a redução do número existente de semáforos. Em movimento, os carros serão capazes de identificar sinais de obstáculos e canteiros de obras, por exemplo. Para escapar de congestionamentos, é previsto que o sistema integrado monitore todas as vias indicando quais possuem fluxo elevado de veículos e devem, portanto, serem evitadas.

Em serviços como os de emergência (ambulâncias e carros de bombeiros), o sistema integrado de tráfego informará aos demais veículos que a via deverá ser liberada para atender às emergências.

Já a comunicação V2V possibilitará aos carros a previsão dos seus movimentos que compartilham a mesma via. Assim, as mudanças de velocidade e faixa, frenagens e acelerações serão mais suaves, desgastando menos o sistema de freios dos veículos e requerendo menos a utilização de combustível.

A comunicação I2I será responsável pela transmissão de dados entre: sensores distribuídos ao longo das vias (RSU, Roadside Unit), semáforos, satélites (utilizados nos Sistemas de Posicionamento Global, GPS, por exemplo) e torres de controle. 
A Figura 1, exemplifica estes tipos de conexão nas cidades.

Figura 1 - Tipos de conexão nas cidades

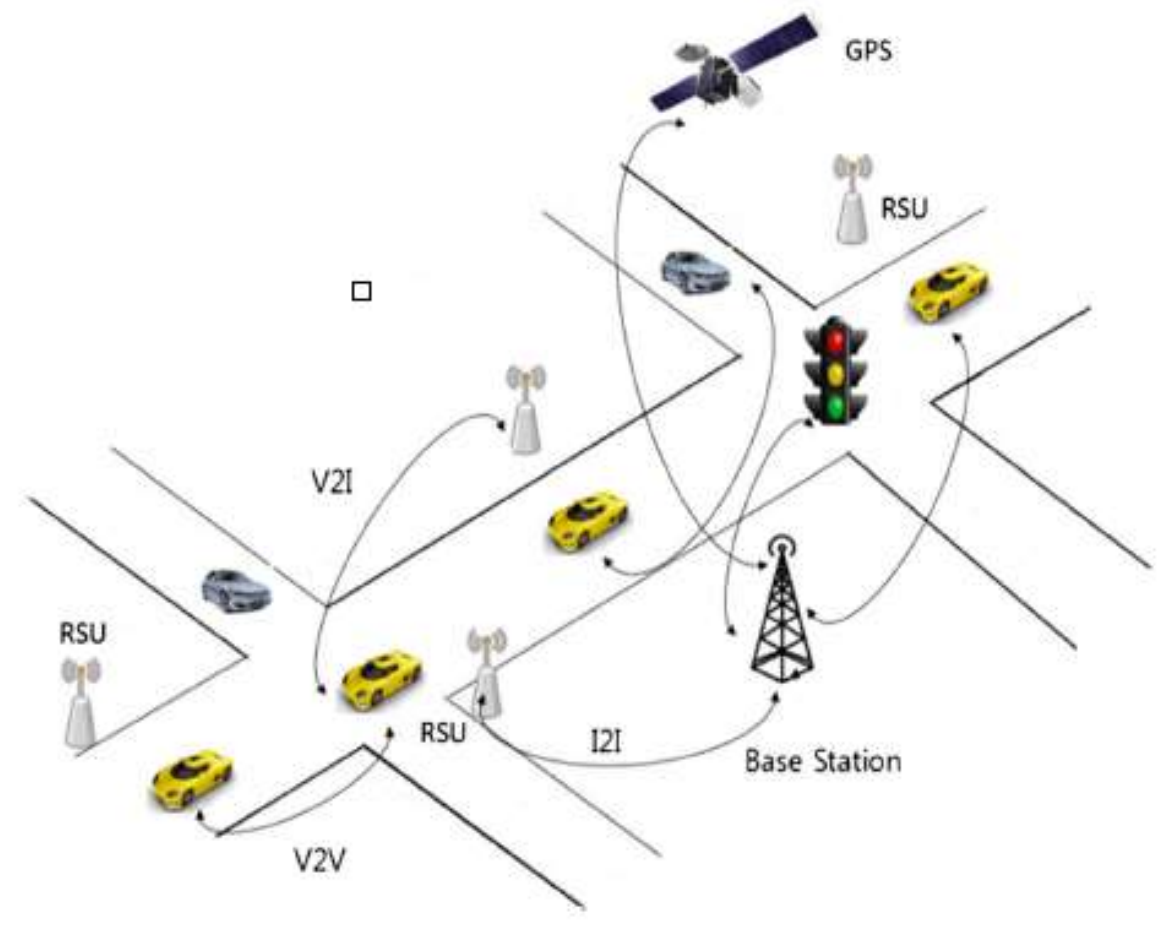

Fonte: Daniel et al (2015)

A grande motivação para o desenvolvimento e pesquisas no campo de veículos autônomos é a possibilidade de redução de congestionamentos nas vias das cidades, maior seguridade nas viagens e possibilidade de locomoção de pessoas inaptas a conduzirem um veículo (idosos e pessoas com deficiência).

\subsection{Possíveis vantagens dos veículos autônomos}

O tamanho estimado do mercado de veículos autônomos em 2015 era de 31 bilhões de euros, de acordo com a Comissão Europeia (2015). Tanto investimento financeiro, científico e industrial para o tema de veículos 
autônomos justifica-se pelas possibilidades de melhorias que estes veículos potencialmente podem ocasionar.

- Redução no congestionamento: Congestionamentos formam-se quando a demanda de veículos excede a capacidade projetada para as vias. Estes engarrafamentos são causadores de problemas em pelo menos três aspectos sociais, de acordo com pesquisadores da Renault (2014):

- Entre 60 e 80 horas perdidas por ano por motorista, com base nos dados de trafego das maiores cidades da Europa e Estados Unidos;

- Relatos de cansaço e stress dos motoristas;

- Gasto de energia de aproximadamente 16 bilhões de litros de gasolina nos Estados Unidos e Europa.

- Aumento da segurança no trânsito: Sivak e Schoettle (2015) através de suas pesquisas, concluíram que a expectativa de extinguir totalmente os acidentes fatais no trânsito é, na prática, utópica. No entanto, é certo que os acidentes seriam reduzidos, pois, por exemplo, motoristas com idade avançada, não dependeriam de seus reflexos para desviar de obstáculos ou reduzir a velocidade em alguma situação necessária. Além disso, os veículos autônomos dispõem de tecnologia avançada de sensores e câmeras e conseguem desviar de grandes buracos na pista e grandes obstáculos.

Os estudos de Sivak e Schoettle (2015) também revelam que no período de transição, quando veículos autônomos e convencionais compartilharem as vias, a segurança dos carros convencionais poderá ser prejudicada. Por exemplo, em muitas situações os motoristas fazem contato visual com os 
outros motoristas e tomam suas decisões baseadas na resposta deste "feedback". Como nos veículos autônomos do Nível 4 não precisam de motoristas no seu interior para realizar uma viagem, este contato não existirá podendo causar incertezas.

- Aumento da mobilidade urbana: Schoettle (2015) sugere que uma potencial consequência dos veículos autônomos será o crescimento da mobilidade urbana, considerando que os indivíduos inaptos a dirigir poderão ser usuários dos veículos autônomos sem restrição.

- Redução da emissão de gases poluentes: Chen et al. (2016) afirmam que existe uma sinergia natural entre as tecnologias aplicadas nos veículos autônomos e a substituição dos combustíveis fósseis, principal fonte de energia dos veículos convencionais.

A emissão de gases poluentes será então minimizada através de duas maneiras: carros totalmente independentes de combustíveis fósseis, ou redução no consumo destes combustíveis por meio da otimização do mecanismo dos motores a combustão dos veículos.

De acordo com Azmat (2015), nos carros convencionais, 40\% da gasolina é utilizada apenas nas tarefas de encontrar vagas de estacionamento em zonas urbanas. Com os veículos autônomos, este percentual seria drasticamente reduzido, uma vez que, o carro terá inteligência para detectar a localização das vagas disponíveis mais próximas.

Além disso, os veículos autônomos serão aptos a desenvolver uma velocidade constante nas vias, não exigindo a queima desnecessária de combustível para troca de marcha e acelerações e frenagens desnecessárias. 
- Transporte de cargas: apesar da maior parte dos estudos estar focada no transporte de passageiros, alguns pesquisadores concentram seus esforços no transporte de cargas. Maurer et al (2016), relembra que os primeiros robôs condutores foram desenvolvidos para operarem em situações de risco ou em ambientes inacessíveis.

A companhia mineradora Rio Tinto utiliza, desde outubro de 2015, veículos autônomos para o transporte em duas minas de minérios de ferro localizadas na Austrália. De acordo com Harding (2015), a produtividade desta nova frota apresenta a vantagem de $12 \%$ em relação ao desempenho da frota tradicional, que utiliza motoristas, devido à eliminação de pausas requeridas, absenteísmos, e mudanças de marcha. Um dos principais problemas no transporte de cargas são as leis trabalhistas, que exigem, por exemplo, um número mínimo de horas de descanso por dia. Como na utilização de veículos autônomos os motoristas não são necessários, os veículos podem fazer os percursos programados sem interrupções, aumentando a produtividade da tarefa. Além disso, automatizar as atividades nas mineradoras implica em menos trabalhadores presentes no local, garantindo maior segurança.

Maurer et al. (2016) também descrevem as operações de uma grande empresa na Alemanha que implantou um sistema autônomo de caminhões para transferência de contêineres entre os blocos de produção e de logística numa companhia de lacticínios. Os caminhões possuem sensores na parte inferior do reboque, e são guiados por marcações na pista.

Também, o transporte de carga pode ser favorecido pela redução do consumo de combustível. De acordo com Schank (2012), como os veículos 
terão a capacidade de prever o movimento dos demais que compartilham as vias, as distâncias entre veículos serão reduzidas, diminuindo também a resistência do ar e os tempos de viagem, uma vez que as rodovias terão maiores capacidades.

- Transporte público: Panter (2018) acredita que com o uso de ônibus autônomos para transporte público não existirão mais paradas fixas para embarque e desembarque de passageiros. Os passageiros poderão agendar, através dos seus dispositivos de celular, o horário e rota que necessitam. Com estes dados, algoritmos de escalonamento irão agrupar os passageiros com horários e rotas compatíveis para a roteirização completa das viagens.

Além disso, o custo de motoristas, cobradores, fiscais, mecânicos e administração que representam $43 \%$ dos custos de operação de transporte público, conforme Martins (2017), poderiam ser reduzidos. Panter (2018) então acredita que ao tirar estes custos, as empresas de ônibus terão uma operação mais rentável.

De acordo com a Trapeze Group (2018) a operação do Trapizio, ônibus movido a energia elétrica e totalmente autônomo que entrou em operação em março de 2018 na cidade de Neuhausen am Rheinfall, Suíca, é o primeiro ônibus autônomo integrado no controle de operações de transporte público, e é monitorado conjuntamente com os veículos tradicionais. A AMoTech, empresa responsável pela tecnologia dos pequenos ônibus, afirma que até dezembro de 2018 mais de 20mil passageiros utilizaram o serviço dos veículos autônomos. 


\subsection{Resiliência da malha logística}

O conceito de resiliência de redes de transporte mostra-se pertinente, já que a automação dos veículos propiciará alterações drásticas no transporte, afirma Miller-Hooks et al (2012).

Khan et al (2016) classifica o conceito de resiliência de redes de transporte em duas categorias: resiliência inerente, que diz respeito às vias e sistemas de controle; e resiliência dinâmica, referindo-se às medidas dinâmicas que aumentam a capacidade das vias (desvio do fluxo de veículos de uma área congestionada, por exemplo).

As medidas de resiliência que podem ser beneficiadas pelos avanços tecnológicos dos veículos autônomos são listadas por Khan et al (2016):

- Resiliência inerente: tráfego e vias com flexibilidade para comportar sobrecargas e evitar congestionamentos; centros inteligentes de controle de trânsito com capacidade de comunicação com os veículos.

- Resiliência dinâmica: roteirização baseado no trafego atual de veículos nas vias; transição para a normalidade do trafego após alguma perturbação emergente do sistema estabelecendo estratégias para acontecimentos futuros.

\subsection{Projetos atuais}

Atualmente, o mais popular projeto de carro autônomo é, provavelmente, o Google Car. De acordo com Hamilton (2015), em abril de 2014 o veículo havia percorrido mais de 1,1 milhões de quilômetros sem se envolver em nenhum acidente. Em maio de 2015, o veículo esteve envolvido em 11 pequenos acidentes depois de 1,6 milhões de quilômetros rodados. 
No ano de 2017, a GM lançou o componente Super Cruise para o Cadillac CTS que combina a tecnologia ACC (Adaptive Cruise Control), capaz de controlar a aceleração e parada dos veículos com a Line Following (tecnologia com a qual é possível um equipamento mover-se ao longo de um percurso marcado com uma linha central). Em 2020 a Cadillac (2018) pretende expandir a tecnologia para todos os veículos da linha.

Desde outubro de 2015 a Toyota (2015) faz testes com um modelo modificado do modelo Lexus GS e equipado com uma tecnologia a bordo para trafegar autonomamente em rodovias e vias expressas. O condutor do veículo pode acionar a função autônoma ao passar por um pedágio de acesso às rodovias. Com esta tecnologia ativa, o carro avalia as condições do trânsito e toma decisões como trocar de faixas ou reduzir/aumentar a velocidade. A Toyota prevê que os modelos de carros autônomos estarão disponíveis no mercado a partir de 2020 .

Com um protótipo equipado com sensores, câmeras e um campo de ultrassom, as equipes da Nissan e Renault (2014) estão juntas desenvolvendo o projeto Next Two. Além de trafegar autonomamente nas vias, o veículo também é capaz de fazer manobras para estacionar. A grande motivação do projeto é, além de garantir uma sociedade com menor ocorrência de acidentes, proporcionar um aumento na qualidade de vida dos motoristas possibilitando que tenham tempo livre para descansar ou participar de conferências telefônicas enquanto estão no trânsito.

Tratando de veículos de grande porte, a Scania (2016) desenvolve projetos com foco inicialmente nas operações de mineradoras, portos e 
terminais de cargas, por trafegarem em ambientes restritos e mais controlados que a cidade. Assim como os projetos de carros autônomos, a previsão de comercialização de caminhões autônomos está estimada para 2020.

\subsection{Adaptação da engenharia de tráfego nas cidades}

Para que todas essas mudanças ocorram e este cenário seja concretizado, as cidades precisarão se adaptar. De acordo com Schank (2012), além dos investimentos em infraestrutura e melhorias operacionais, as leis que regulamentam o trânsito deverão ser revisitadas, a fim de incorporar estes novos tipos de veículos. Questões legais complexas de responsabilidades, privacidade e regulamento de seguros devem ser revistas.

Maurer et al (2016) concluíram que, como os veículos autônomos poderão trafegar em uma velocidade constante, será possível reduzir a área destinada ao tráfego nas vias, limitando por exemplo, o número de faixas destinadas aos veículos. Estas faixas poderão ser utilizadas para incentivar o uso de meio alternativos, como bicicletas, por exemplo.

Maurer et al. (2016) também afirmam que os veículos autônomos poderão ainda alterar a forma como o solo é utilizado nas cidades. Por exemplo, grandes áreas para estacionamentos poderão ser substituídas por ciclovias ou calçadas maiores para pedestres, ou por parques e edifícios.

Os pedestres também sentirão uma diferença ao caminharem nas ruas quando todos os veículos forem substituídos pelos autônomos. Maurer et al (2016) afirma que serão necessárias passarelas por cima ou por baixo das vias de maior movimento, uma vez que os semáforos não serão mais necessários para controlar o trânsito de veículos, que se comunicarão entre eles. 
Segundo Bose e loannou (2003), a introdução dos veículos autônomos no mercado ocorrerá de forma gradual, assim como foi com a inclusão da tecnologia dos freios $A B S$, air-bags e computadores de bordo.

As incertezas em torno do futuro dos veículos autônomos fazem com que o planejamento das cidades seja uma tarefa complexa. McGehee (2016) aponta como questionáveis, os seguintes aspectos:

- Capacidade das vias: as vias terão menor capacidade devido ao comportamento menos assertivo nas interseções que não possuem semáforos (as incertezas são em torno da prioridade de locomoção: pedestres e veículos convencionais terão prioridade de locomoção?) ou mais assertivo devido à possibilidade de menor espaçamento entre os veículos, tempos de reação reduzidos nas saídas dos semáforos, fluxos harmônicos e menores ocorrências de acidentes.

- Condição da pavimentação: maior desgaste, pois os veículos poderão escolher passar pelas melhores rotas (rotas mais curtas ou com maiores velocidades permitidas, por exemplo) na escolha entre todos os caminhos possíveis, ou menor desgaste já que os veículos irão se movimentar sem bruscas mudanças de velocidade e poderão desviar de deficiências já existentes nos pavimentos.

- Distância total percorrida por veículo: aumento da distância total, como consequência do custo reduzido das viagens em comparação com outros modais, acarretando na possibilidade de existirem viagens mais longas ou até mesmo veículos trafegando sem ocupantes (por exemplo, caso um indivíduo utilize um carro autônomo para ir ao trabalho, após 
chegar ao destino, o veículo volta sozinho para a residência, para ficar à disposição de outros membros da família); ou diminuição das distâncias viajadas, considerando que o compartilhamento de veículos seria mais eficiente e atrativo.

As incertezas indicadas por McGehee (2016) reforçam os apontamentos levantados por Khan et al (2016) sobre a necessidade de pesquisas com foco na resiliência das malhas viárias para superar vulnerabilidades, evitando interrupções no tráfego e reduzindo a gravidade dos impactos, caso venham a existir.

Como mencionado anteriormente, a tecnologia de veículos autônomos também poderá ser utilizada nos transportes de carga. Se por um lado afirmouse que existe a possibilidade de redução de combustível devido ao menor espaçamento entre veículos e menor resistência do ar; por outro, de acordo com Schank (2012), isto pode significar um inconveniente para os veículos que tentam entrar ou sair das rodovias, sendo necessário então, repensar a infraestrutura de rodovias e até mesmo pesquisar um material para pavimentação mais resistente para suportar o tráfego intenso destes veículos pesados.

\subsection{Simulação: definições e conceitos}

O processo de simulação, de acordo com Carvalho (2003) consiste na técnica de criar modelos que representem a realidade para testar diferentes situações sem a necessidade de se alterar efetivamente o ambiente real. Chwif e Medina (2006) esclarecem que existem dois grandes tipo de simulação: a 
computacional e a não computacional. A simulação computacional é a utilização de técnicas matemáticas empregadas em computadores para reproduzir o comportamento de praticamente qualquer tipo de operação ou processo real. Por outro lado, protótipos em escala reduzida podem ser considerados como simulações não computacionais, por não dependerem de um computador para serem realizadas.

Freitas Filho (2008) declara que a resolução de problemas através da simulação computacional permite ao pesquisador a facilidade de alterar as condições do sistema para verificação dos diferentes resultados do modelo, sem desordenar a lógica computacional construída. Ou seja, é possível obter respostas rápidas a perguntas do tipo "E se?" sem a necessidade de alterações nos sistemas de operações reais.

A facilidade na geração de cenários (variações "E se?") e a eficiência dos ambientes de desenvolvimento computacionais, faz com que a técnica de simulação popularize-se na resolução de problemas práticos organizacionais, conforme constatado por Lobão e Porto (1999)

Kelton (2002) classifica os sistemas de simulação como:

- Dinâmico ou estático: esta classificação está relacionada com o comportamento do modelo em relação ao tempo. Os sistemas dinâmicos representam alterações no estado do sistema ao longo do tempo; já os sistemas estáticos não apresentam nenhuma alteração vinculada ao tempo.

- Determinísticos ou estocásticos: esta classificação relaciona-se com os dados de entrada do sistema. Os modelos que não fazem uso de variáveis aleatórias são determinísticos. Os modelos estocásticos possuem 
uma ou mais variáveis aleatórias. As entradas com dados aleatórios levam a respostas aleatórias, e os resultados de um sistema determinístico serão sempre os mesmos para o mesmo conjunto de dados de entrada.

- Discretos ou contínuos: evolução do sistema no tempo. Se o sistema evolui continuamente no tempo, ele é classificado como contínuo. Caso ele se altere somente em pontos discretos no tempo, classifica-se como discreto.

Já para Freitas Filho (2008), os sistemas de simulação são classificados de acordo com seus propósitos:

- Modelos voltados à previsão: aplicados para prever o comportamento do sistema em um tempo futuro.

- Modelos voltados à investigação: utilizados para auxiliar na criação de hipóteses sobre o comportamento do sistema.

- Modelos voltados à comparação: usados para analisar as consequências da troca nas variáveis do sistema.

\subsection{Modelos de simulação de tráfego de veículos}

As complexas interações dos sistemas de transporte podem ser traduzidas de forma relativamente descomplicadas para os ambientes de simulação disponíveis atualmente no mercado. 
Além da diferenciação em relação à tratativa do tempo da simulação, Parivasi (2006) determina três níveis de detalhamento de modelos de simulação possíveis:

- Modelo microscópico

Este modelo simula a característica de deslocamento dos veículos individualmente.

A modelagem de veículos individualizados permite a diferenciação de características como aceleração, velocidade máxima, tamanhos para cada entidade e troca de faixa (lane-change).

As interações entre os veículos são baseadas no modelo "car-following". Esta modelagem é fundamentada no conceito de que um veículo segue o outro. Assim, as ações do veículo à frente da fila influenciam nas ações do veículo que o segue. Simplificadamente, caso o primeiro veículo reduza sua velocidade, os carros que o seguem responderão com uma desaceleração, por exemplo.

Com este modelo é possível observar os aspectos de apenas um veículo, como o progresso temporal (tempo), o espaço entre os demais veículos (distância) e velocidade.

Pelo nível de detalhamento, veículo a veículo, este modelo requer recursos computacionais mais complexos do que os necessários para os demais modelos. 
- Modelo macroscópico

Simula o fluxo de tráfego considerando um conjunto de veículos, e não cada veículo independentemente. Como o comportamento de cada unidade individual é irrelevante, este modelo apresenta um baixo nível de detalhamento.

A análise das relações de tráfego como um todo possibilita o estudo das limitações da capacidade das vias e das ocorrências que provocam pontos de engarrafamento nas mesmas.

As grandezas que podem ser analisadas neste tipo de modelo são: volume de tráfego (número de veículos que passam por um trecho de via), densidade de tráfego (distribuição dos veículos em um trecho de via) e velocidade média.

- Modelo mesoscópico

Apesar de alguns pesquisadores não considerarem este como um modelo diferente do modelo macroscópico, outros, como Silva (2007) afirma que existem diferenças nas formulações teóricas. As vias, por exemplo, são modeladas em duas zonas: livre para circular, onde os veículos não sofrem atrasos por causa de um congestionamento; e zona enfileirada, onde ficam os veículos que não conseguiram deixar a via por consequência de algum obstáculo.

É muito utilizado em estudos de coordenação de semáforos e dos atrasos que eles causam. 


\subsection{Ambientes de simulação de tráfego}

A principal diferença dos simuladores de trafego em comparação com os simuladores de propósito geral é a possibilidade de configuração de uma malha viária e dos veículos que circularão pelas vias de maneira simplificada. A facilidade destas tarefas dá-se pela existência de "bibliotecas" pré-definidas nestes simuladores.

Existem inúmeros simuladores de trânsito disponíveis no mercado. Além dos projetados para fins comerciais, como o VISSIM e AIMSUN, existem simuladores desenvolvidos especificadamente para pesquisas acadêmicas, como o SUMO e o ITSUMO.

Apesar da superioridade dos softwares comerciais nos que diz respeito à interface amigável, facilidade de interação, manuais e tutoriais (HALLMANN, 2011), a gratuidade dos softwares acadêmicos e a possibilidade de modificação das suas funcionalidades por terem código fonte aberto garantem o desempenho necessário para a elaboração de pesquisas. A possibilidade de realizar modificações no programa e liberar estas alterações para toda a comunidade acadêmica é um grande atrativo, pois o software passa por constantes atualizações e melhorias, sempre se renovando.

Entre os dois softwares acadêmicos disponíveis para a realização da pesquisa, o SUMO apresenta vantagens em relação ao ITSUMO no que diz respeito a recursos mais maduros, comunidade mais ampla para discussões e maior abrangência de usuários e aplicações. O ITSUMO ainda se mostra um software novo que ainda necessita de casos de sucesso para sua consolidação no mercado (HALLMANN, 2011). 
Para o desenvolvimento desta pesquisa, o software SUMO (Simulation of Urban MObility) foi o escolhido, por ser um programa voltado para o ambiente acadêmico, possuir licença aberta, linguagem de programação relativamente simples e modelagem para simulação contínua e microscópica de trânsito, além de já estar sendo utilizado por outras pesquisas dentro do GAS - Grupo de Análise de Segurança da Escola Politécnica da Universidade de São Paulo.

\subsubsection{SUMO}

EM 2001, o Instituto de Sistemas de Transporte alemão (DLR) iniciou o desenvolvimento do SUMO (Simulation of Urban MObility).

Os inputs e outputs do software são arquivos em formato .xml. Todas as configurações do sistema (vias, veículos, restrições, fluxos etc) e os relatórios de resultados são realizados em arquivos separados. Os desenvolvedores optaram pela utilização de linhas de comando, visando à velocidade nas simulações.

O SUMO utiliza a modelagem car-following desenvolvida por Krauss (1998) para determinar a velocidade dos veículos no sistema. Nesta modelagem, a velocidade dos veículos é definida considerando a premissa de que não existe colisão entre os veículos. Assim, a velocidade segura, é a máxima velocidade que o veículo pode trafegar sem atingir o veículo à frente e é dada pela seguinte equação:

$$
v_{\text {segura }}(t)=v_{l}(t)+\frac{g(t)-v_{l}(t) \tau}{\left(\frac{\bar{v}}{b(\bar{v})}\right)+\tau}
$$


Onde:

$v_{l}(t)$ : velocidade do veículo líder no instante $t[\mathrm{~m} / \mathrm{s}]$

$g(t)$ : espaço entre o veículo perseguidor e o veículo líder no instante $t$ [m]

T: tempo de reação do motorista [s]

$\bar{v}:$ velocidade média $[\mathrm{m} / \mathrm{s}] b:$ taxa de desaceleração do veículo $\left[\mathrm{m} / \mathrm{s}^{2}\right]$

A velocidade desejada é o mínimo valor entre: a velocidade segura, a velocidade máxima permitida na via e a velocidade que o veículo é capaz de atingir de acordo com a sua taxa de aceleração.

$$
v_{\text {desejada }}(t)=\min \left\{v_{\text {segura }}(t), v_{\text {máx }}, v(t-1)+a\right\}
$$

Onde:

a: aceleração do veículo $\left[\mathrm{m} / \mathrm{s}^{2}\right]$

Assumindo que o condutor não é perfeito para manter a velocidade desejada, a velocidade final do veículo é dada pela equação:

$$
v(t)=\max \left\{0, \text { aleatório }\left[v_{\text {desejada }}(t)-\sigma . a, v_{\text {desejada }}(t)\right]\right\}
$$

Onde:

$\sigma:$ imperfeição do motorista

Ou seja, a velocidade final do veículo será o máximo valor entre a velocidade desejada pura, a velocidade desejada aplicando o fator de imperfeição do motorista, e zero para garantir que a velocidade não tenha valores negativos. 
Este parâmetro retrata a imperfeição do motorista no sentido de não alcançar e manter a velocidade máxima como constante, assim como ocorre com os motoristas reais.

\section{PROPOSTA DE MÉtOdo de AVALIAÇÃo do IMPACTO DA INTRODUÇÃO DE VEÍCULOS AUTÔNOMOS}

Como método de avaliação utiliza-se a técnica de simulação visando a análise do impacto logístico, sobre diversos aspectos, da introdução crescente de veículos autônomos no sistema de tráfego convencional e possíveis adaptações na engenharia de tráfego visando um maior desempenho e segurança.

O método de avaliação proposto nesta pesquisa refere-se à utilização de um modelo contínuo, determinístico e microscópico de trafego, desenvolvido por meio do simulador de tráfego SUMO (2019), para criar uma malha logística e estudar seu comportamento com diferentes configurações de veículos convencionais e autônomos trafegando simultaneamente.

Inicialmente foram desenvolvidos cenários preliminares para a pesquisa. Estes cenários de investigação foram incrementados em função dos resultados obtidos pela pesquisa e dos desafios que surgiram em função da complexidade do problema em questão. Posteriormente, o cenário foi alterado para um mais complexo em relação ao número e configuração das vias e volume de veículos para aproximação da realidade. 
Todos os cenários foram executados com a mesma configuração de vias de sentido único e número de intersecções. Cada veículo terá a mesma rota pré-definida em todos os cenários. Dentro deste panorama, o primeiro cenário a ser analisado é o correspondente a $100 \%$ da frota convencional (cenário atual). Os demais cenários serão configurados para alterar gradualmente 0 percentual de veículos autônomos, até atingir $100 \%$ de autonomia. A pesquisa não entra no contexto de segurança, focando-se apenas nos aspectos. Os veículos autônomos são configurados para terem uma menor distância em relação ao veículo adiante. Todos os veículos são configurados para respeitarem a ordem das filas nas intersecções.

O método de avaliação proposto neste trabalho de pesquisa é composto por uma série de etapas que se baseiam num processo de simulação, ou seja, a denominada metodologia de simulação. Freitas Filho (2008) aborda a metodologia clássica para formulação do estudo envolvendo modelagem e simulação segmentada em 4 etapas, conforme apresentado na Figura 2. 
Figura 2 - Formulação de um estudo de simulação e modelagem

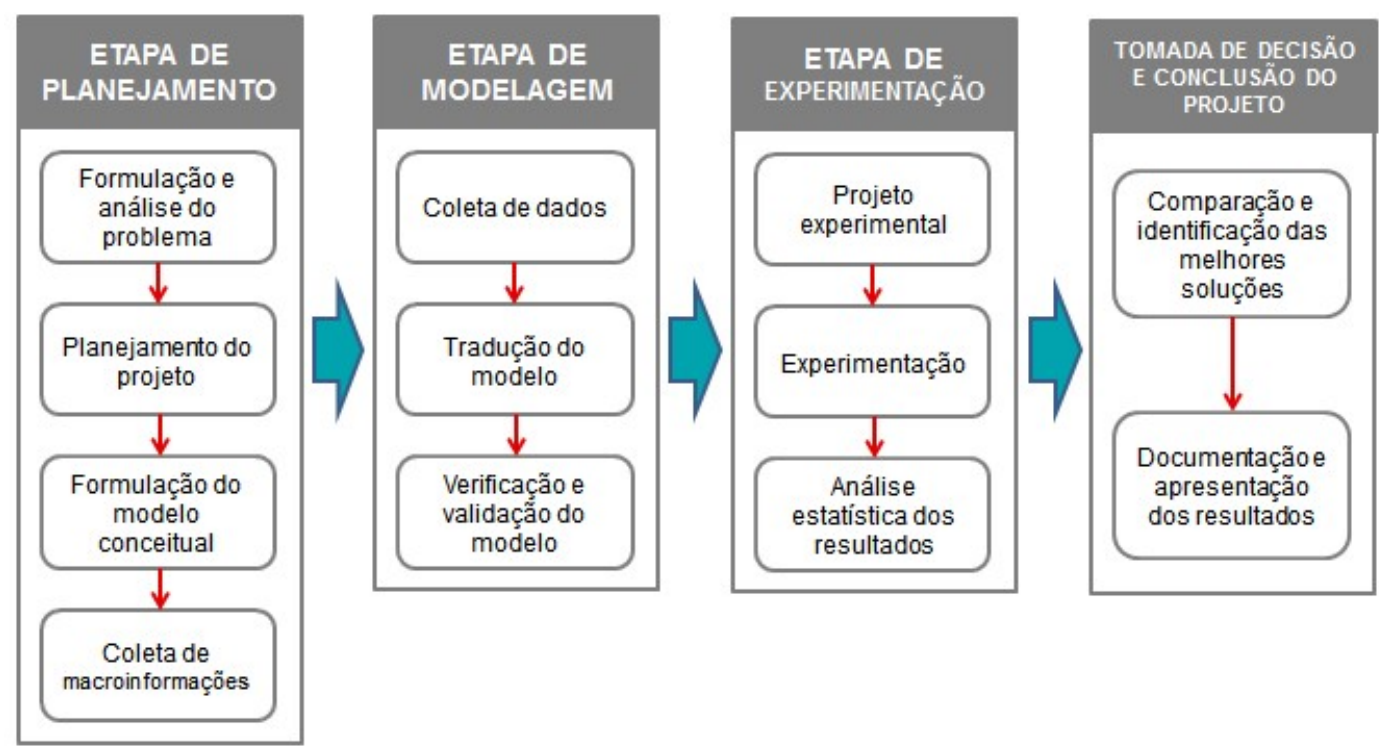

Fonte: Freitas Filho (2008) - Adaptado pela autora

Etapa 1 - Planejamento: definição da essência do problema a ser estudado. Avalição da existência de recursos suficientes para a realização do experimento de simulação, delineamento das técnicas de características da modelagem e coleta inicial de macro informações. Nesse sentido para o foco da pesquisa em questão estabeleceu-se que:

- Formulação e análise do problema: definiu-se que a questão a ser respondida pela simulação é: Como se comporta o tráfego numa malha viária que possua veículos convencionais e veículos autônomos trafegando simultaneamente?

- Formulação do modelo conceitual: para atingir as conclusões esperadas neste trabalho, faz-se necessário um modelo de simulação com um conjunto de vias onde os veículos, carros e caminhões, possam trafegar 
livremente. Além disso, é de extrema importância que o modelo seja capaz de suportar parâmetros para diferenciação de veículos convencionais e autônomos. - Definição da ferramenta de simulação a ser utilizada: após tentativa de realizar a modelagem do problema através da ferramenta de simulação ARENA (voltada para processos), verificou-se que apesar da não familiaridade da pesquisadora com a linguagem de programação do SUMO, como este software possui bibliotecas prontas para simulação de tráfego, a modelagem do cenário teria maior fluidez. Além disso, como os pesquisadores do GAS (Grupo de Análise de Segurança) da Escola Politécnica da Universidade de São Paulo também trabalham com este software em suas diversas pesquisas na área de segurança com foco em veículos autônomos, existiria a possibilidade de troca de conhecimentos. Outro benefício na utilização deste software é a possibilidade de utilização dos dados do Google Maps através da plataforma openstreet.- Coleta de macro informações: por meio de pesquisa bibliográfica, fez-se o entendimento do estado da arte de simulação de veículos e da concepção de veículos autônomos.

Etapa 2 - Modelagem: codificação do modelo conceitual esboçado na etapa anterior em linguagem matemática; e validação através de testes. $\mathrm{Na}$ aplicação desta etapa na pesquisa atual estabeleceu-se:

- Coleta de dados: através de pesquisa bibliográfica, os parâmetros físicos dos veículos foram definidos. Para o cenário de aproximação da realidade, as vias e volume de veículos também foram baseados na pesquisa bibliográfica. 
- Tradução do modelo: o SUMO possui uma interface que traduz os arquivos .xml que contém todas as informações da malha, veículos e fluxos. Através da plataforma openstreet, também é possível traduzir os dados de mapas reais do Google Maps, para a linguagem do programa.

- Verificação e validação do modelo: a validação do modelo foi feita em duas etapas. A primeira etapa consiste na validação dos parâmetros definidos para distinção entre veículos autônomos e convencionais, realizada no modelo inicial de estudo. A segunda etapa, realizada no modelo de aproximação da realidade, compreende a calibração do modelo em relação ao número de veículos em cada via.

Nas duas etapas foram realizados testes com cenários iniciais para verificação de incidência de falhas como bugs do sistema, colisão de veículos, tele-transporte e outros comportamentos anormais dos veículos. Nesta fase de testes, os resultados das simulações foram analisados detalhadamente para cada veículo a cada instante. Desta maneira, foi possível constatar um bug no código fonte do simulador que fazia com que os veículos recuassem erroneamente por um instante nas intersecções.

Etapa 3 - Experimentação: execução do modelo para obtenção de resultados para a análise estatística e documentação final do modelo. Neste sentido, esta etapa constitui-se na definição das características dos cenários a serem avaliados por meio da extração de relatórios de dados e análise dos resultados.

Etapa 4 - Tomada de decisões e conclusão do projeto: Através da análise dos resultados de todos os cenários simulados, foi possível concluir 
alguns pontos relevantes sobre a inserção dos veículos autônomos na malha viária e sugerir aspectos pertinentes para o aprofundamento e continuidade da pesquisa.

\section{MODELO INICIAL DE ESTUDO}

Como estudo de caso preliminar, desenvolveu-se um sistema de tráfego automotivo em uma malha viária simplificada, como mostra a Figura 3.

Figura 3 - Malha logística

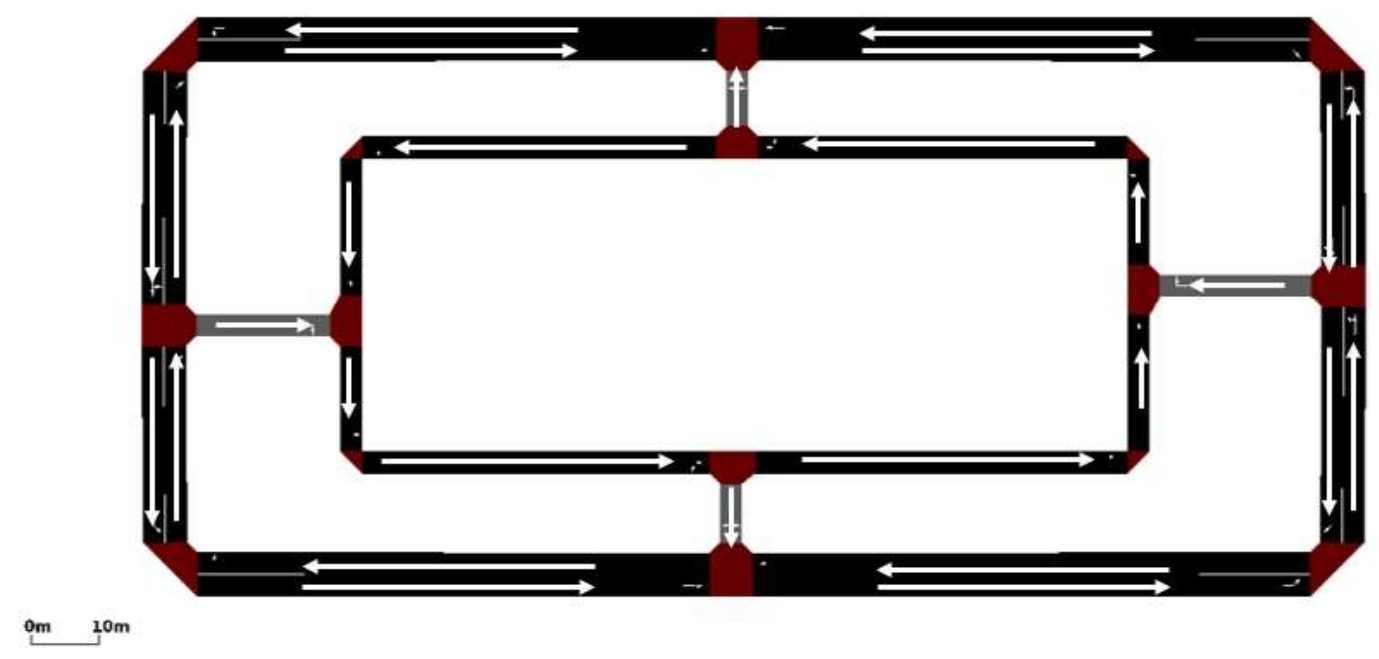

Os veículos movimentam-se nas vias, respeitando as seguintes premissas:

i. Nenhum tipo de veículo, seja autônomo ou convencional, pode realizar ultrapassagens.

ii. Nenhum tipo de colisão entre veículos é permitido.

iii. Nenhum veículo pode deixar o sistema. Uma vez que a entidade foi inserida, ela trafega até o tempo final da simulação (600 segundos). 
Os veículos trafegam no sistema por três rotas pré-determinadas e nomeadas Rota A (Figura 4), Rota B (Figura 5) e Rota C (Figura 6). Os veículos da Rota A percorrem as vias no sentido anti-horário no arco externo, os veículos da Rota B no sentido horário também no arco externo e os veículos da Rota $C$ passam pelos cruzamentos das vias para alternarem entre os arcos interno e externo.

Figura 4 - Rota A

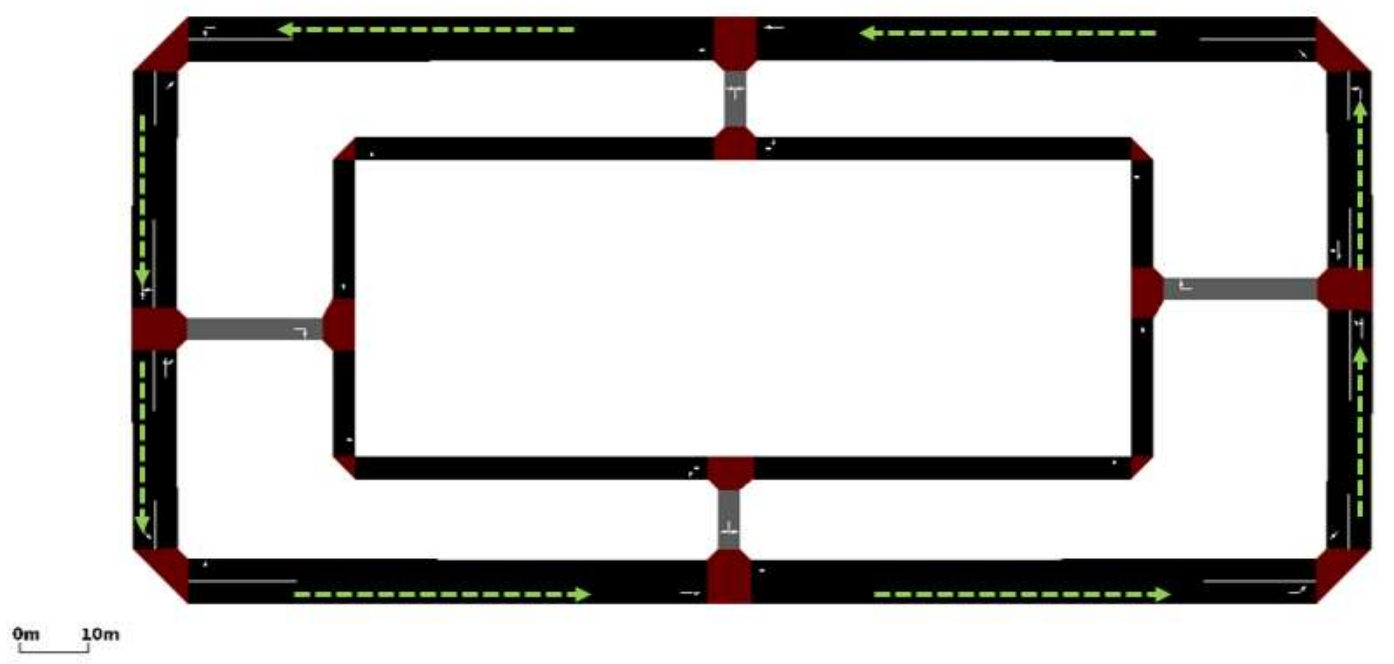

Figura 5 - Rota B

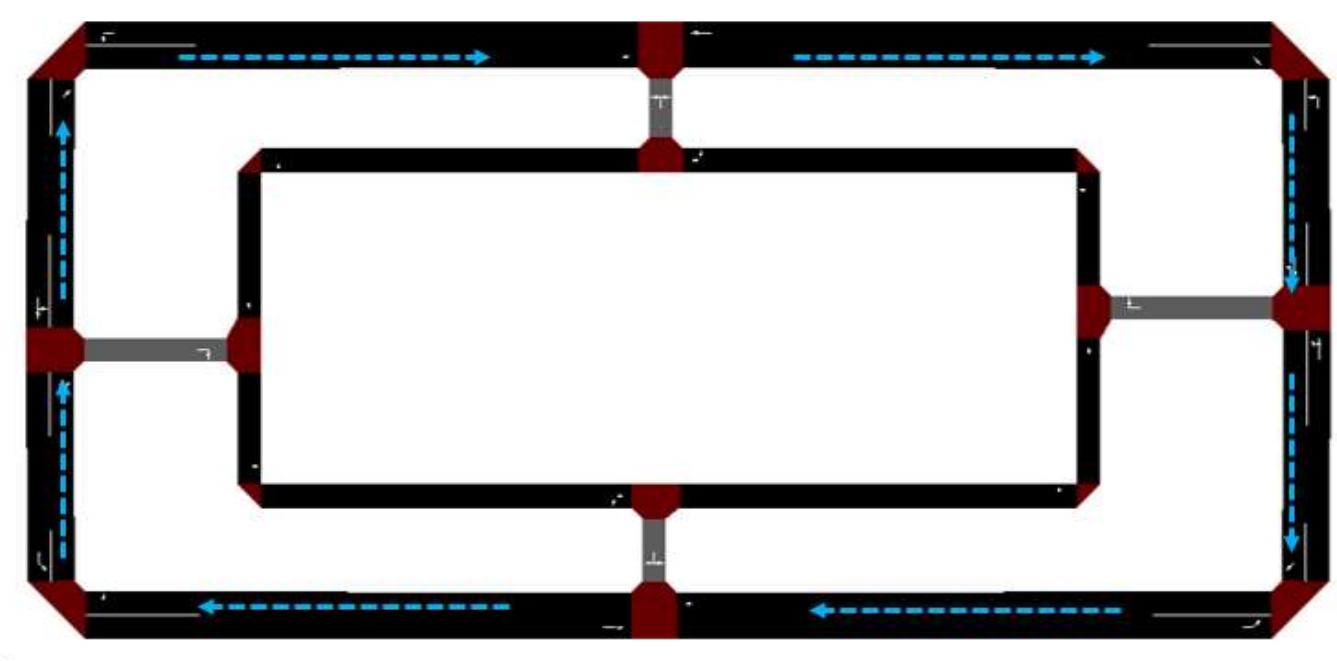

$0 \mathrm{~m} \quad 10 \mathrm{~m}$ 
Figura 6 - Rota C

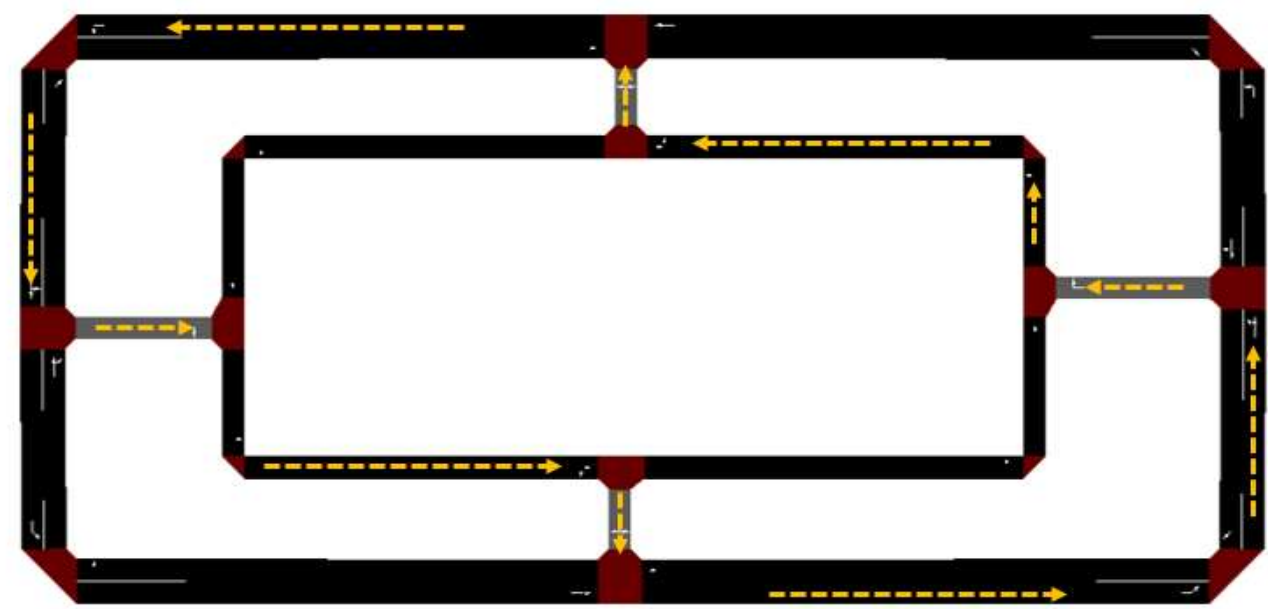

Para a caracterização do modelo, foi definido que cada rota possui 8 veículos sendo 4 automóveis e 4 caminhões, nomeados de acordo com a Tabela 2.

Tabela 2 - Nomenclatura dos veículos

\begin{tabular}{|c|c|c|c|c|c|}
\hline Rota & Veículo & Rota & Veículo & Rota & Veículo \\
\hline A & Carro1A & $B$ & Carro1B & $\mathrm{C}$ & Carro1C \\
\hline A & Carro2A & B & Carro2B & C & Carro2C \\
\hline A & Carro3A & B & Carro3B & C & Carro3C \\
\hline A & Carro4A & B & Carro4B & C & Carro4C \\
\hline A & Caminhao1A & B & Caminhao1B & C & Caminhao1C \\
\hline A & Caminhao2A & B & Caminhao2B & C & Caminhao2C \\
\hline A & Caminhao3A & B & Caminhao3B & C & Caminhao3C \\
\hline A & Caminhao4A & B & Caminhao4B & C & Caminhao4C \\
\hline
\end{tabular}

A Figura 7 mostra como fica a malha viária quando todos os veículos estão em circulação. 
Figura 7 - Configuração das vias com todos os veículos

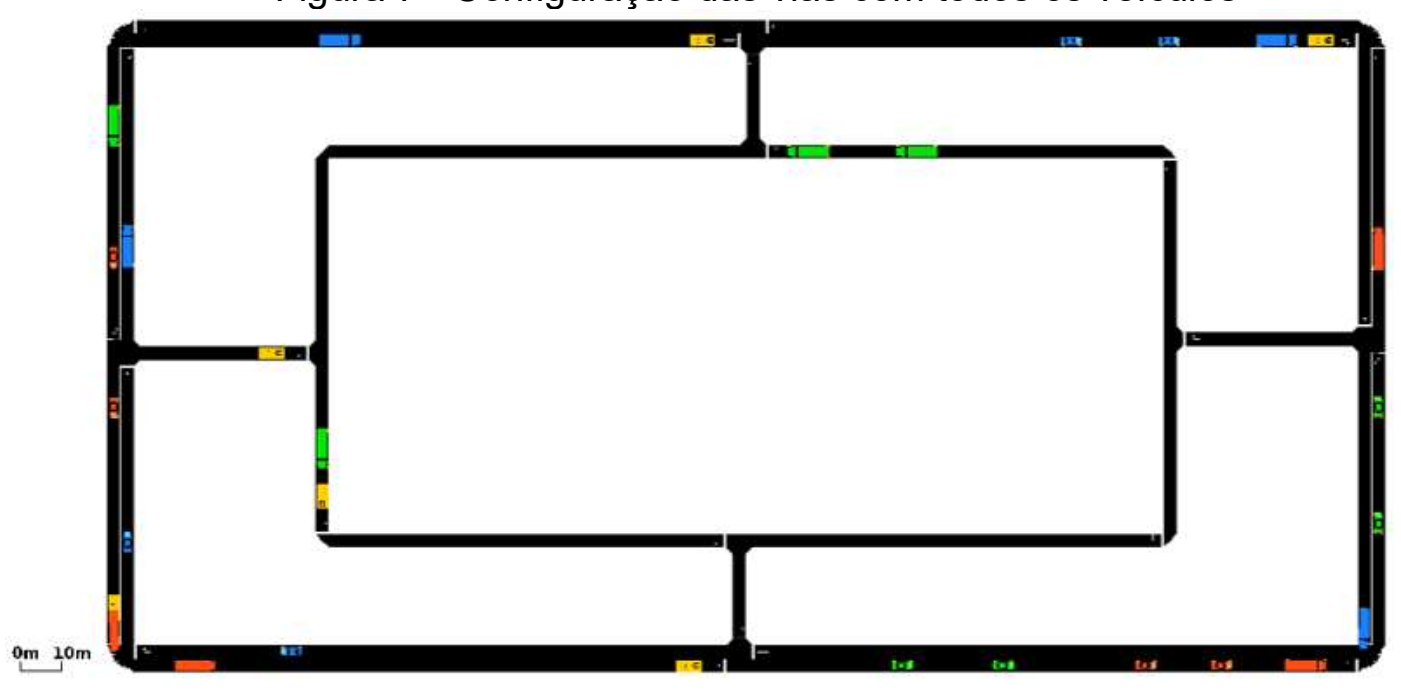

\subsection{Características dos veículos}

As características físicas dos veículos são definidas através do comando "vType" no SUMO. Neste projeto, os parâmetros configurados para a diferenciação entre os tipos de veículos são:

- Tamanho do veículo (length): comprimento total do veículo.

- Aceleração (accel): define a aceleração máxima.

- Desesaceleração (decel): valor da desaceleração dos veículos.

- Velocidade máxima (maxSpeed): velocidade máxima do veículo.

- т: define o tempo de reação, em segundos, do motorista.

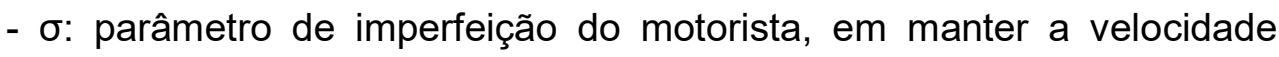
constante.

De acordo com Departamento Nacional de Infra-Estrutura de Transportes - DNIT (2005), a aceleração máxima possível de carros de passeio é $3,6 \mathrm{~m} / \mathrm{s}^{2}$, e de caminhões e veículos pesados, $0,9 \mathrm{~m} / \mathrm{s}^{2}$ no máximo. 
Para os parâmetros de desaceleração, de acordo com a pesquisa de Sousa (2001), a desaceleração média de veículos de pequeno porte chega a $4 \mathrm{~m} / \mathrm{s}^{2}$, enquanto a desaceleração de veículos maiores atinge em média $2,5 \mathrm{~m} / \mathrm{s}^{2}$

Com base nestas considerações, as características dos veículos foram definidas conforme a Tabela 3.

Tabela 3 - Características dos veículos

\begin{tabular}{|c|c|c|c|c|}
\hline Veículo & Tamanho [m] & $\begin{array}{l}\text { Vel Máx } \\
{[\mathrm{km} / \mathrm{h}]}\end{array}$ & Aceleração $\left[\mathrm{m} / \mathrm{s}^{2}\right]$ & $\begin{array}{c}\text { Desaceleração } \\
{\left[\mathrm{m} / \mathrm{s}^{2}\right]}\end{array}$ \\
\hline Carro & 5 & 90 & 3,6 & 4 \\
\hline Caminhão & 10 & 60 & 0,9 & 2,5 \\
\hline
\end{tabular}

Todos estes parâmetros não sofrem alterações nos diferentes cenários simulados.

\subsection{Cenários estudados}

Como o objetivo é comparar cenários com diferentes quantidades de veículos autônomos e convencionais, foram configurados 7 cenários para a análise comparativa dos resultados. São eles:

- Cenário Conv: Todos os veículos de todas as rotas são convencionais.

- Cenário A: Todos os veículos que trafegam na Rota A são autônomos.

- Cenário B: Todos os veículos que trafegam na Rota B são autônomos.

- Cenário C: Todos os veículos que trafegam na Rota C são autônomos.

- Cenário Parcial: 2 automóveis e 2 caminhões das rotas A, B e C são autônomos. 
- Cenário AC: Todos os veículos que trafegam nas rotas A e C são autônomos.

- Cenário Auto: Todos os veículos de todas as rotas são autônomos.

Já para a diferenciação entre os veículos convencionais e autônomos foram utilizados os parâmetros:

- T: define o tempo de reação, em segundos, do motorista.

- $\sigma$ : parâmetro de imperfeição do motorista, em manter a velocidade constante

Leksono e Andriyana (2012) explicam que o valor de sigma ( $\sigma$ ) pode variar entre 0 e 1 , onde um valor maior representa um motorista com pouca habilidade para manter a velocidade do veículo constante. $\mathrm{O}$ valor de 0 corresponde a um veículo que se comporta deterministicamente (respeitando os limites de segurança o veículo trafega sem oscilações na sua velocidade). Assim, para os veículos autônomos, como não são operados por humanos, considerou-se que a imperfeição do motorista (capacidade de manter a velocidade constante) é igual zero. E, para os veículos convencionais, adotouse o nível de imperfeição 1 , representando a irregularidade da condução humana.

Para os veículos convencionais, o parâmetro T, foi considerado 3 segundos. Para os veículos autônomos, de acordo com WAGNER (2016), este intervalo pode ser reduzido a 0,3 ou 0,5 segundos. Porém, como uma das configurações do modelo car-following adotado pelo simulador é a premissa de que t possua valor mínimo de 1 segundo para evitar colisões (premissa ii 
apresentada no início deste capítulo), foi definido o valor de 1 segundo (menor possível) para os veículos autônomos.

Os parâmetros $\sigma$ e t de todos os veículos e cenários estão detalhados na Tabela 4.

Tabela 4 - Caracterização dos cenários

\begin{tabular}{|c|c|c|c|c|c|c|c|c|c|c|c|c|c|c|}
\hline \multirow[t]{2}{*}{ Veículo } & \multicolumn{2}{|c|}{$\begin{array}{l}\text { Cenário } \\
\text { CONV }\end{array}$} & \multicolumn{2}{|c|}{$\begin{array}{c}\text { Cenário } \\
\text { A }\end{array}$} & \multicolumn{2}{|c|}{$\begin{array}{c}\text { Cenário } \\
\mathrm{B}\end{array}$} & \multicolumn{2}{|c|}{$\begin{array}{c}\text { Cenário } \\
\text { C }\end{array}$} & \multicolumn{2}{|c|}{$\begin{array}{r}\text { Cenário } \\
\text { PARCIAL }\end{array}$} & \multicolumn{2}{|c|}{$\begin{array}{c}\text { Cenário } \\
\text { A C }\end{array}$} & \multicolumn{2}{|c|}{$\begin{array}{c}\text { Cenário } \\
\text { AUTO }\end{array}$} \\
\hline & $\sigma$ & $\mathbf{T}$ & $\sigma$ & $\mathbf{T}$ & $\sigma$ & $\mathbf{T}$ & $\sigma$ & $\mathbf{T}$ & $\sigma$ & $\mathbf{T}$ & $\sigma$ & $\mathbf{T}$ & $\sigma$ & $\mathbf{T}$ \\
\hline Carro1A & 1 & 3 & 0 & 1 & 1 & 3 & 1 & 3 & 0 & 1 & 0 & 1 & 0 & 1 \\
\hline Carro2A & 1 & 3 & 0 & 1 & 1 & 3 & 1 & 3 & 0 & . & 0 & 1 & 0 & \\
\hline Carro3A & 1 & 3 & 0 & 1 & 1 & 3 & 1 & 3 & 1 & & 0 & 1 & 0 & \\
\hline Carro4A & 1 & 3 & 0 & 1 & 1 & 3 & 1 & 3 & 1 & 3 & 0 & 1 & 0 & 1 \\
\hline Caminhao1A & 1 & 3 & 0 & 1 & 1 & 3 & 1 & 3 & 0 & 1 & 0 & 1 & 0 & 1 \\
\hline Caminhao2A & 1 & 3 & 0 & 1 & 1 & 3 & 1 & 3 & 0 & & 0 & 1 & 0 & \\
\hline Caminhao3A & 1 & 3 & 0 & 1 & 1 & 3 & 1 & 3 & 1 & 3 & 0 & 1 & 0 & 1 \\
\hline Caminhao4A & 1 & 3 & 0 & 1 & 1 & 3 & 1 & 3 & 1 & 3 & 0 & 1 & 0 & 1 \\
\hline Carro1B & 1 & 3 & 1 & 3 & 0 & 1 & 1 & 3 & 0 & 1 & 1 & 3 & 0 & \\
\hline Carro2B & 1 & 3 & 1 & 3 & 0 & 1 & 1 & 3 & 0 & 1 & 1 & 3 & 0 & \\
\hline Carro3B & 1 & 3 & 1 & 3 & 0 & 1 & 1 & 3 & 1 & 3 & 1 & 3 & 0 & 1 \\
\hline Carro4B & 1 & 3 & 1 & 3 & 0 & 1 & 1 & 3 & 1 & 3 & 1 & 3 & 0 & \\
\hline Caminhao1B & 1 & 3 & 1 & 3 & 0 & 1 & 1 & 3 & 0 & & 1 & 3 & 0 & \\
\hline Caminhao2B & 1 & 3 & 1 & 3 & 0 & 1 & 1 & 3 & 0 & 1 & 1 & 3 & 0 & 1 \\
\hline Caminhao3B & 1 & 3 & 1 & 3 & 0 & 1 & 1 & 3 & 1 & 3 & 1 & 3 & 0 & 1 \\
\hline Caminh & 1 & 3 & 1 & 3 & 0 & 1 & 1 & 3 & 1 & 3 & 1 & 3 & 0 & \\
\hline Carro1C & 1 & 3 & 1 & 3 & 1 & 3 & 0 & 1 & 0 & 1 & 0 & 1 & 0 & 1 \\
\hline Carro2C & 1 & 3 & 1 & 3 & 1 & 3 & 0 & 1 & 0 & 1 & 0 & 1 & 0 & 1 \\
\hline Carro3C & 1 & 3 & 1 & 3 & 1 & 3 & 0 & 1 & 1 & 3 & 0 & 1 & 0 & 1 \\
\hline Carro4C & 1 & 3 & 1 & 3 & 1 & 3 & 0 & 1 & 1 & 3 & 0 & 1 & 0 & 1 \\
\hline Caminhao1C & 1 & 3 & 1 & 3 & 1 & 3 & 0 & 1 & 0 & 1 & 0 & 1 & 0 & 1 \\
\hline Caminhao2C & 1 & 3 & 1 & 3 & 1 & 3 & 0 & 1 & 0 & 1 & 0 & 1 & 0 & \\
\hline Caminhao3C & 1 & 3 & 1 & 3 & 1 & 3 & 0 & 1 & 1 & 3 & 0 & 1 & 0 & 1 \\
\hline Caminhao4C & 1 & 3 & 1 & 3 & 1 & 3 & 0 & 1 & 1 & 3 & 0 & 1 & 0 & \\
\hline
\end{tabular}

\subsection{Resultados do modelo}

Para a análise do comportamento dos cenários, foram comparados três fatores: distância total percorrida, velocidade média de cada veículo e tempo total em fila (instantes em que a velocidade do veículo é igual a zero). Com 
estes três fatores é possível avaliar se o comportamento do tráfego nos cenários apresenta melhoria (maiores velocidades médias, maiores distâncias percorridas e menores tempos em filas) em relação aos outros.

\subsubsection{Distâncias totais percorridas}

A Tabela 5 mostra as distâncias totais percorridas de cada veículo em cada um dos cenários simulados. As células sinalizadas em cinza são os veículos configurados como autônomos. As barras coloridas auxiliam na visualização das distâncias totais percorridas por veiculo em cada cenário.

Tabela 5 - Distância total percorrida [km]

\begin{tabular}{|c|c|c|c|c|c|c|c|}
\hline Veículo & CENÁRIO CONV & CENÁRIO A & CENÁRIO B & CENÁRIO C & CENÁRIO PARCIAL & CENÁRIO A C & CENÁRIO AUTO \\
\hline Carro1A & 5.309 & 6.855 & 5.881 & 7.987 & $\begin{array}{r}5.929 \\
\end{array}$ & 10.274 & 9.311 \\
\hline Carro2A & 5.259 & 6.837 & 5.843 & 7.921 & 5.921 & 10.250 & 9.287 \\
\hline Carro3A & 4.525 & 6.051 & 5.078 & 7.312 & 5.880 & 9.496 & 8.533 \\
\hline Carro4A & 4.495 & 6.029 & 5.045 & 7.246 & $5.85 t$ & 9.472 & 8.509 \\
\hline Caminhao1A & 4.571 & 6.104 & 5.167 & 7.465 & 5.909 & 9.550 & 8.586 \\
\hline Caminhao2A & 4.553 & 6.075 & 5.117 & 7.382 & 5.895 & 9.520 & 8.557 \\
\hline Caminhao $3 \mathrm{~A}$ & 4.451 & 5.994 & 5.008 & 7.153 & 5.815 & 9.422 & 8.459 \\
\hline Caminhao4A & 4.296 & 5.969 & 4.888 & 6.923 & 5.031 & 9.393 & 8.430 \\
\hline Carro1B & 9.400 & 9.044 & 10.186 & 9.516 & 9.496 & 9.566 & 10.244 \\
\hline Carro2B & 9.330 & 8.977 & 10.162 & 9.447 & 9.472 & 9.494 & 10.220 \\
\hline Carro3B & 8.915 & 8.359 & 9.635 & 8.862 & 9.305 & 8.910 & 9.644 \\
\hline Carro4B & 8.846 & 8.295 & 9.612 & 8.792 & 9.222 & 8.843 & 9.619 \\
\hline Caminhao1B & 9.044 & 8.482 & 9.738 & 9.043 & 9.423 & 9.047 & 9.716 \\
\hline Caminhao2B & 8.979 & 8.419 & 9.658 & 8.929 & 9.395 & 8.980 & 9.668 \\
\hline Caminhao3B & 8.580 & 8.220 & 9.356 & 8.701 & 8.934 & 8.748 & 9.414 \\
\hline Caminhao4B & 8.224 & 7.763 & 9.326 & 8.462 & 8.636 & 8.232 & 9.384 \\
\hline Carro1C & 2.516 & 2.759 & 2.703 & 2.511 & 3.498 & 3.291 & 4.753 \\
\hline Carro2C & 2.335 & 2.739 & 2.596 & 2.504 & 3.477 & 3.270 & 4.746 \\
\hline Carro3C & 1.850 & 2.497 & 1.886 & 1.166 & 2.754 & 2.744 & 4.308 \\
\hline Carro4C & 1.627 & 2.473 & 1.852 & 1.159 & 2.625 & 2.732 & 4.296 \\
\hline Caminhao1C & 2.065 & 2.519 & 2.063 & 1.622 & 2.955 & 2.967 & 4.513 \\
\hline Caminhao2C & 1.856 & 2.506 & 1.983 & 1.174 & 2.942 & 2.753 & 4.321 \\
\hline Caminhao3C & 1.401 & 2.234 & 1.552 & 1.146 & 2.305 & 2.444 & 4.124 \\
\hline Caminhao4C & 1.237 & 1.905 & 1.184 & 1.134 & 2.070 & 2.416 & 3.864 \\
\hline
\end{tabular}




\subsubsection{Velocidade Média}

A Tabela 6 mostra a velocidade média dos veículos em cada um dos cenários. Para o cálculo, foram considerados todos os instantes da simulação, a partir do momento em que o veículo foi inserido no sistema. Mesmo nos casos em que o veículo esteve parado em fila, sua velocidade nula é contabilizada no cálculo da velocidade média.

Tabela 6 - Velocidade média dos veículos $[\mathrm{km} / \mathrm{h}]$

\begin{tabular}{|c|c|c|c|c|c|c|c|}
\hline Veículo & CENÁRIO CONV & CENÁRIO A & CENÁRIO B & CENÁRIO C & CENÁRIO PARCIAL & CENÁRIO A C & CENÁRIO AUTO \\
\hline Carro1A & 32 & 41 & 35 & 48 & 36 & 62 & 56 \\
\hline Carro2A & 32 & 41 & 35 & 48 & 36 & 62 & 56 \\
\hline Carro3A & 28 & 37 & 32 & 46 & 36 & 58 & 52 \\
\hline Carro4A & 28 & 37 & 32 & 46 & 36 & 58 & 53 \\
\hline Caminhao1A & 28 & 37 & 31 & 45 & 36 & 58 & 52 \\
\hline Caminhao2A & 28 & 37 & 31 & 45 & 36 & 58 & 52 \\
\hline Caminhao $3 \mathrm{~A}$ & 28 & 37 & 32 & 46 & 36 & 58 & 53 \\
\hline Caminhao4A & 28 & 37 & 32 & 46 & 32 & 59 & 53 \\
\hline Carro1B & 56 & 54 & 61 & 57 & 57 & 57 & 61 \\
\hline Carro2B & 56 & 54 & 61 & 57 & 57 & 57 & 62 \\
\hline Carro3B & 55 & 52 & 59 & 55 & 57 & 55 & 59 \\
\hline Carro4B & 55 & 52 & 59 & 55 & 57 & 55 & 59 \\
\hline Caminhao1B & 55 & 51 & 59 & 55 & 57 & 55 & 59 \\
\hline Caminhao2B & 55 & 52 & 59 & 55 & 57 & 55 & 59 \\
\hline Caminhao3B & 54 & 52 & 58 & 55 & 56 & 55 & 58 \\
\hline Caminhao4B & 54 & 51 & 58 & 56 & 54 & 54 & 59 \\
\hline Carro1C & 17 & 17 & 18 & 17 & 23 & 21 & 30 \\
\hline Carro2C & 16 & 17 & 18 & 17 & 23 & 21 & 30 \\
\hline Carro3C & 15 & 17 & 15 & 9 & 19 & 18 & 28 \\
\hline Carro4C & 13 & 19 & 15 & 9 & 19 & 18 & 28 \\
\hline Caminhao1C & 16 & 16 & 16 & 11 & 20 & 19 & 29 \\
\hline Caminhao2C & 15 & 17 & 16 & 9 & 20 & 18 & 28 \\
\hline Caminhao3C & 15 & 17 & 16 & 9 & 18 & 16 & 27 \\
\hline Caminhao4C & 14 & 15 & 13 & 9 & 17 & 16 & 26 \\
\hline
\end{tabular}




\subsubsection{Tempo total dos veículos em filas}

A Tabela 7 mostra o tempo total de espera em filas em cada cenário. É considerado que o veículo está esperando em fila quando a sua velocidade é igual a zero.

Tabela 7 - Tempo total de espera em fila [s]

\begin{tabular}{|c|c|c|c|c|c|c|c|}
\hline Veículo & CENÁRIO CONV & CENÁRIO A & CENÁRIO B & CENÁRIO C & CENÁRIO PARCIAL & CENÁRIO A C & CENÁRIO AUTO \\
\hline Carro1A & 0 & 9 & 0 & 0 & 0 & 0 & 6 \\
\hline Carro2A & 0 & 9 & 0 & 0 & 0 & 0 & 6 \\
\hline Carro3A & 3 & 9 & 0 & 0 & 0 & 0 & 15 \\
\hline Carro4A & 1 & 9 & 0 & 0 & 0 & 0 & 15 \\
\hline Caminhao1A & 12 & 9 & 6 & 1 & 5 & 0 & 17 \\
\hline Caminhao2A & 3 & 9 & 0 & 0 & 2 & 0 & 15 \\
\hline Caminhao3A & 1 & 9 & 0 & 0 & 0 & 0 & 9 \\
\hline Caminhao4A & 0 & 9 & 0 & 0 & 0 & 0 & 6 \\
\hline Carro1B & 0 & 0 & 0 & 0 & 0 & 0 & 0 \\
\hline Carro2B & 0 & 0 & 0 & 0 & 0 & 0 & 0 \\
\hline Carro3B & 0 & 0 & 0 & 0 & 0 & 0 & 0 \\
\hline Carro4B & 0 & 0 & 0 & 0 & 0 & 0 & 0 \\
\hline Caminhao1B & 0 & 0 & 0 & 0 & 0 & 0 & 0 \\
\hline Caminhao2B & 0 & 0 & 0 & 0 & 0 & 0 & 0 \\
\hline Caminhao3B & 1 & 1 & 0 & 1 & 0 & 1 & 0 \\
\hline Caminhao4B & 0 & 0 & 0 & 0 & 0 & 0 & 0 \\
\hline Carro1C & 35 & 38 & 46 & 309 & 57 & 241 & 94 \\
\hline Carro2C & 54 & 35 & 63 & 308 & 56 & 243 & 93 \\
\hline Carro3C & 44 & 37 & 88 & 328 & 54 & 244 & 120 \\
\hline Carro4C & 62 & 8 & 70 & 320 & 29 & 244 & 130 \\
\hline Caminhao1C & 39 & 34 & 48 & 349 & 208 & 231 & 94 \\
\hline Caminhao2C & 45 & 56 & 78 & 327 & 197 & 244 & 109 \\
\hline Caminhao3C & 23 & 39 & 35 & 288 & 18 & 258 & 97 \\
\hline Caminhao4C & 46 & 65 & 56 & 284 & 51 & 252 & 117 \\
\hline
\end{tabular}

5.4 Avaliação dos resultados obtidos através do modelo inicial de estudo

Analisando o desempenho dos veículos, considerando a velocidade média e a distância total percorrida, nota-se que os veículos da Rota A tiveram melhor desempenho no Cenário $A C$, no qual os veículos das rotas $A$ e $C$ são autônomos. Todos os veículos da Rota B tem melhor desempenho no Cenário Auto, com exceção do Caminhão1B, que tem melhor desempenho no Cenário B. Os veículos da Rota C possuem maiores velocidades médias e distâncias percorridas no Cenário Auto. 
Já os cenários menos favoráveis para os veículos da rota $A$ é o cenário Conv, para os veículos da rota $\mathrm{B}$, é o cenário $A$; e para os veículos da rota $\mathrm{C}$, o cenário $C$, com exceção do Carro2C, que possui pior desempenho no cenário Auto.

Quando o foco é o tempo total em filas, os cenários com pior desempenho (maior tempo em fila) são os cenários $A$ e Auto, para os veículos da rota $A$ e o cenário $C$ para os veículos da rota $C$. Nenhum veículo da rota $B$ permanece parado no sistema, com exceção do Caminhao3B, que possui uma pausa de 1 segundo logo quando entra no sistema.

Os veículos da rota $C$ são os únicos que possuem filas em todos os cenários simulados.

Os melhores e piores desempenhos de cada veículo estão expostos na Tabela 8 e Tabela 9, a seguir. 
Tabela 8 - Melhores desempenhos por veículo

\begin{tabular}{|c|c|c|}
\hline \multirow[b]{2}{*}{ Veículo } & \multicolumn{2}{|c|}{ MELHOR DESEMPENHO } \\
\hline & $\begin{array}{l}\text { Máx Velocidade Média e } \\
\text { dist percorrida }\end{array}$ & Menor Tempo em Fila [s] \\
\hline Carro1A & Cenário A C & Cenário CONV, B, C, Parcial, AC \\
\hline Carro2A & Cenário A C & Cenário CONV, B, C, Parcial, AC \\
\hline Carro3A & Cenário A C & Cenário B, C, Parcial, AC \\
\hline Carro4A & Cenário A C & Cenário $\mathrm{B}, \mathrm{C}$, Parcial, $\mathrm{AC}$ \\
\hline Caminhao1A & Cenário A C & Cenário A C \\
\hline Caminhao2A & Cenário A C & Cenário $B, C, A C$ \\
\hline Caminhao3A & Cenário A C & Cenário $\mathrm{B}, \mathrm{C}$, Parcial, AC \\
\hline Caminhao4A & Cenário A C & Cenário CONV, B, C, Parcial, AC \\
\hline Carro1B & Cenário AUTO & Cenário CONV, A, B, C, Parcial, AC, Auto \\
\hline Carro2B & Cenário AUTO & Cenário CONV, A, B, C, Parcial, AC, Auto \\
\hline Carro3B & Cenário AUTO & Cenário CONV, A, B, C, Parcial, AC, Auto \\
\hline Carro4B & Cenário AUTO & Cenário CONV, A, B, C, Parcial, AC, Auto \\
\hline Caminhao1B & Cenário B & Cenário CONV, A, B, C, Parcial, AC, Auto \\
\hline Caminhao2B & Cenário AUTO & Cenário CONV, A, B, C, Parcial, AC, Auto \\
\hline Caminhao3B & Cenário AUTO & Cenário B, Parcial, Auto \\
\hline Caminhao4B & Cenário AUTO & Cenário CONV, A, B, C, Parcial, AC, Auto \\
\hline Carro1C & Cenário AUTO & Cenário CONV \\
\hline Carro2C & Cenário AUTO & Cenário $\mathrm{A}$ \\
\hline Carro3C & Cenário AUTO & Cenário A \\
\hline Carro4C & Cenário AUTO & Cenário A \\
\hline Caminhao1C & Cenário AUTO & Cenário A \\
\hline Caminhao2C & Cenário AUTO & Cenário CONV \\
\hline Caminhao3C & Cenário AUTO & Cenário PARCIAL \\
\hline Caminhao4C & Cenário AUTO & Cenário CONV \\
\hline
\end{tabular}


Tabela 9 - Piores desempenhos por veículo

\begin{tabular}{ccl}
\hline \multirow{2}{*}{ Veículo } & \multicolumn{2}{c}{ PIOR DESEMPENHO } \\
\cline { 2 - 3 } & $\begin{array}{c}\text { Mín Velocidade Média e } \\
\text { distância percorrida }\end{array}$ & Maior Tempo em Fila \\
\hline Carro1A & Cenário CONV & Cenário A \\
\hline Carro2A & Cenário CONV & Cenário A \\
\hline Carro3A & Cenário CONV & Cenário AUTO \\
\hline Carro4A & Cenário CONV & Cenário AUTO \\
\hline Caminhao1A & Cenário CONV & Cenário AUTO \\
\hline Caminhao2A & Cenário CONV & Cenário AUTO \\
\hline Caminhao3A & Cenário CONV & Cenário A \\
\hline Caminhao4A & Cenário CONV & Cenário A \\
\hline Carro1B & Cenário A & Cenário CONV \\
\hline Carro2B & Cenário A & Cenário CONV \\
\hline Carro3B & Cenário A & Cenário CONV \\
\hline Carro4B & Cenário A & Cenário CONV \\
\hline Caminhao1B & Cenário A & Cenário CONV \\
\hline Caminhao2B & Cenário A & Cenário CONV \\
\hline Caminhao3B & Cenário A & Cenário CONV \\
\hline Caminhao4B & Cenário A & Cenário CONV \\
\hline Carro1C & Cenário C & Cenário C \\
\hline Carro2C & Cenário CONV & Cenário C \\
\hline Carro3C & Cenário C & Cenário C \\
\hline Carro4C & Cenário C & Cenário C \\
\hline Caminhao1C & Cenário C & Cenário C \\
\hline Caminhao2C & Cenário C & Cenário C \\
\hline Caminhao3C & Cenário C & Cenário C \\
\hline Caminhao4C & Cenário C & Cenário C \\
\hline
\end{tabular}

O desempenho de um cenário é definido como 'bom' quando os veículos apresentam maiores velocidades médias, maiores distâncias percorridas e menores tempos em fila. Assim, analisando o desempenho dos veículos, notase que:

- Todos os carros e caminhões da Rota B tem melhor desempenho no Cenário Auto, com exceção de apenas um caminhão, que tem melhor performance no Cenário $B$. Como a Rota $B$ é interferida pela Rota $C$ no sentido inverso, esse resultado era esperado. Talvez, a diferença para 
o ocorrido com um caminhão seja em função da menor agilidade em aceleração e desaceleração.

- Os veículos da Rota C possuem maiores velocidades médias e distâncias percorridas no Cenário Auto.

Já os cenários com piores desempenhos para os veículos da rota $\mathrm{A}$ é o cenário Conv, para os veículos da rota $\mathrm{B}$, é o cenário $A$; e para os veículos da rota $C$, o cenário $C$, com exceção de um carro, que possui pior desempenho no cenário Conv.

Uma possível explicação para estes resultados pode ser o diferente tipo de interferência da automação em diferentes tipos de rotas. Como o caminho dos veículos da rota $C$ coincide com parte da rota $A$ e interfere na rota $B$ (no cruzamento de acesso ao arco interior da malha), as melhorias esperadas com a existência de veículos autônomos apenas na Rota C não são concretizadas, pois os veículos desta rota atuam simultaneamente com veículos com características convencionais.

Quando o foco é o tempo total em filas, os cenários com pior desempenho (maior tempo em fila) são os cenários $A$ e Auto, para os veículos da rota $A$ e o cenário $C$ para os veículos da rota $C$. Em ambos os casos anteriores, quando todos os veículos da Rota B são convencionais eles interferem negativamente na fluidez do tráfego. Nenhum veículo da rota B permanece parado no sistema, com exceção de apenas um caminhão.

Intuitivamente, espera-se que o Cenário Auto possua melhor desempenho (maiores velocidades médias, distâncias percorridas e menores tempos em filas) e o Cenário Conv apresente o oposto disto. Porém, 
contabilizando as ocorrências em que cada cenário aparece na classificação de Melhor Desempenho (cenário no qual o mesmo veículo aparece com menor tempo de fila e maior velocidade média), isso não ocorre; o Cenário Conv é o quarto melhor colocado no ranking de melhores desempenhos, conforme mostra a Tabela 10. É interessante notar que o Cenário B (Rota B com todos autônomos) apresenta bom desempenho, provavelmente, devido ao menor grau de interferência nas demais rotas ( $\mathrm{A}$ e $\mathrm{C}$ ) em função de todos seus veículos serem autônomos na Rota B.

Tabela 10 - Cenário com melhores desempenhos

\begin{tabular}{cc}
\hline CENÁRIO & $\begin{array}{c}\text { Ocorrências como Melhor } \\
\text { Desempenho }\end{array}$ \\
\hline Cenário AUTO & 23 \\
Cenário B & 20 \\
Cenário A C & 16 \\
Cenário CONV & 13 \\
\hline Cenário A & 11 \\
\hline Cenário PARCIAL & 9 \\
Cenário C & 7 \\
\hline
\end{tabular}

É interessante notar que dos sete cenários testados, os três piores classificados no ranking de melhor desempenho possuem veículos autônomos trafegando em vias compartilhadas com veículos convencionais (Cenário $A$, Cenário Parcial e Cenário C).

Já os cenários com piores desempenhos estão na Tabela 11. 
Tabela 11 - Cenários com piores desempenhos

\begin{tabular}{c|c}
\hline CENÁRIO & $\begin{array}{c}\text { Ocorrências como Pior } \\
\text { Desempenho }\end{array}$ \\
\hline Cenário CONV & 17 \\
\hline Cenário C & 15 \\
Cenário A & 12 \\
Cenário AUTO & 4 \\
\hline Cenário A C & 0 \\
\hline Cenário B & 0 \\
\hline Cenário PARCIAL & 0 \\
\hline
\end{tabular}

Como esperado, o Cenário Conv aparece como o cenário que mais possui ocorrências de pior desempenho, seguido pelo Cenário $C$, Cenário $A$ e Cenário Auto. Os cenários $A C, B$ e Parcial não são citados nenhuma vez como piores desempenhos.

Combinando os resultados de melhor e pior desempenho, e atribuindo valores positivos para cada citação como Melhor Desempenho e valores negativos para citações como Pior Desempenho, criou-se uma métrica para classificação geral dos cenários (Tabela 12).

Tabela 12 - Classificação geral dos cenários

\begin{tabular}{c|c|c|c}
\hline CENÁRIO & $\begin{array}{c}\text { Melhor Desempenho } \\
(+)\end{array}$ & $\begin{array}{c}\text { Pior Desempenho } \\
(-)\end{array}$ & Saldo Total \\
\hline Cenário B & 20 & 0 & 20 \\
\hline Cenário AUTO & 23 & 4 & 19 \\
\hline Cenário A C & 16 & 0 & 16 \\
\hline Cenário PARCIAL & 9 & 0 & 9 \\
\hline Cenário A & 11 & 12 & -1 \\
\hline Cenário CONV & 13 & 17 & -4 \\
\hline Cenário C & 7 & 15 & -8 \\
\hline
\end{tabular}

Analisando os resultados desta métrica, ao contrário do esperado, o Cenário $B$ mostra-se como melhor cenário e o cenário Auto aparece como segundo melhor. O pior cenário é o Cenário $C$, seguido do Cenário Conv. 
Assim, nas condições desta malha viária, o tráfego ótimo de veículos acontece quando apenas os veículos da rota B possuem características autônomas, rota esta que interfere no cruzamento dos veículos das rotas A e C. Quando todos os veículos são autônomos (Cenário Auto) o saldo do fluxo de veículos passa de 20 a 19, perdendo $5 \%$ de eficiência.

De acordo com análises apresentadas por Santos, Camargo Júnior e Vismari (2018), pode-se observar, de forma quantitativa, que os veículos trafegam com menor tempo em fila e maiores velocidades médias quando toda a frota de veículos presentes em uma rota é autônoma.

\section{MODELO DE APROXIMAÇÃO DA REALIDADE}

Uma vez que foram observados comportamentos diferentes de acordo com os parâmetros adotados para a caracterização entre os veículos autônomos e convencionais no cenário preliminar, partiu-se para a experimentação em um novo cenário com a malha viária mais complexa no sentido de volume de veículos, extensão das vias, duplicidade de pistas (possibilidade de mudança de faixa), semáforos e número de interseções.

Assim, como forma de aproximar o modelo de estudo com situações reais, foram escolhidas 21 vias do município de São Paulo para modelagem do tráfego com base no Relatório de Mobilidade no Sistema Viário Principal (CET, 2017).

As vias foram modeladas no SUMO representando suas configurações reais de extensão, número de faixas e número de semáforos. A modelagem foi 
realizada através da ferramenta overpassturbo.eu que é capaz de reproduzir informações do Google Maps para a linguagem .xml que o SUMO é capaz de processar.

A Figura 8 destaca em vermelho as vias selecionadas para estudo.

Figura 8 - Vias modeladas

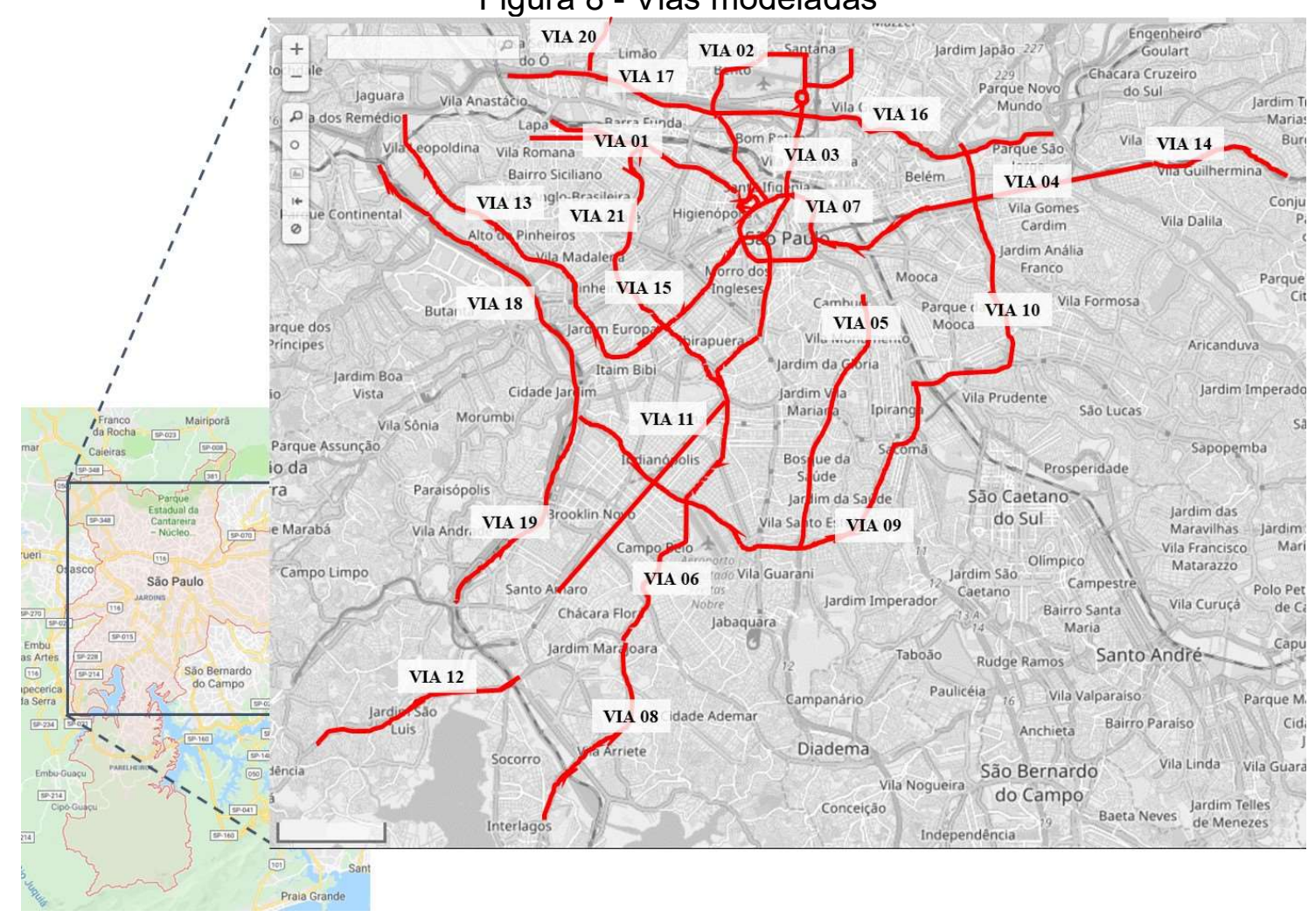

Algumas vias correspondem à extensão completa de algumas ruas e avenidas, como por exemplo a Via 01 (Rua Clélia, Rua Guaicurus, Avenida Francisco Matarazzo e Avenida São João), e outras correspondem apenas a um trecho, como é o caso das Vias 18 e 19 que juntas percorrem a Marginal Pinheiros.

Com exceção da Via 07 , todas as vias possuem dois sentidos, classificados predominantemente como Bairro-Centro e Centro-Bairro. A Via 07 representa a rótula central da cidade e, assim como na realidade atual, possui 
apenas o sentido anti-horário. Neste caso a via foi dividida entre pista direita e pista esquerda.

As figuras de Figura 9 a Figura 29 mostram detalhadamente os percursos e sentidos de cada uma das vias.

Figura 9 - Detalhe dos sentidos da Via 01

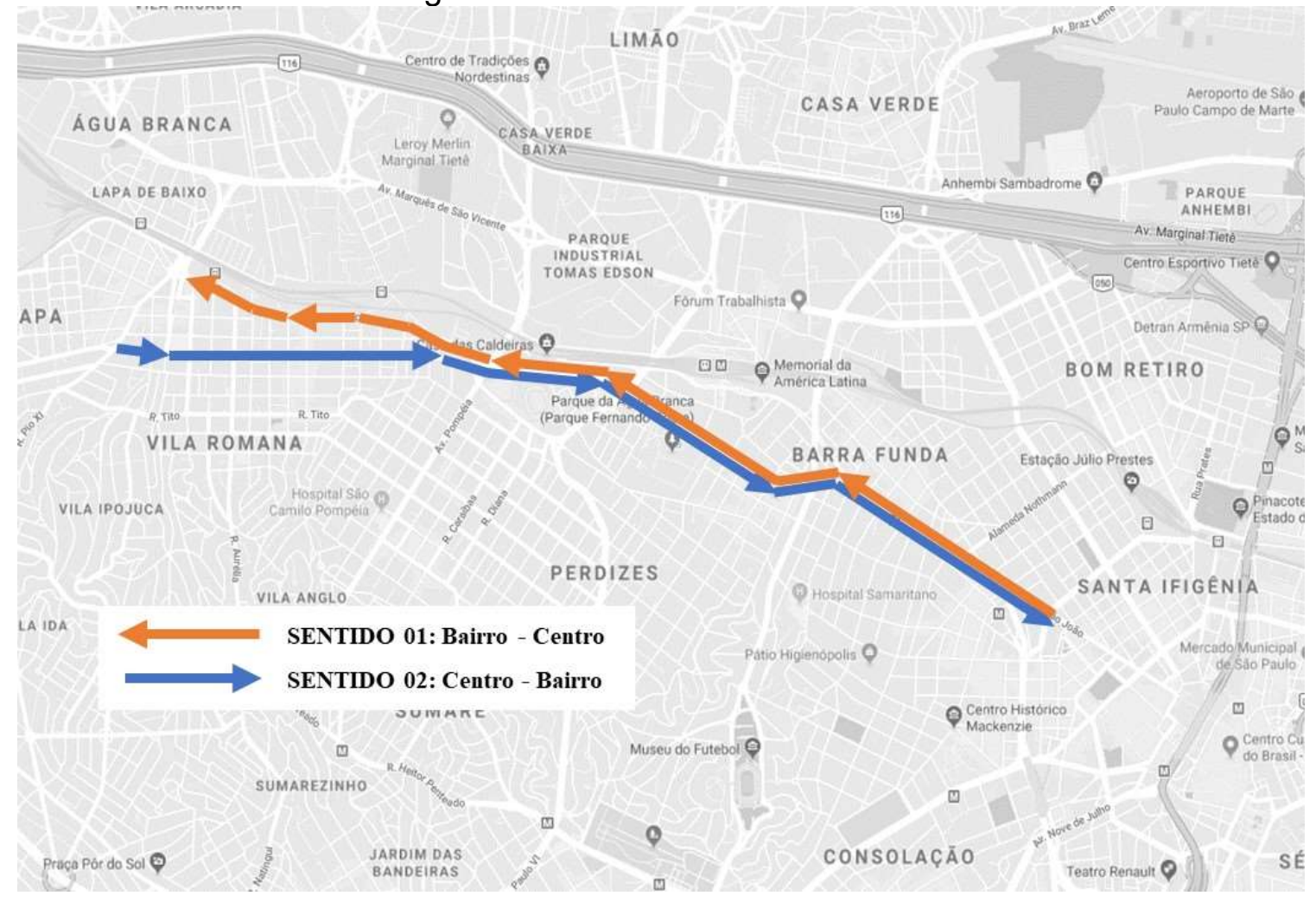


Figura 10- Detalhe dos sentidos da Via 02

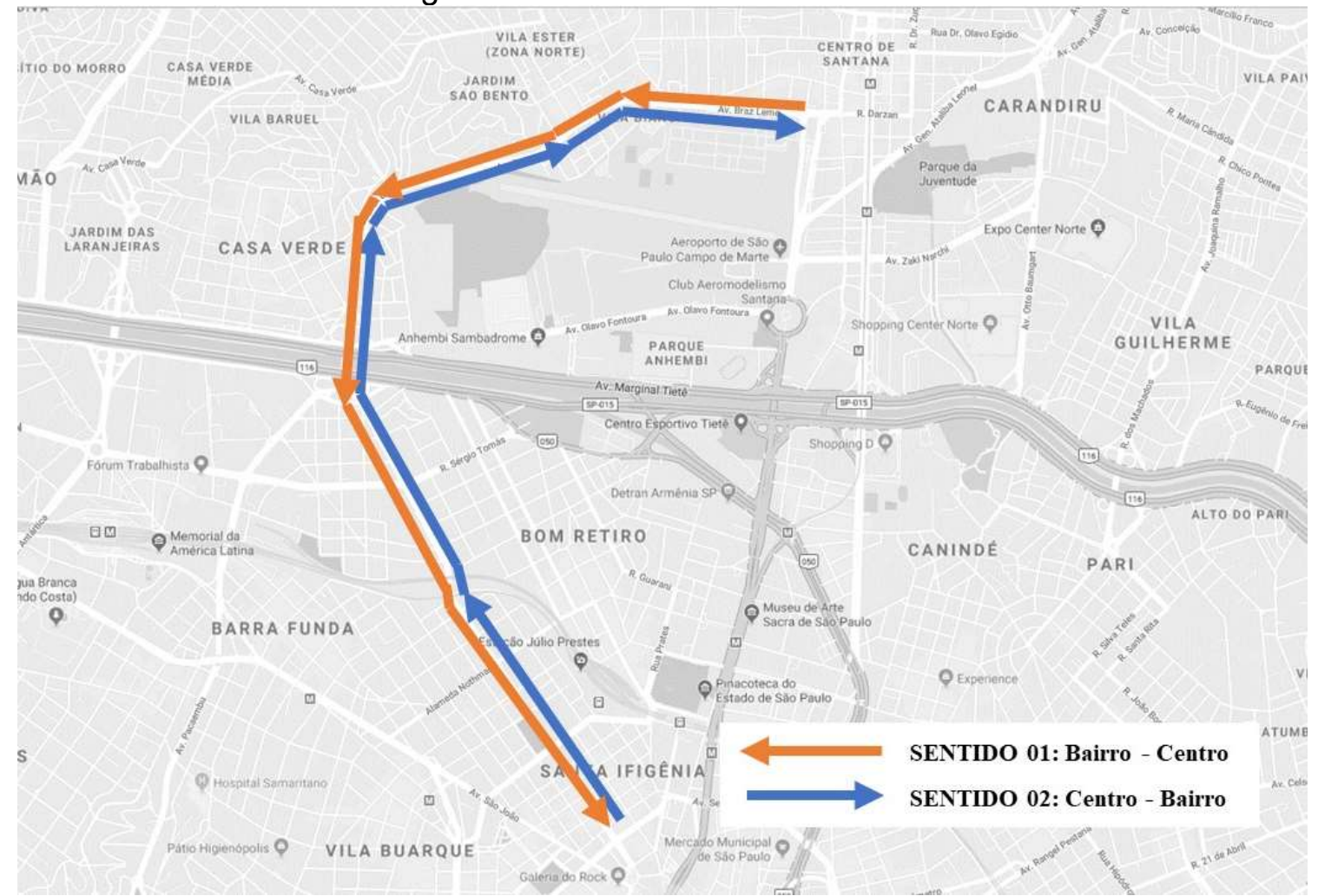

Figura 11 - Detalhe dos sentidos da Via 03

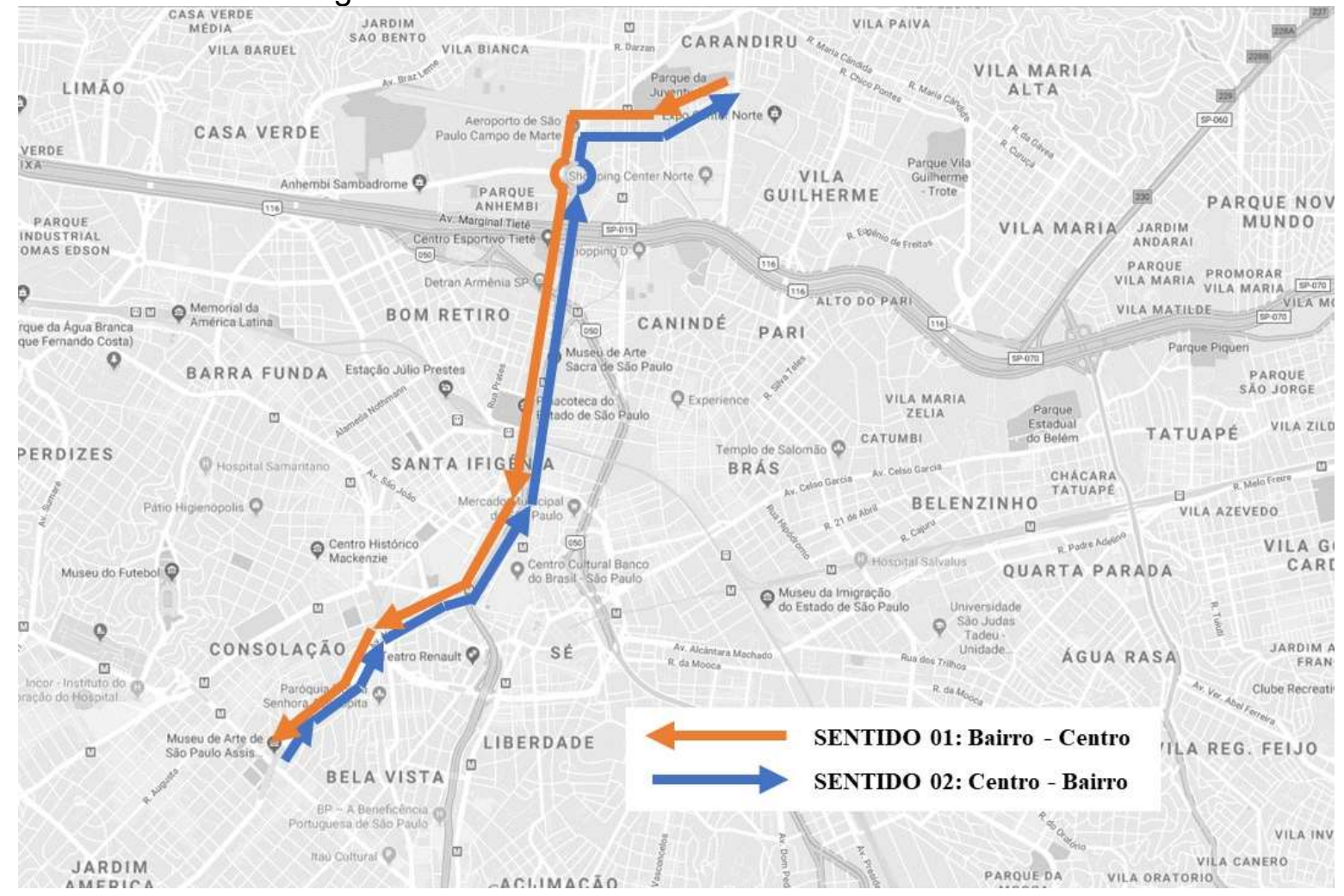


Figura 12 - Detalhe dos sentidos da Via 04

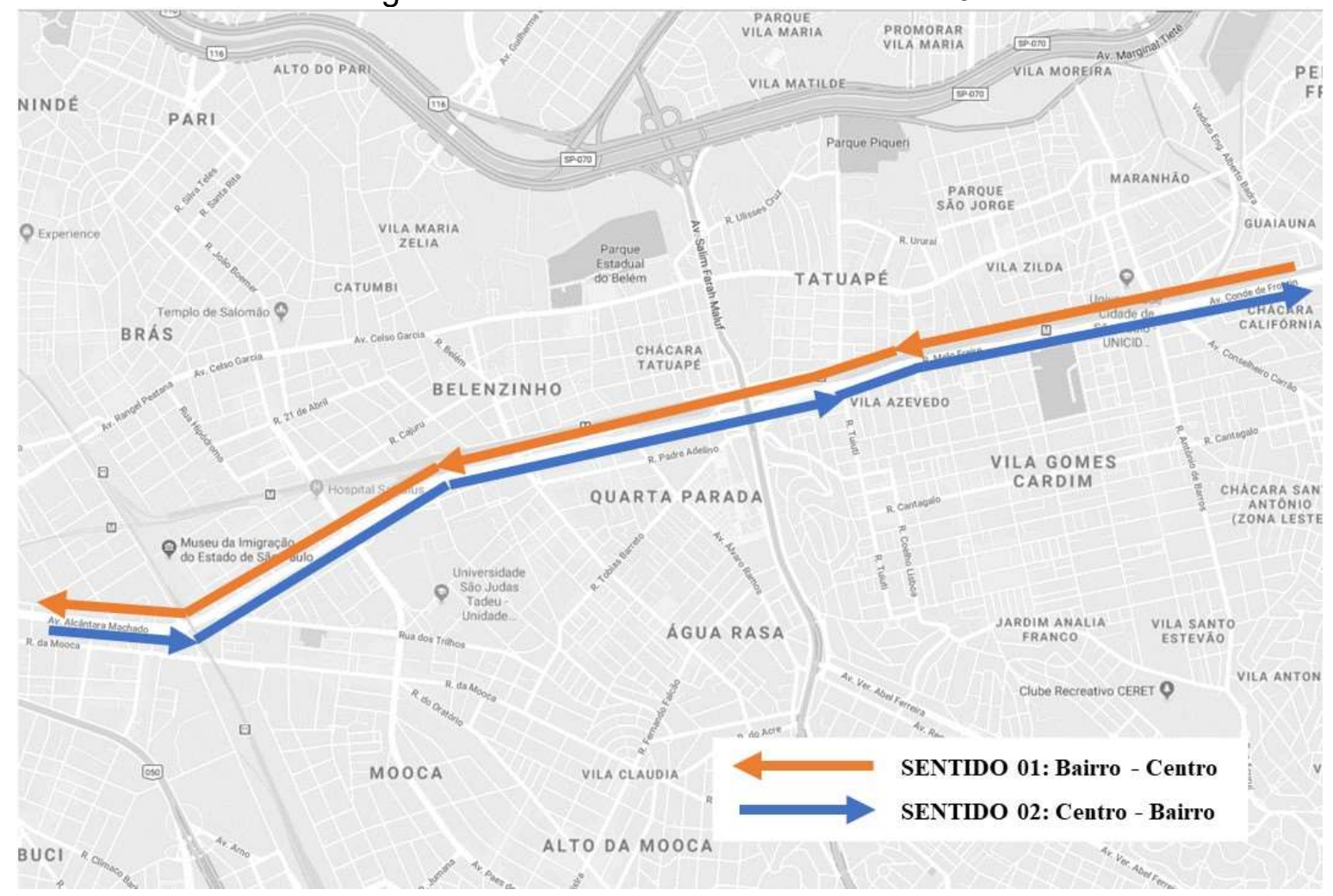

Figura 13 - Detalhe dos sentidos da Via 05

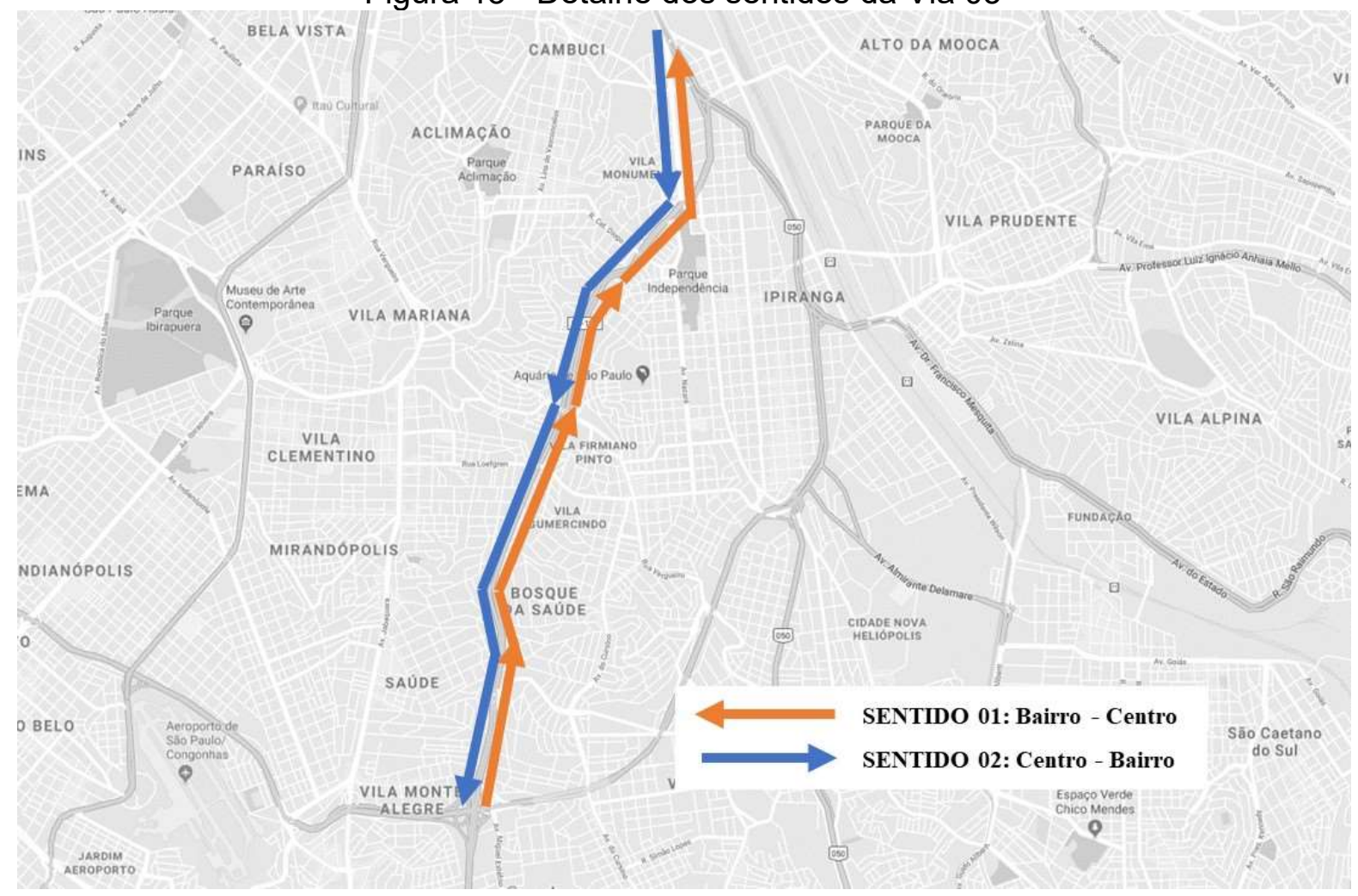


Figura 14 - Detalhe dos sentidos da Via 06

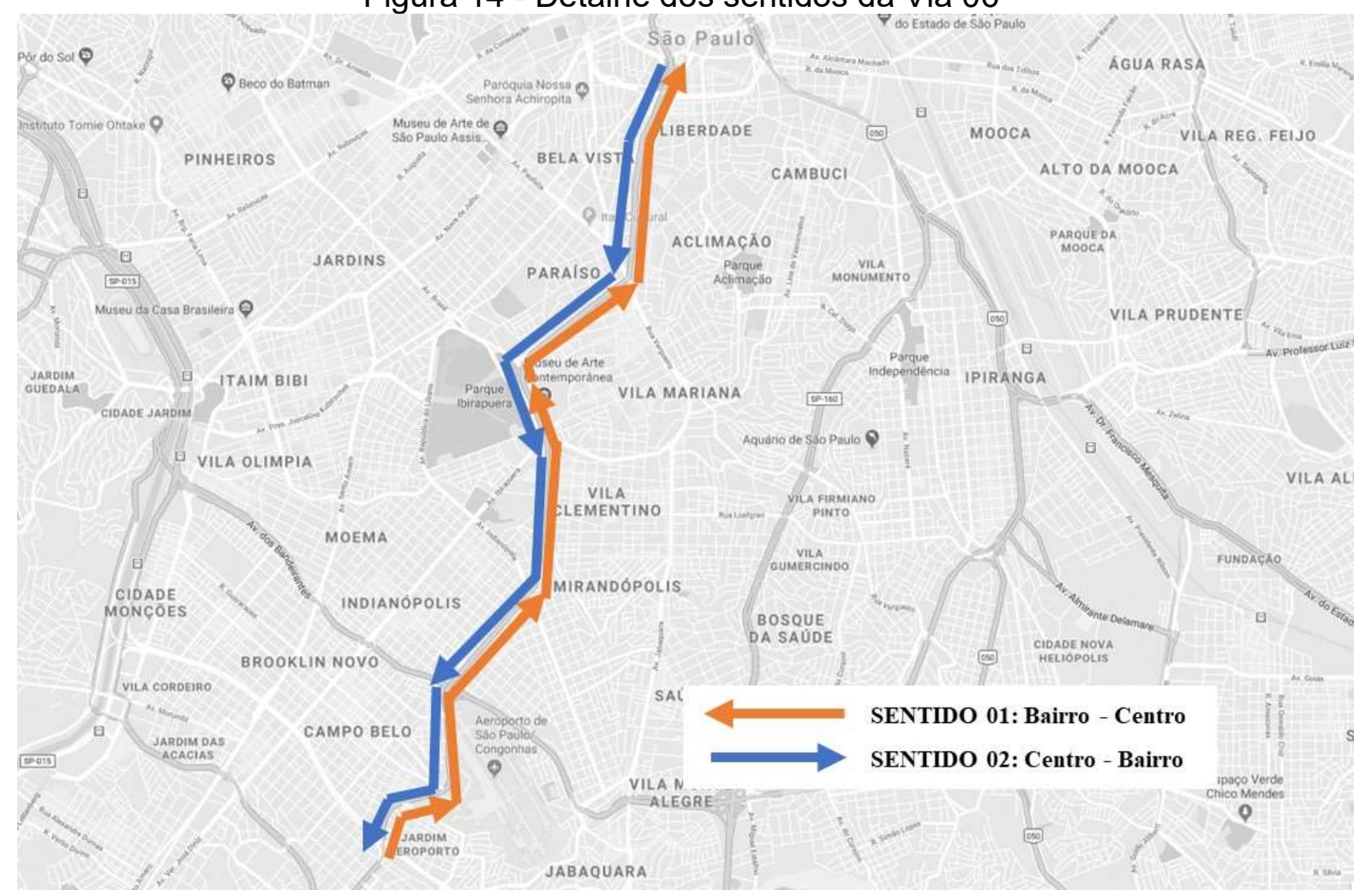

Figura 15 - Detalhe dos sentidos da Via 07

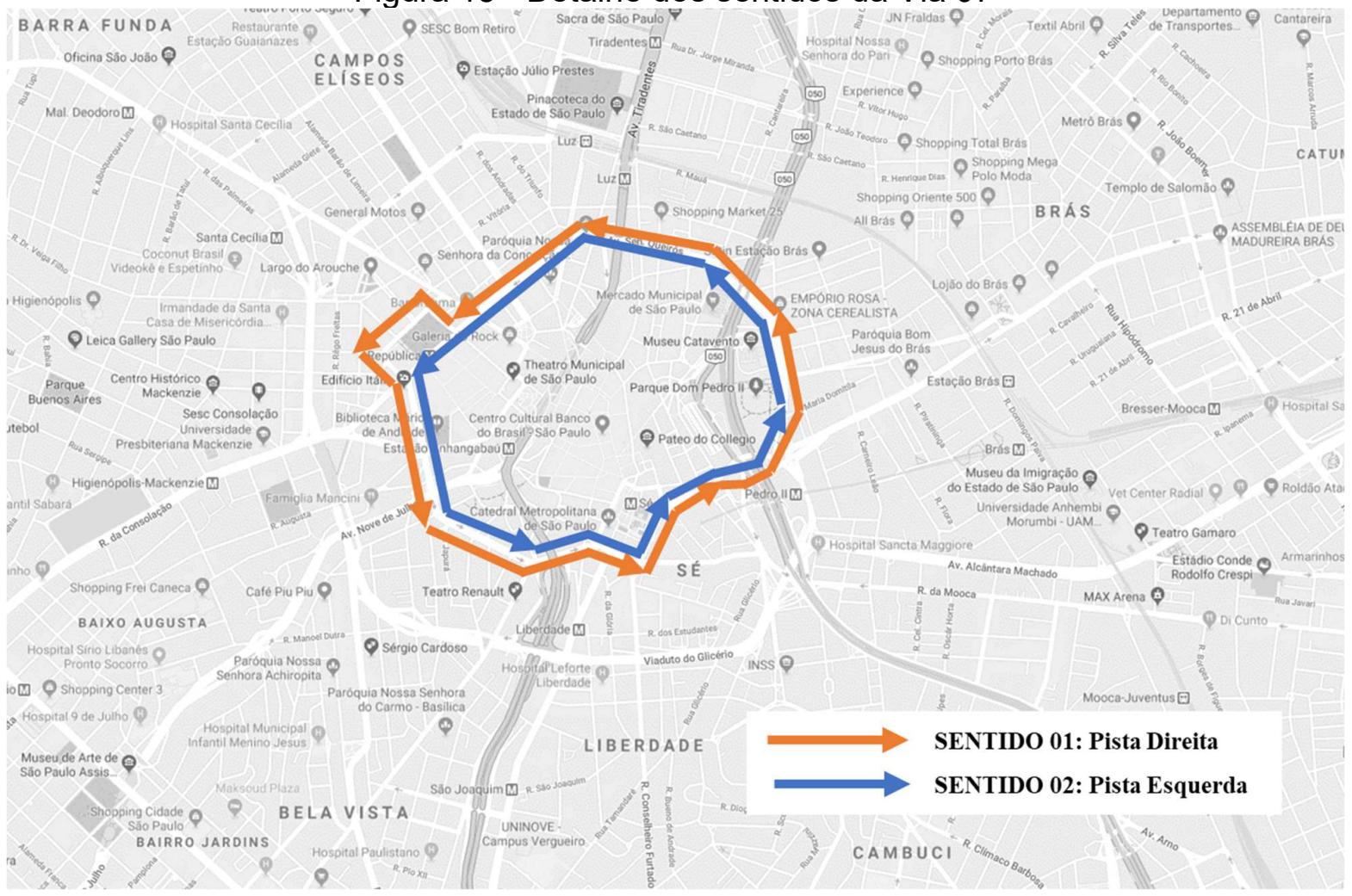


Figura 16 - Detalhe dos sentidos da Via 08

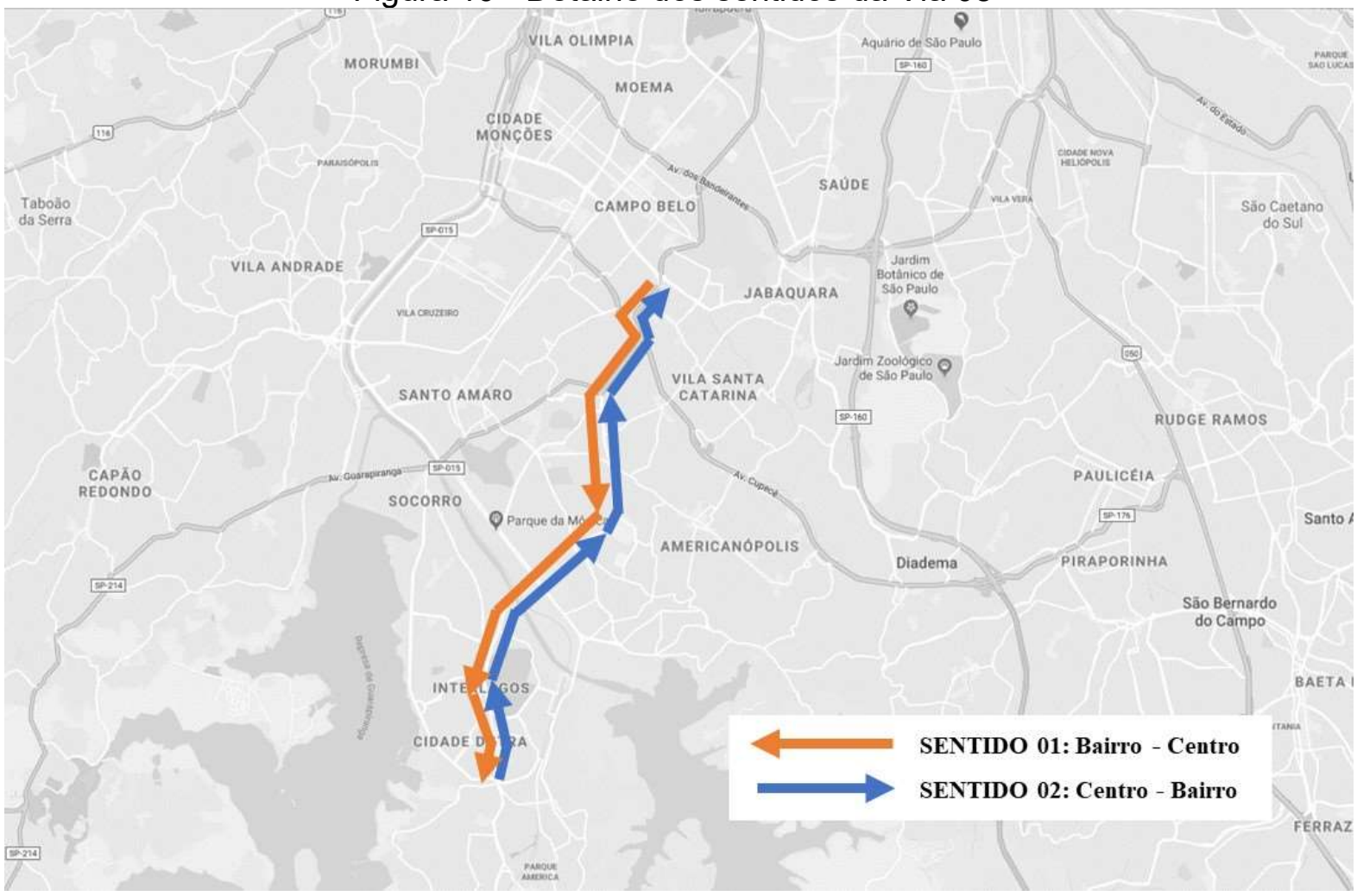

Figura 17 - Detalhe dos sentidos da Via 09

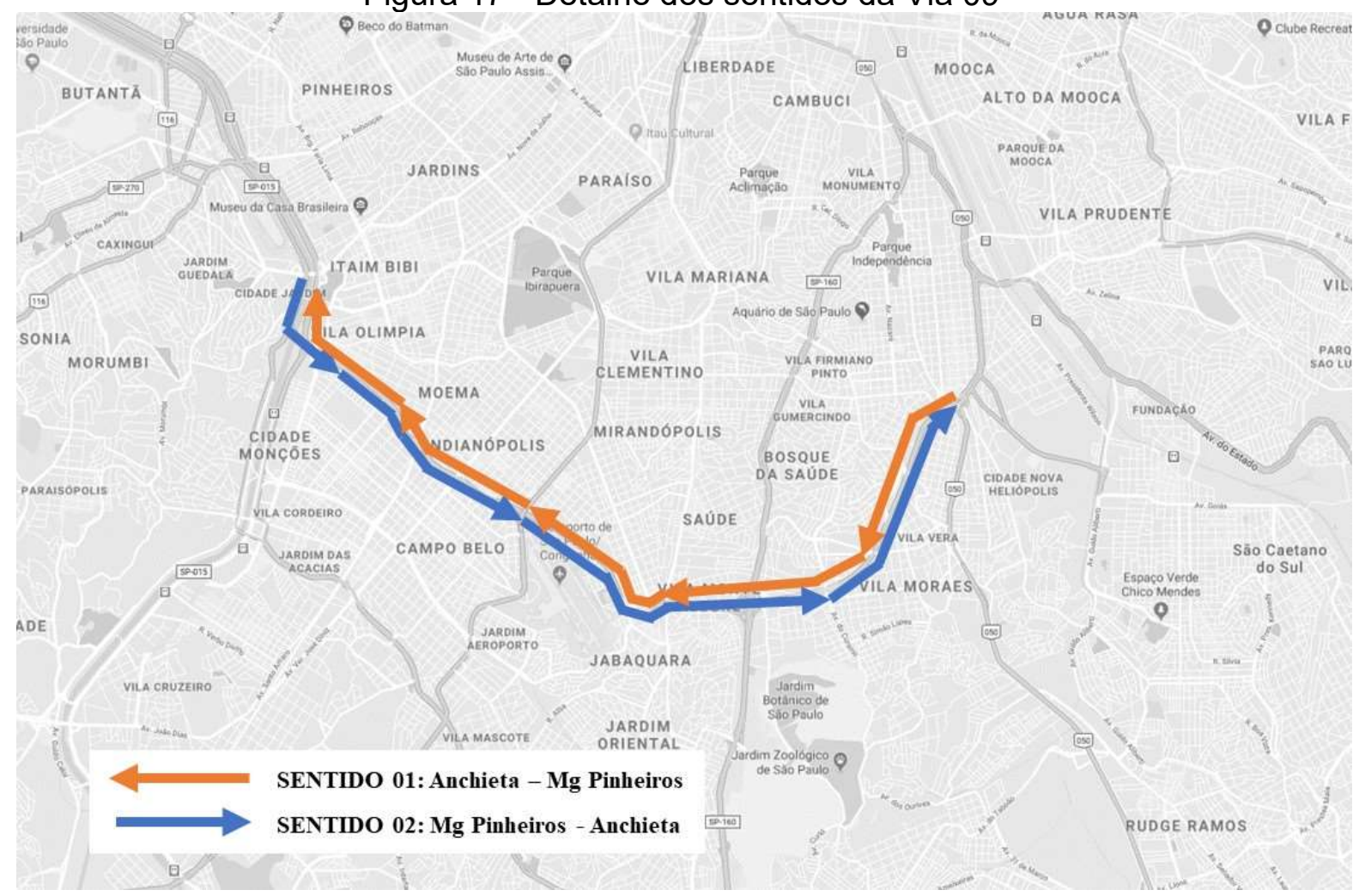


Figura 18 - Detalhe dos sentidos da Via 10

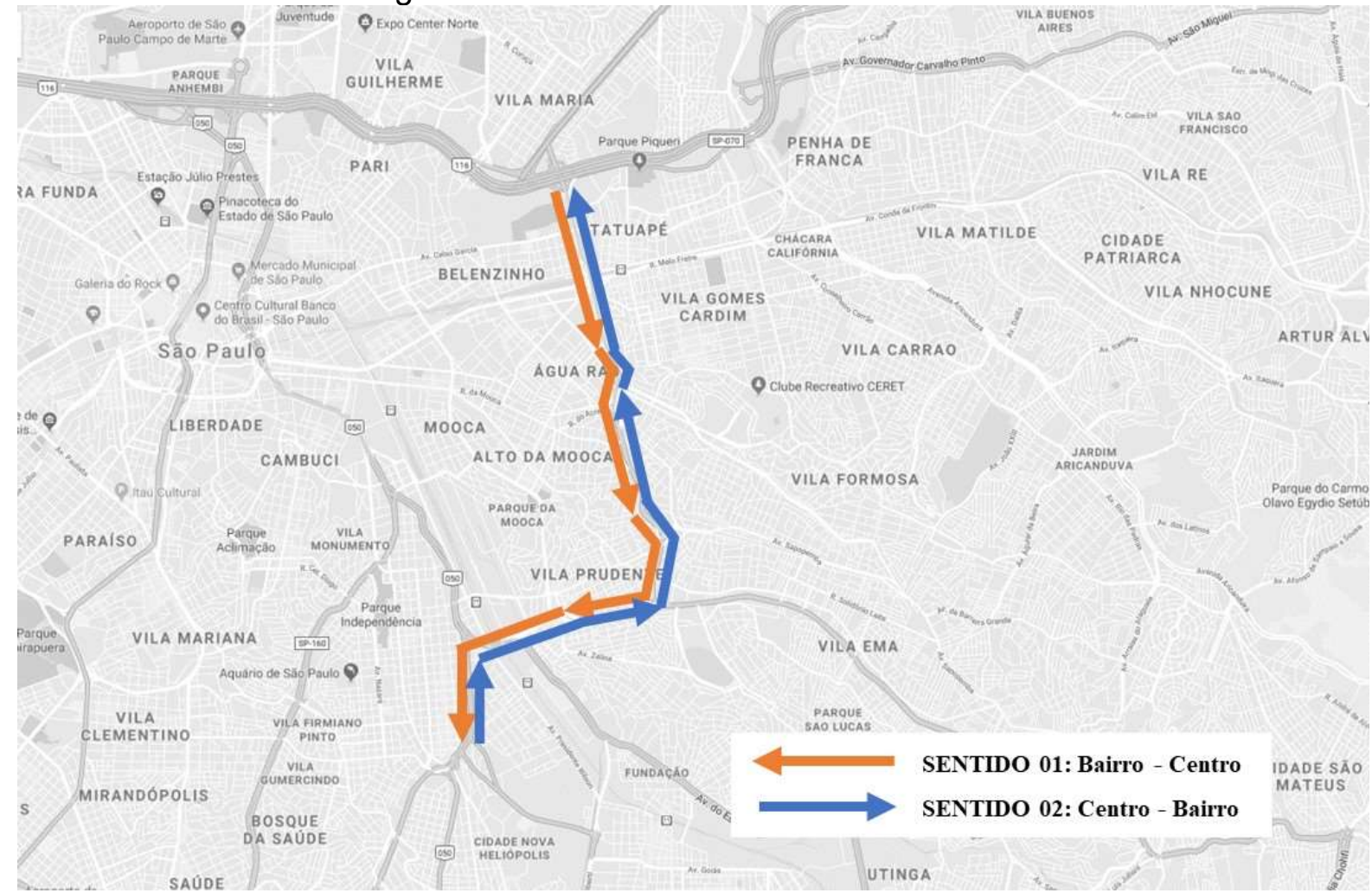

Figura 19 - Detalhe dos sentidos da Via 11

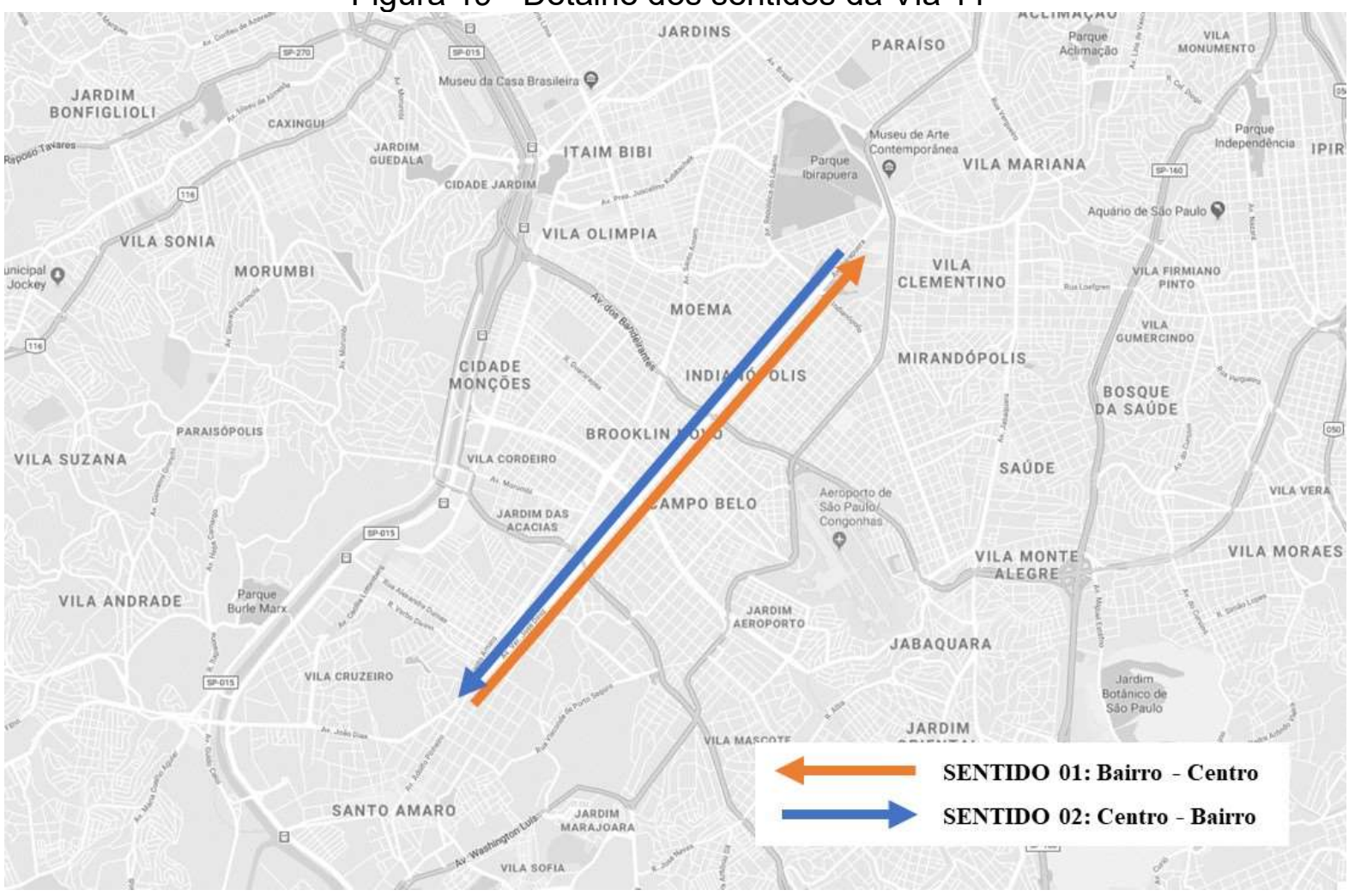


Figura 20 - Detalhe dos sentidos da Via 12

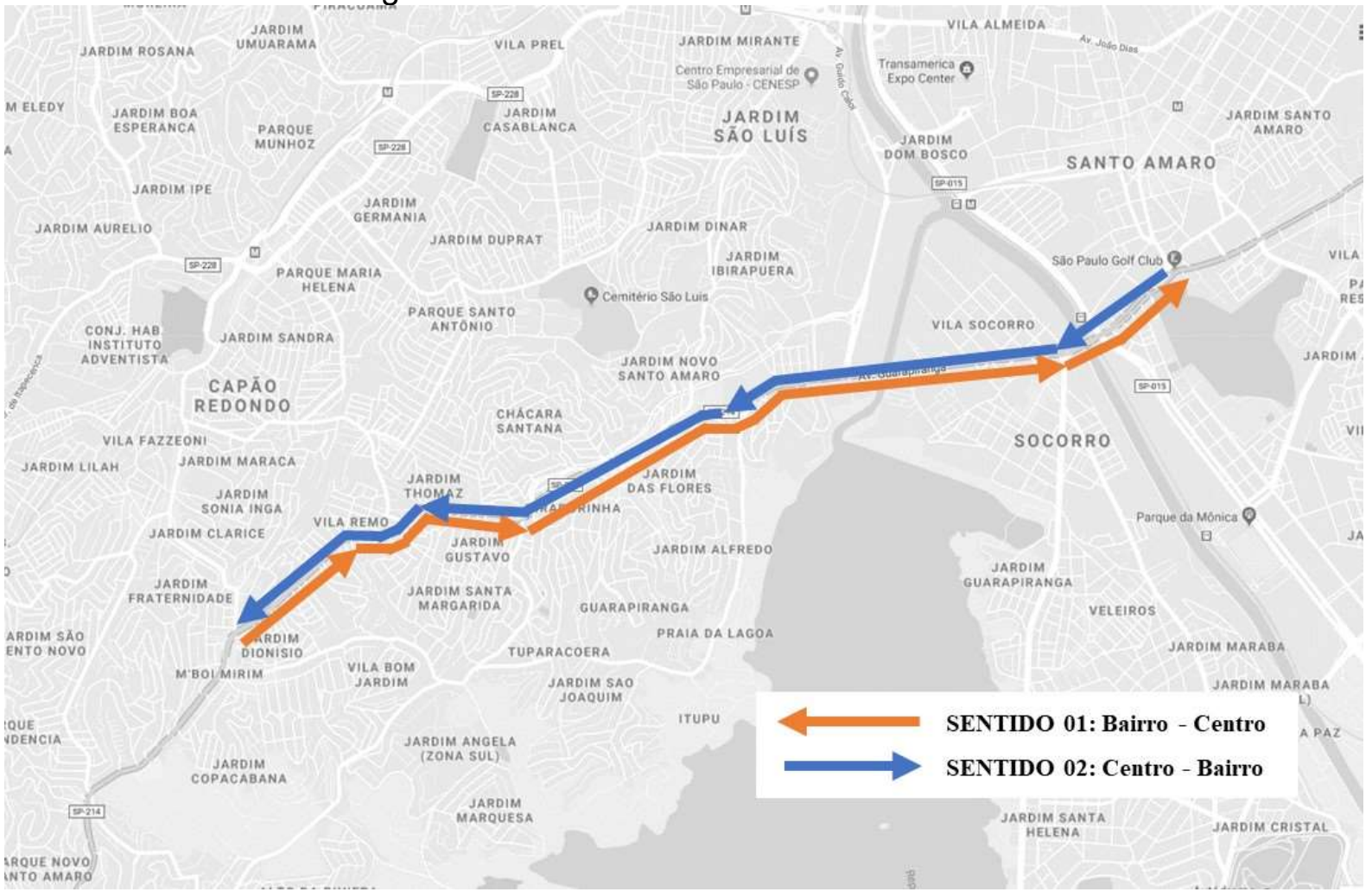

Figura 21 - Detalhe dos sentidos da Via 13

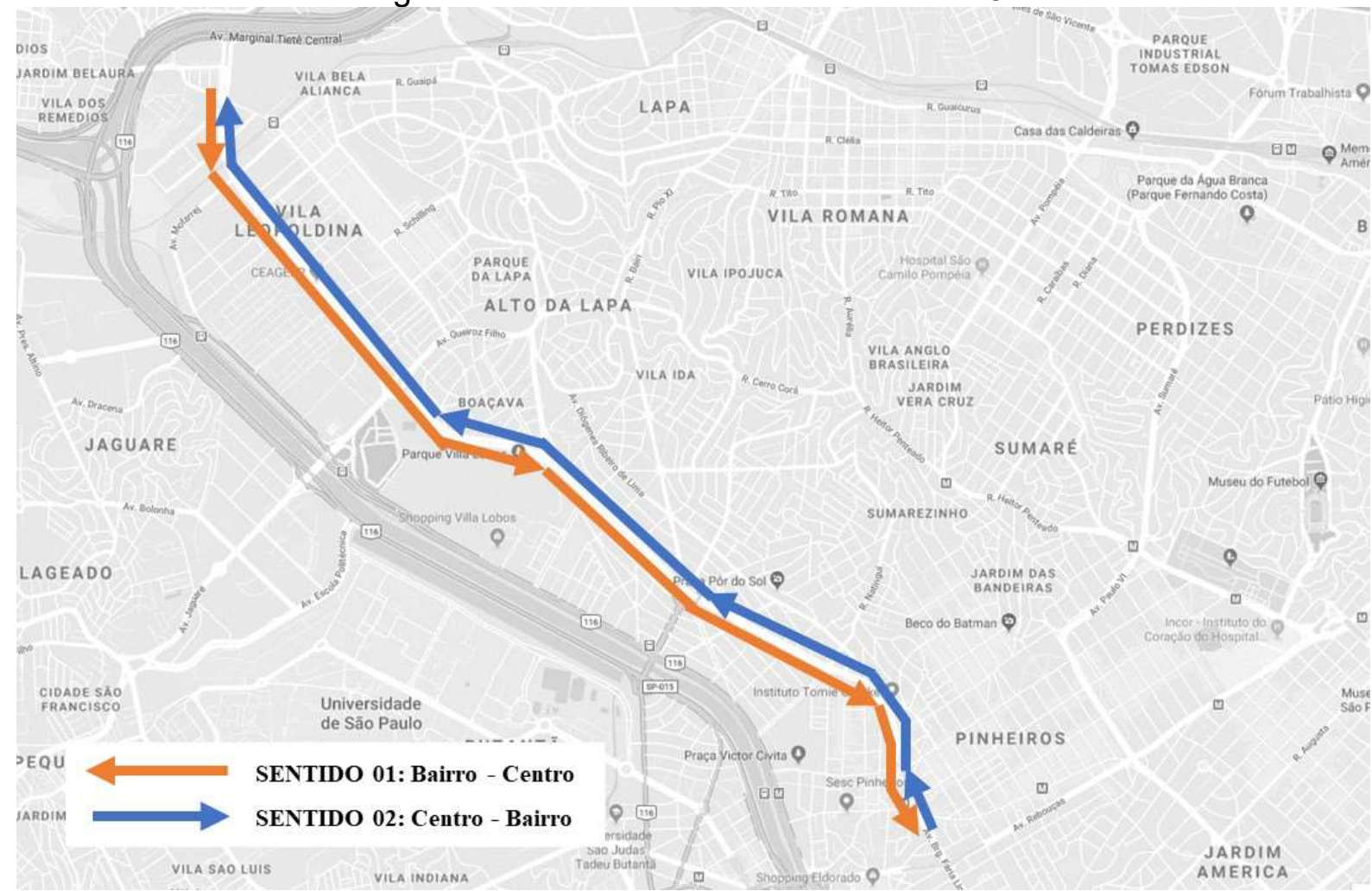


Figura 22 - Detalhe dos sentidos da Via 14

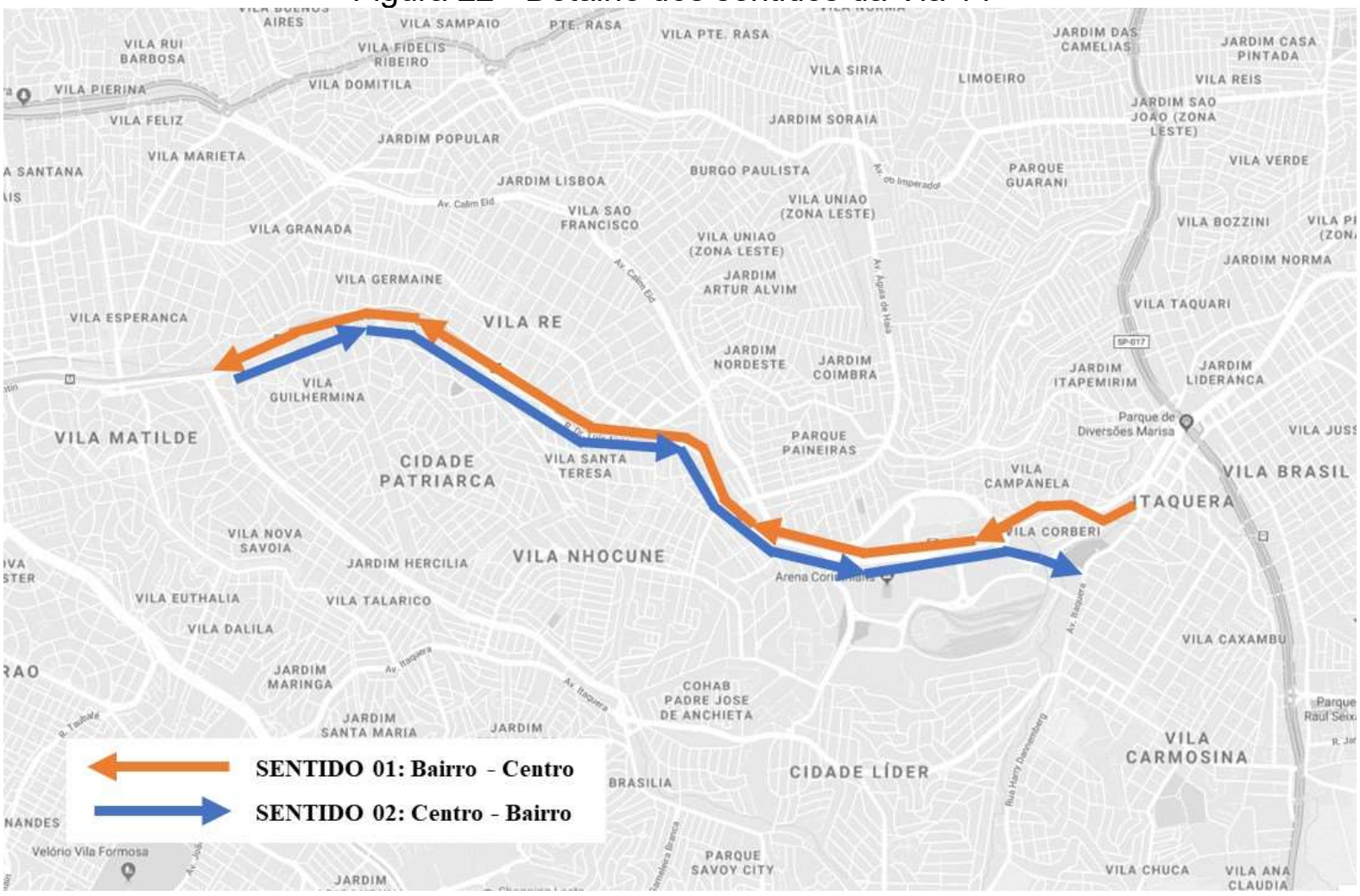

Figura 23 - Detalhe dos sentidos da Via 15

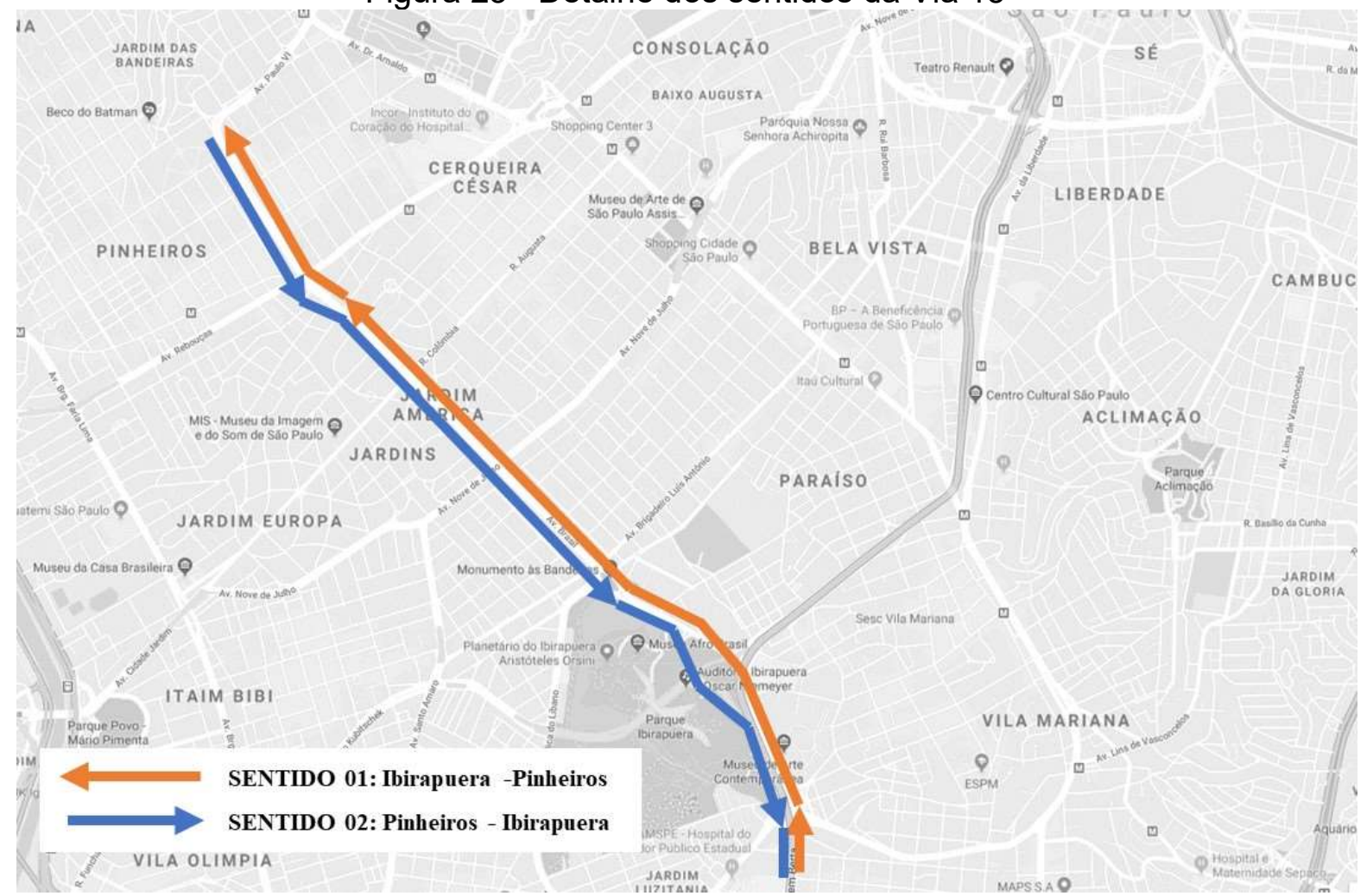


Figura 24 - Detalhe dos sentidos da Via 16

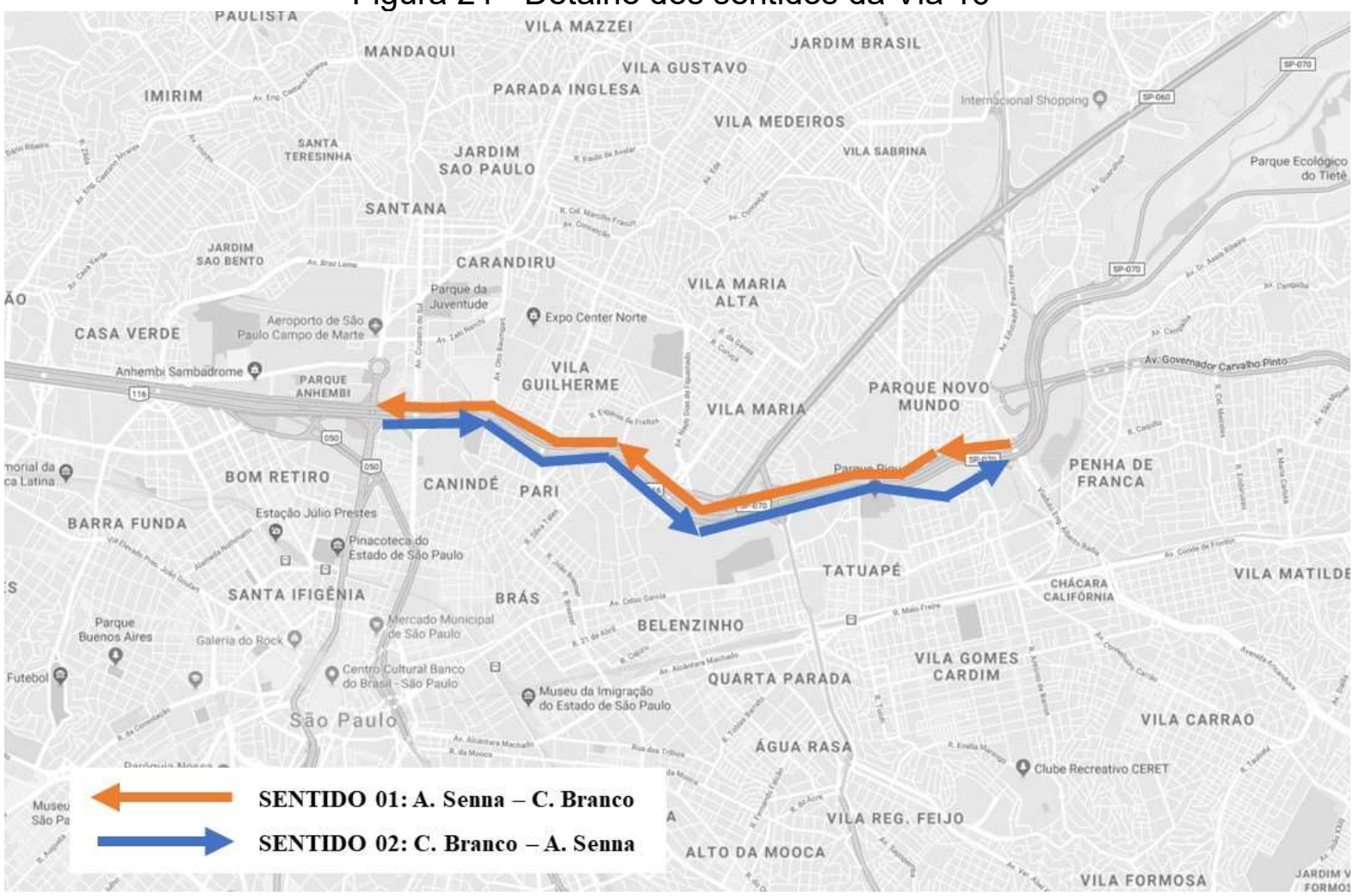

Figura 25 - Detalhe dos sentidos da Via 17

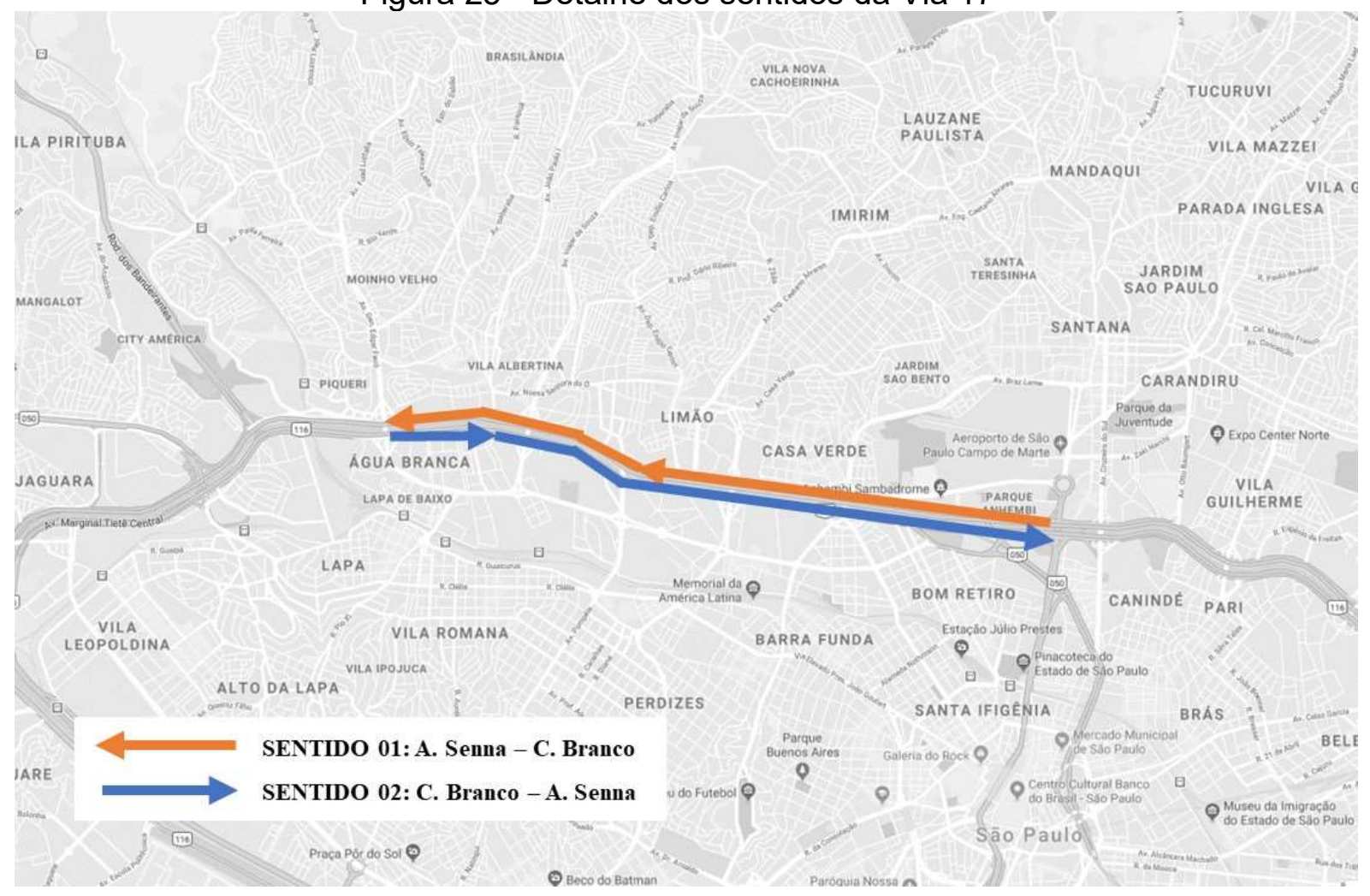


Figura 26 - Detalhe dos sentidos da Via 18

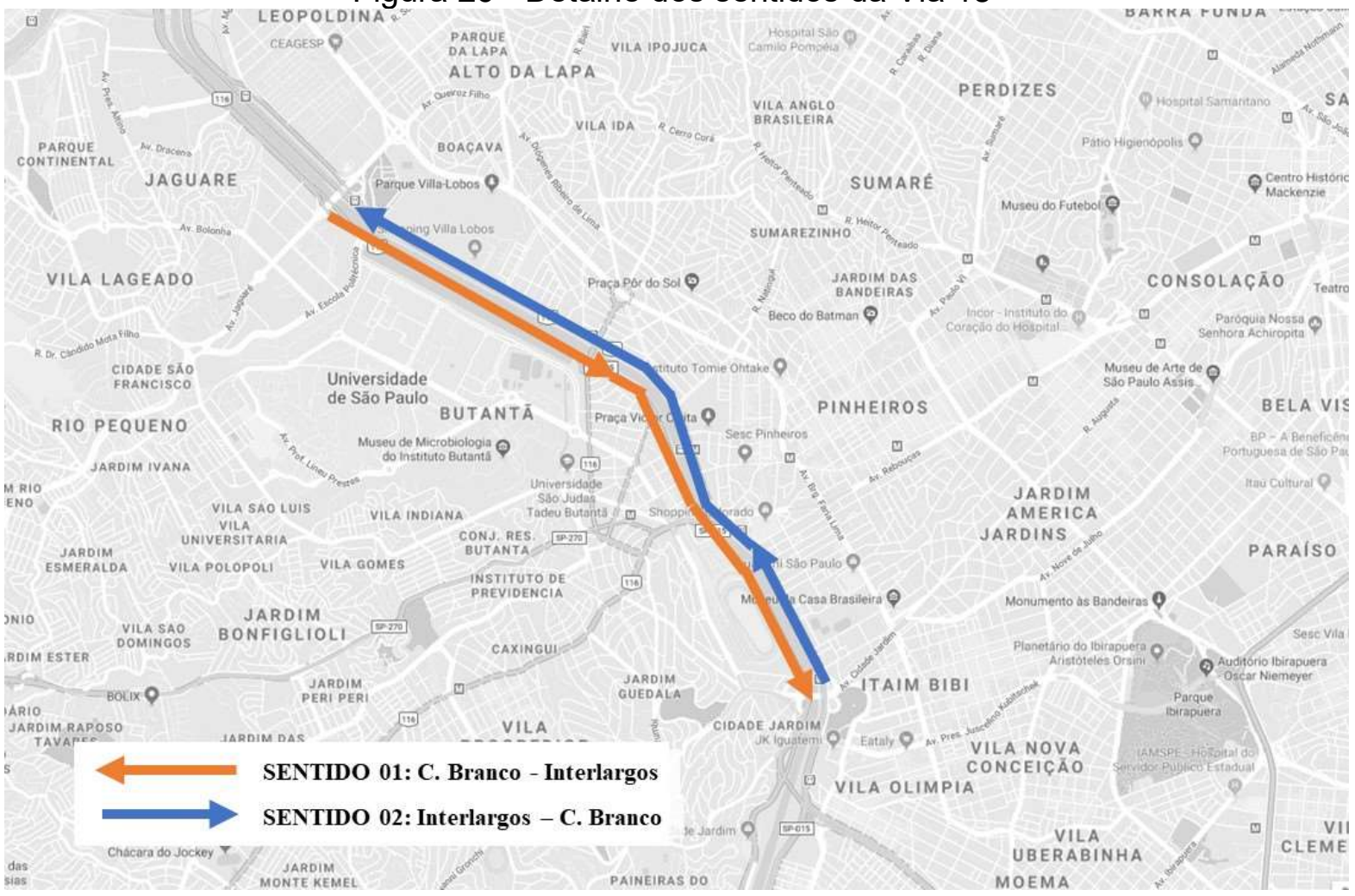

Figura 27 - Detalhe dos sentidos da Via 19

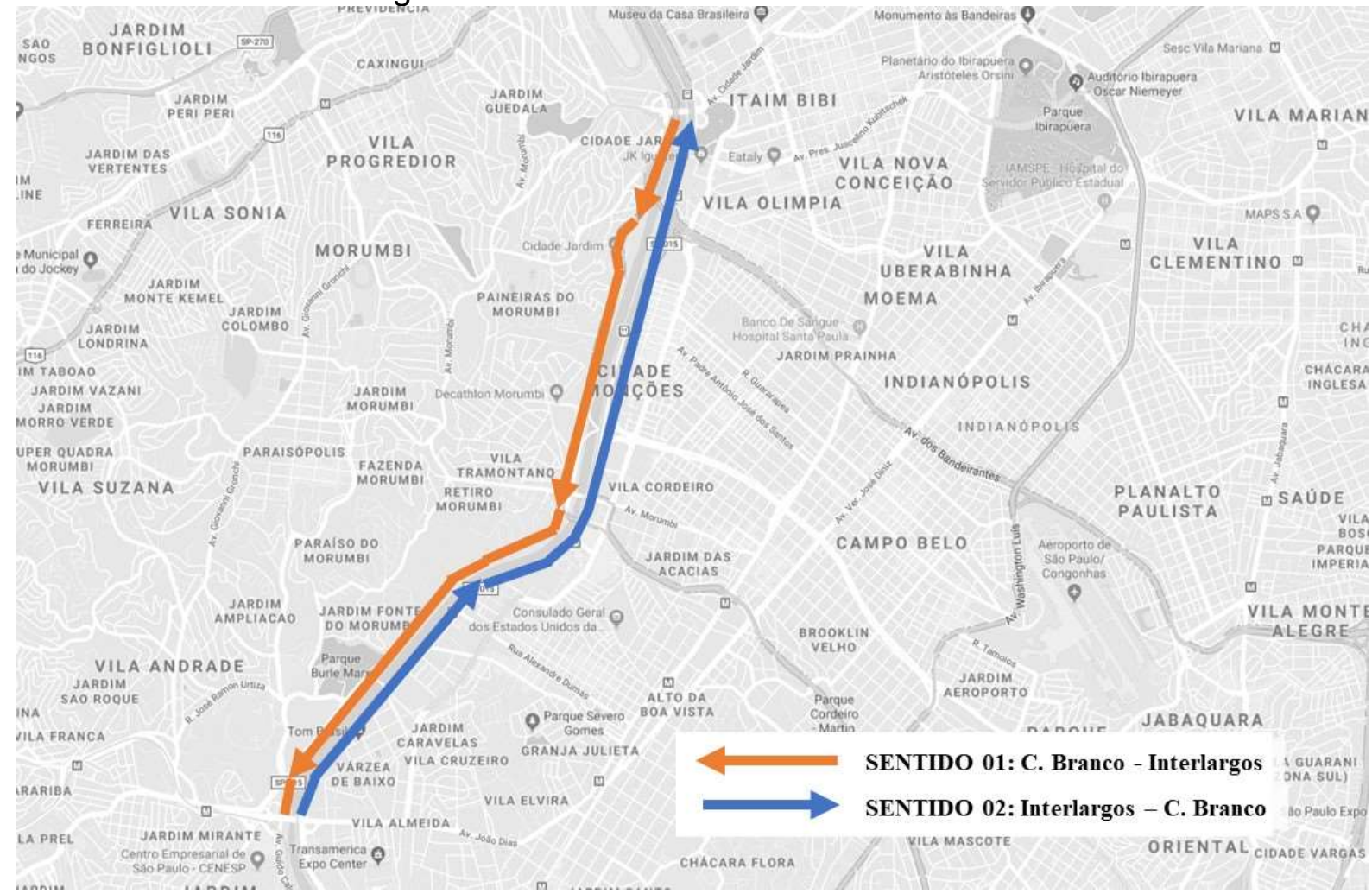


Figura 28 - Detalhe dos sentidos da Via 20

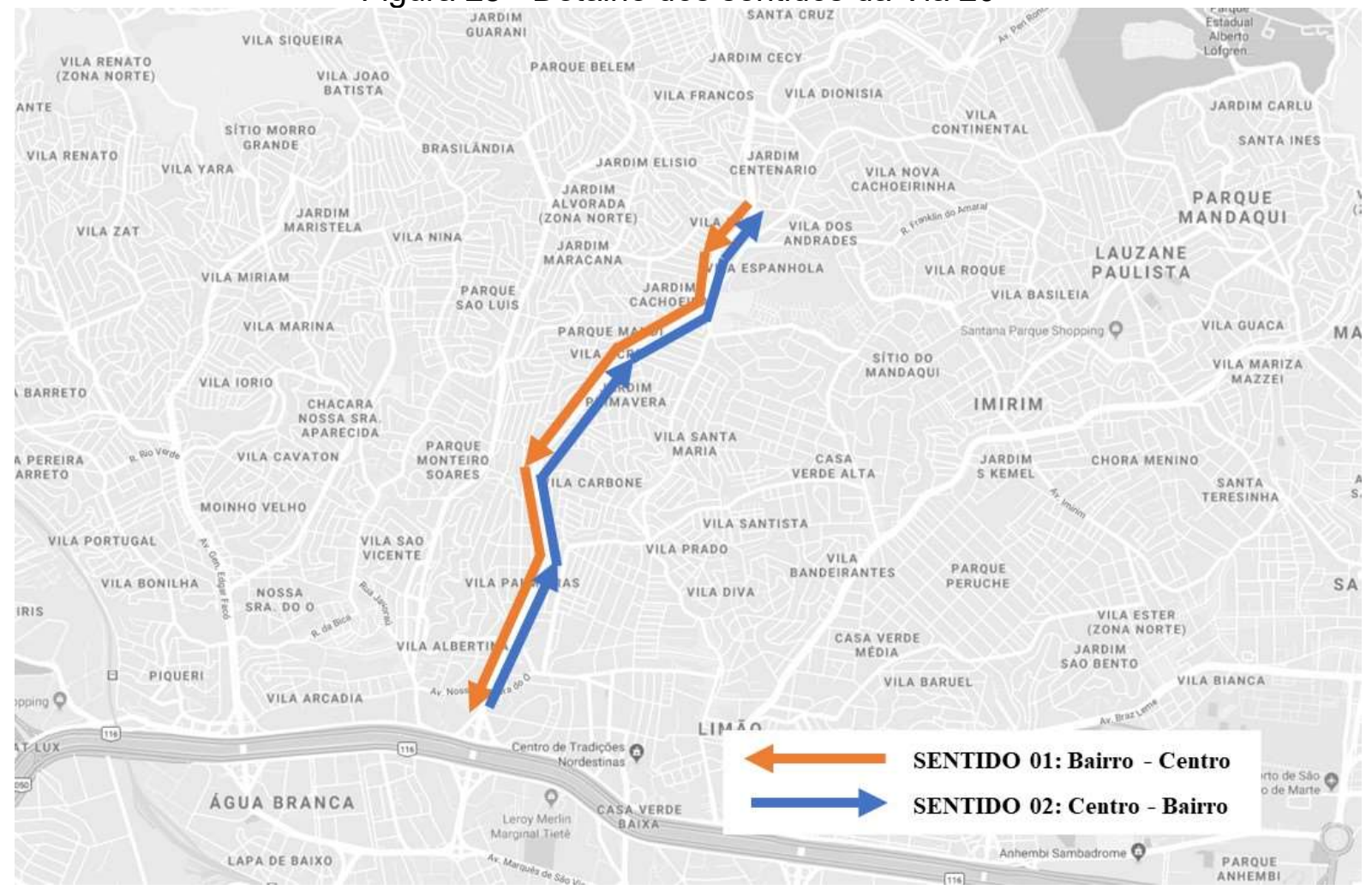

Figura 29 - Detalhe dos sentidos da Via 21

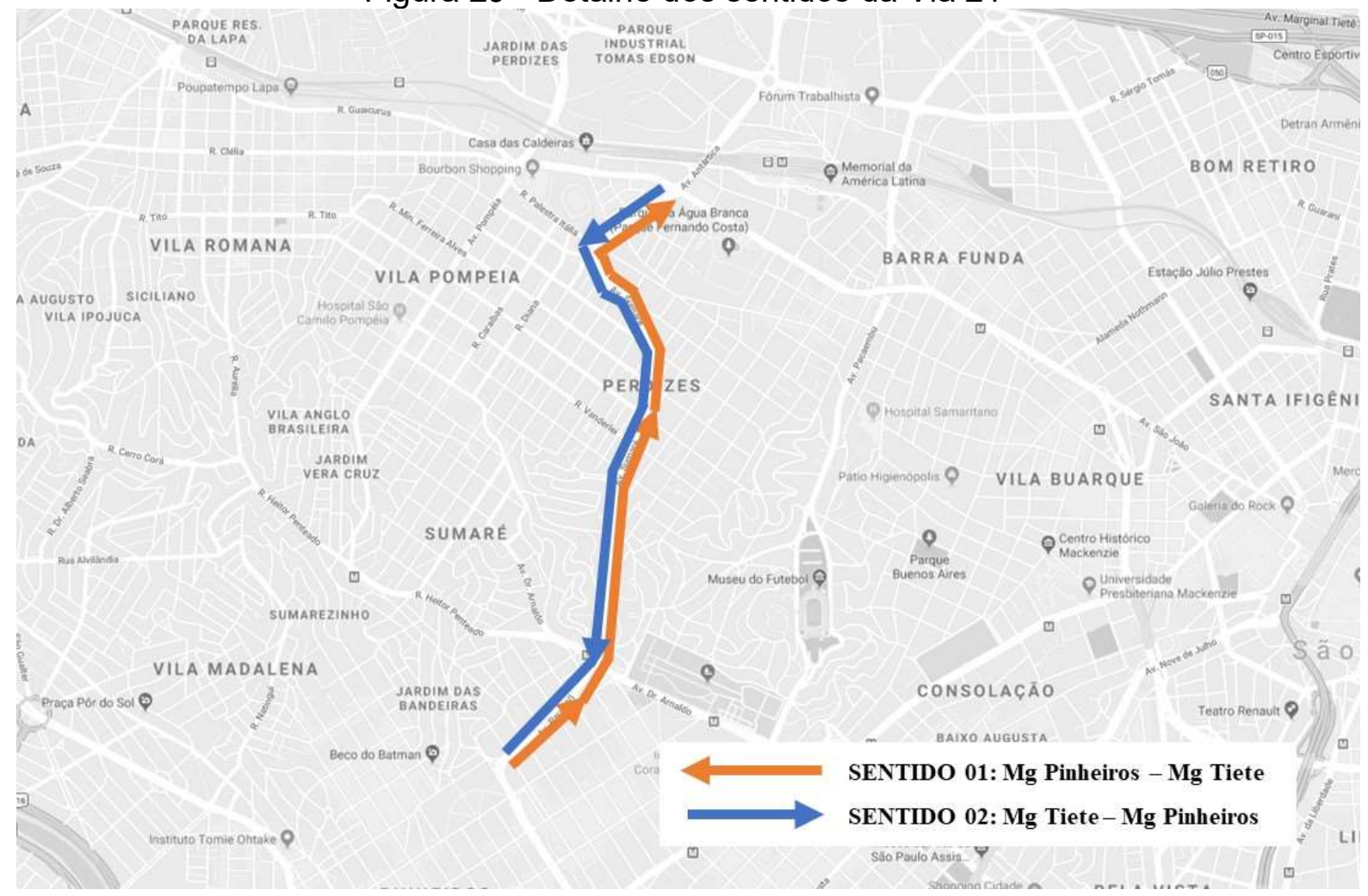


A Tabela 13 detalha os endereços das rotas e os sentidos de cada via.

Tabela 13 - Rotas e sentidos das vias

\begin{tabular}{|c|c|c|c|}
\hline \multirow{2}{*}{ VIA } & \multirow{2}{*}{ ROTA } & \multicolumn{2}{|c|}{ SENTIDO } \\
\hline & & 01 & 02 \\
\hline VIA 01 & $\begin{array}{l}\text { R. Clélia, R. Guaicurus, Av. Francisco } \\
\text { Matarazzo, Av. São João Bairro }\end{array}$ & Bairro - Centro & Centro - Bairro \\
\hline VIA 02 & Av. Braz Leme, Av. Rudge, Av. Rio Branco & Bairro - Centro & Centro - Bairro \\
\hline VIA 03 & $\begin{array}{l}\text { Av. Zaki Narchi, Av. Santos Dumont, Av. } \\
\text { Prestes Maia }\end{array}$ & Bairro - Centro & Centro - Bairro \\
\hline VIA 04 & $\begin{array}{l}\text { Radial Leste (R. Melo Freire, Av. Alcântara } \\
\text { Machado) }\end{array}$ & Bairro - Centro & Centro - Bairro \\
\hline VIA 05 & $\begin{array}{l}\text { Av. Dom Pedro I, Av. Dr. Ricardo Jafet, Av. } \\
\text { Prof. Abraão de Morais }\end{array}$ & Bairro - Centro & Centro - Bairro \\
\hline VIA 06 & $\begin{array}{l}\text { Av. Washington Luís, Av. Rubem Berta, Av. } \\
23 \text { de Maio }\end{array}$ & Bairro - Centro & Centro - Bairro \\
\hline VIA 07 & $\begin{array}{l}\text { Rótula Central (R. Maria Paula, Av. Senador } \\
\text { Queiróz, Av. Ipiranga) }\end{array}$ & Pista Direita & Pista Esquerda \\
\hline VIA 08 & $\begin{array}{l}\text { Av. Sen. Teotônio Vilela, Av. Interlagos, Av. } \\
\text { Washington Luís }\end{array}$ & Bairro - Centro & Centro - Bairro \\
\hline VIA 09 & $\begin{array}{l}\text { Av. dos Bandeirantes, Av. Pres. Tancredo } \\
\text { Neves }\end{array}$ & $\begin{array}{l}\text { Anchieta - Mg } \\
\text { Pinheiros }\end{array}$ & $\begin{array}{l}\text { Mg Pinheiros - } \\
\text { Anchieta }\end{array}$ \\
\hline VIA 10 & $\begin{array}{l}\text { Av. das Juntas Provisórias, Av. Luís Inácio } \\
\text { Anhaia Melo, Av. Salim Farah Maluf }\end{array}$ & Bairro - Centro & Centro - Bairro \\
\hline VIA 11 & Av. Ver. José Diniz, Av. Ibirapuera & Bairro - Centro & Centro - Bairro \\
\hline VIA 12 & Estr. do M'Boi Mirim, Av. Guarapiranga & Bairro - Centro & Centro - Bairro \\
\hline VIA 13 & $\begin{array}{l}\text { Av. Gastão Vidigal, Av. Prof. F. Rodrigues, } \\
\text { Av. Pedroso de Morais }\end{array}$ & Bairro - Centro & Centro - Bairro \\
\hline VIA 14 & $\begin{array}{l}\text { Av. Radial Leste (Av. Dr. Luís Aires, Av. } \\
\text { Antônio Estevão de Carvalho, Av. Conde de } \\
\text { Frontin) }\end{array}$ & Bairro - Centro & Centro - Bairro \\
\hline VIA 15 & $\begin{array}{l}\text { R. Henrique Schaumann, Av. Brasil, Av. } \\
\text { Pedro Álvares Cabral }\end{array}$ & $\begin{array}{l}\text { Ibirapuera - } \\
\text { Pinheiros }\end{array}$ & $\begin{array}{l}\text { Pinheiros - } \\
\text { Ibirapuera }\end{array}$ \\
\hline VIA 16 & $\begin{array}{l}\text { Marg. Tietê (Av. Pres. Castelo Branco, Av. } \\
\text { Condessa Elisabeth de Robiano, Av. Morvan } \\
\text { Dias Figueiredo) }\end{array}$ & $\begin{array}{l}\text { A. Senna - C. } \\
\text { Branco }\end{array}$ & $\begin{array}{l}\text { C. Branco - A. } \\
\text { Senna }\end{array}$ \\
\hline VIA 17 & $\begin{array}{l}\text { Marginal do Rio Tietê (Av. Assis } \\
\text { Chateaubriand, Av. Otaviano A. de Lima, Av. } \\
\text { Emb. Macedo Soares, Av. Pres. Castelo } \\
\text { Branco) }\end{array}$ & $\begin{array}{l}\text { A. Senna - C. } \\
\text { Branco }\end{array}$ & $\begin{array}{l}\text { C. Branco - A. } \\
\text { Senna }\end{array}$ \\
\hline VIA 18 & $\begin{array}{l}\text { Marg. Pinheiros (Av. das Nações Unidas, Av. } \\
\text { Magalhães de Castro, Av. Eng. Billings) }\end{array}$ & $\begin{array}{l}\text { C. Branco - } \\
\text { Interlargos }\end{array}$ & $\begin{array}{l}\text { Interlargos - C. } \\
\text { Branco }\end{array}$ \\
\hline VIA 19 & $\begin{array}{l}\text { Marginal do Rio Pinheiros (Av. das Nações } \\
\text { Unidas, Av. Magalhães de Castro, Av. } \\
\text { Alcides Sangirardi) }\end{array}$ & $\begin{array}{l}\text { C. Branco - } \\
\text { Interlargos }\end{array}$ & $\begin{array}{l}\text { Interlargos - C. } \\
\text { Branco }\end{array}$ \\
\hline VIA 20 & Av. Inajar de Souza & Bairro - Centro & Centro - Bairro \\
\hline VIA 21 & Av. Paulo VI, Av. Sumaré, Av. Antártica & $\begin{array}{l}\text { Mg Pinheiros - } \\
\text { Mg Tietê }\end{array}$ & $\begin{array}{l}\text { Mg Tietê - Mg } \\
\text { Pinheiros }\end{array}$ \\
\hline
\end{tabular}


Todas as vias possuem dois sentidos de tráfego, totalizando 42 rotas. Por ser um sistema aberto, diferente do cenário adotado no modelo inicial, os veículos entram no sistema pelas extremidades das vias e deixam o sistema após completarem suas viagens passando pela extensão total das vias. As premissas deste cenário são:

i. Os veículos deixam o sistema após completarem as viagens

ii. Nenhuma colisão é permitida e todos os veículos respeitam os tempos semafóricos nas interseções onde estes existirem.

iii. Mudanças de faixas são permitidas desde que não resultem em colisões.

iv. Os veículos não podem trocar de vias no meio do percurso para entrarem em outras vias.

\subsection{Características dos veículos}

A Tabela 14 mostra o número de carros e caminhões em cada um dos sentidos durante as 3 horas do horário de pico da manhã ( $7 \mathrm{~h}$ as 10h) conforme consta no mapeamento da CET (2017). 
Tabela 14 - Número de veículos por rota

\begin{tabular}{|c|c|c|c|c|c|}
\hline Rota & Carros & Caminhões & Rota & Carros & Caminhões \\
\hline VIA 01 - Sentido 01 & 3.020 & 29 & VIA 01 - Sentido 02 & 2.864 & 27 \\
\hline VIA 02 - Sentido 01 & 4.590 & 52 & VIA 02 - Sentido 02 & 6.571 & 54 \\
\hline VIA 03 - Sentido 01 & 10.118 & 58 & VIA 03 - Sentido 02 & 8.195 & 32 \\
\hline VIA 04 - Sentido 01 & 14.614 & 39 & VIA 04 - Sentido 02 & 9.226 & 91 \\
\hline VIA 05 - Sentido 01 & 6.582 & 47 & VIA 05 - Sentido 02 & 5.381 & 85 \\
\hline VIA 06 - Sentido 01 & 18.003 & 26 & VIA 06 - Sentido 02 & 19.162 & 35 \\
\hline VIA 07 - Sentido 01 & 2.495 & 29 & VIA 07 - Sentido 02 & 3.750 & 28 \\
\hline VIA 08 - Sentido 01 & 4.929 & 114 & VIA 08 - Sentido 02 & 5.055 & 131 \\
\hline VIA 09 - Sentido 01 & 6.835 & 75 & VIA 09 - Sentido 02 & 7.773 & 108 \\
\hline VIA 10 - Sentido 01 & 7.785 & 213 & VIA 10 - Sentido 02 & 7.241 & 242 \\
\hline VIA 11 - Sentido 01 & 3.335 & 19 & VIA 11 - Sentido 02 & 4.303 & 24 \\
\hline VIA 12 - Sentido 01 & 3.353 & 60 & VIA 12 - Sentido 02 & 1.999 & 115 \\
\hline VIA 13 - Sentido 01 & 6.621 & 116 & VIA 13 - Sentido 02 & 2.494 & 67 \\
\hline VIA 14 - Sentido 01 & 4.264 & 78 & VIA 14 - Sentido 02 & 4.771 & 105 \\
\hline VIA 15 - Sentido 01 & 6.348 & 25 & VIA 15 - Sentido 02 & 6.232 & 36 \\
\hline VIA 16 - Sentido 01 & 13.610 & 336 & VIA 16 - Sentido 02 & 9.744 & 413 \\
\hline VIA 17 - Sentido 01 & 11.343 & 370 & VIA 17 - Sentido 02 & 12.078 & 348 \\
\hline VIA 18 - Sentido 01 & 13.686 & 147 & VIA 18 - Sentido 02 & 8.240 & 93 \\
\hline VIA 19 - Sentido 01 & 5.834 & 47 & VIA 19 - Sentido 02 & 9.269 & 60 \\
\hline VIA 20 - Sentido 01 & 4.341 & 75 & VIA 20 - Sentido 02 & 2.485 & 83 \\
\hline VIA 21 - Sentido 01 & 5.246 & 67 & VIA 21 - Sentido 02 & 4.500 & 24 \\
\hline
\end{tabular}

Assim como no modelo inicial de estudo, os veículos possuem as características fixas para todos os cenários conforme a Tabela 15.

Tabela 15 - Características fixas dos veículos

\begin{tabular}{ccccc}
\hline Veículo & $\begin{array}{c}\text { Tamanho } \\
{[\mathrm{m}]}\end{array}$ & Vel Máx [km/h] & $\begin{array}{c}\text { Aceleração } \\
{\left[\mathrm{m} / \mathbf{s}^{2}\right]}\end{array}$ & $\begin{array}{c}\text { Desaceleração } \\
{\left[\mathrm{m} / \mathbf{s}^{\mathbf{2}}\right]}\end{array}$ \\
\hline Carro & 5 & 90 & 3,6 & 4 \\
Caminhão & 10 & 60 & 0,9 & 2,5 \\
\hline
\end{tabular}

A diferenciação entre veículos autônomos e convencionais também mantém o padrão do modelo simulado anteriormente e repetido na Tabela 16. 
Tabela 16 - Parâmetros

\begin{tabular}{ccc}
\hline TIPO DE VEÍcULO & $\begin{array}{c}\text { Imperfeição do } \\
\text { motorista }(\boldsymbol{\sigma})\end{array}$ & $\begin{array}{c}\text { Tempo de reação } \\
\text { do motorista (T) }\end{array}$ \\
\hline Convencional & 1 & 3 \\
Autônomo & 0 & 1
\end{tabular}

\subsection{Características dos cenários}

Os três cenários simulados nesta malha, mostrados na Tabela 17, diferem-se com relação ao número de veículos autônomos e convencionais trafegando simultaneamente.

Tabela 17 - Cenários simulados

\begin{tabular}{c|cc|cc}
\hline \multirow{2}{*}{ CENÁRIO } & \multicolumn{2}{|c|}{ CARROS } & \multicolumn{2}{c}{ CAMINHÕES } \\
\cline { 2 - 5 } & Convencionais & Autônomos & Convencionais & Autônomos \\
\hline Convencional & $100 \%$ & - & $100 \%$ & - \\
Autônomo & - & $100 \%$ & - & $100 \%$ \\
Parcial & $50 \%$ & $50 \%$ & $50 \%$ & $50 \%$
\end{tabular}

Como a contagem de veículos do Relatório de Mobilidade no Sistema Viário Principal (CET, 2017) utilizada nesta pesquisa foi feita para o período de pico da manhã (7h as 10h) os cenários também foram executados durante três horas. Por ser um sistema aberto, os veículos entram na malha pelas extremidades da via e deixam o sistema após completarem as viagens.

\subsection{Resultados iniciais e calibração do modelo}

Os primeiros resultados observados são correspondentes ao volume de veículos. Nem todos os veículos conseguiram entrar no sistema durante as 3 horas de simulação. A Tabela 18 e Tabela 19 mostram o número total de veículos que foram inseridos na malha em cada um dos cenários. 
Tabela 18 - Número de veículos por cenário nos Sentidos 01 de cada via

\begin{tabular}{lcccc}
\hline \multicolumn{1}{c}{ Rota } & Convencional & Parcial & Autônomo & $\begin{array}{c}\text { Relatório CET } \\
(\mathbf{2 0 1 7})\end{array}$ \\
\hline VIA 01 - Sentido 01 & 1.576 & 1.995 & 2.699 & 3.049 \\
\hline VIA 02 - Sentido 01 & 2.230 & 2.264 & 2.805 & 4.642 \\
\hline VIA 03 - Sentido 01 & 1.994 & 2.394 & 3.427 & 10.176 \\
\hline VIA 04 - Sentido 01 & 2.369 & 2.751 & 3.586 & 14.653 \\
\hline VIA 05 - Sentido 01 & 2.911 & 3.318 & 3.838 & 6.629 \\
\hline VIA 06 - Sentido 01 & 2.641 & 2.817 & 2.851 & 18.029 \\
\hline VIA 07 - Sentido 01 & 774 & 882 & 889 & 2.524 \\
\hline VIA 08 - Sentido 01 & 1.391 & 1.837 & 2.901 & 5.043 \\
\hline VIA 09 - Sentido 01 & 137 & 779 & 137 & 6.910 \\
\hline VIA 10 - Sentido 01 & 2.321 & 2.918 & 3.572 & 7.998 \\
\hline VIA 11 - Sentido 01 & 1.135 & 1.136 & 1.754 & 3.354 \\
\hline VIA 12 - Sentido 01 & 2.493 & 2.835 & 3.413 & 3.413 \\
\hline VIA 13 - Sentido 01 & 2.325 & 3.326 & 5.153 & 6.737 \\
\hline VIA 14 - Sentido 01 & 2.345 & 3.086 & 4.259 & 4.342 \\
\hline VIA 15 - Sentido 01 & 1.089 & 1.137 & 1.215 & 6.373 \\
\hline VIA 16 - Sentido 01 & 3.485 & 4.096 & 5.400 & 13.946 \\
\hline VIA 17 - Sentido 01 & 3.496 & 4.114 & 5.400 & 11.713 \\
\hline VIA 18 - Sentido 01 & 4.195 & 4.690 & 5.400 & 13.833 \\
\hline VIA 19 - Sentido 01 & 134 & 518 & 134 & 5.881 \\
\hline VIA 20 - Sentido 01 & 3.188 & 3.620 & 4.119 & 4.416 \\
\hline VIA 21 - Sentido 01 & 2.131 & 2.781 & 4.111 & 5.313 \\
\hline TOTAL & 44.360 & 53.294 & $\mathbf{6 7 . 0 6 3}$ & $\mathbf{1 5 8 . 9 7 4}$ \\
\hline
\end{tabular}


Tabela 19 - Número de veículos por cenário nos Sentidos 02 de cada via

\begin{tabular}{lcccc}
\hline Rota & Convencional & Parcial & Autônomo & $\begin{array}{c}\text { Relatório CET } \\
\mathbf{( 2 0 1 7 )}\end{array}$ \\
\hline VIA 01 - Sentido 02 & 1.933 & 2.445 & 2.891 & 2.891 \\
\hline VIA 02 - Sentido 02 & 1.602 & 2.237 & 3.629 & 6.625 \\
\hline VIA 03 - Sentido 02 & 1.082 & 1.097 & 1.098 & 8.227 \\
\hline VIA 04 - Sentido 02 & 4.192 & 5.447 & 5.919 & 9.317 \\
\hline VIA 05 - Sentido 02 & 1.193 & 1.724 & 3.088 & 5.466 \\
\hline VIA 06 - Sentido 02 & 2.350 & 4.243 & 5.400 & 19.197 \\
\hline VIA 07 - Sentido 02 & 1.603 & 2.304 & 2.424 & 3.778 \\
\hline VIA 08 - Sentido 02 & 348 & 2.139 & 348 & 5.186 \\
\hline VIA 09 - Sentido 02 & 1.978 & 2.275 & 3.283 & 7.881 \\
\hline VIA 10 - Sentido 02 & 2.418 & 3.180 & 5.105 & 7.483 \\
\hline VIA 11 - Sentido 02 & 2.330 & 3.393 & 4.327 & 4.327 \\
\hline VIA 12 - Sentido 02 & 2.114 & 2.114 & 2.114 & 2.114 \\
\hline VIA 13 - Sentido 02 & 2.561 & 2.561 & 2.561 & 2.561 \\
\hline VIA 14 - Sentido 02 & 2.245 & 2.873 & 4.044 & 4.876 \\
\hline VIA 15 - Sentido 02 & 2.181 & 2.902 & 4.541 & 6.268 \\
\hline VIA 16 - Sentido 02 & 1.157 & 1.157 & 1.157 & 10.157 \\
\hline VIA 17 - Sentido 02 & 3.483 & 4.121 & 5.400 & 12.426 \\
\hline VIA 18 - Sentido 02 & 171 & 628 & 171 & 8.333 \\
\hline VIA 19 - Sentido 02 & 4.741 & 5.606 & 5.414 & 9.329 \\
\hline VIA 20 - Sentido 02 & 1.673 & 1.985 & 2.568 & 2.568 \\
\hline VIA 21 - Sentido 02 & 74 & 74 & 74 & 4.524 \\
\hline TOTAL & 41.429 & 54.505 & 65.556 & 143.534 \\
\hline
\end{tabular}

Observa-se que nenhum cenário foi capaz de comportar o tráfego do volume total de veículos baseados na CET (2017). O cenário Convencional não foi capaz de absorver a totalidade dos veículos em nenhuma das 42 rotas. $\mathrm{O}$ cenário Parcial atingiu a totalidade dos veículos em apenas 2 rotas e no cenário Autônomo a frota de veículos conseguiu fluir totalmente em 6 rotas.

A diferença no número de veículos pode ser justificada pela simplificação adotada no modelo: todos os veículos entram no sistema pela extremidade da rota e deixam o sistema no final da mesma. Não existe a possibilidade dos veículos saírem do sistema pelas vias perpendiculares à 
considerada, e entende-se que durante o mapeamento da CET (2017) nem todos os veículos entraram e saíram da via mapeada apenas pelas extremidades da via.

Como o objetivo da pesquisa é comparar os resultados de desempenho dos cenários com relação à velocidade média e tempo de viagem, fez-se necessário ajustar a frota de veículos para que todos os cenários tivessem o mesmo volume. As comparações terão como base o cenário atual, onde todos os veículos são convencionais. Adotou-se, como volume padrão, então, as frotas atingidas no cenário Convencional. A Tabela 20 e Tabela 21 mostram os volumes de carros e caminhões a serem considerados em cada rota.

Tabela 20 - Ajuste do número de veículos por tipo e rota para Sentido

\begin{tabular}{lccc}
\hline \multicolumn{1}{c}{ Rota } & Carros & Caminhões & TOTAL \\
\hline VIA 01 - Sentido 01 & 1.562 & 14 & 1.576 \\
\hline VIA 02 - Sentido 01 & 2.208 & 22 & 2.230 \\
\hline VIA 03 - Sentido 01 & 1.994 & 0 & 1.994 \\
\hline VIA 04 - Sentido 01 & 2.369 & 0 & 2.369 \\
\hline VIA 05 - Sentido 01 & 2.911 & 0 & 2.911 \\
\hline VIA 06 - Sentido 01 & 2.641 & 0 & 2.641 \\
\hline VIA 07 - Sentido 01 & 766 & 8 & 774 \\
\hline VIA 08 - Sentido 01 & 1.359 & 32 & 1.391 \\
\hline VIA 09 - Sentido 01 & 136 & 1 & 137 \\
\hline VIA 10 - Sentido 01 & 2.275 & 46 & 2.321 \\
\hline VIA 11 - Sentido 01 & 1.130 & 5 & 1.135 \\
\hline VIA 12 - Sentido 01 & 2.463 & 30 & 2.493 \\
\hline VIA 13 - Sentido 01 & 2.298 & 27 & 2.325 \\
\hline VIA 14 - Sentido 01 & 2.308 & 37 & 2.345 \\
\hline VIA 15 - Sentido 01 & 1.086 & 3 & 1.089 \\
\hline VIA 16 - Sentido 01 & 3.485 & 0 & 3.485 \\
\hline VIA 17 - Sentido 01 & 3.496 & 0 & 3.496 \\
\hline VIA 18 - Sentido 01 & 4.195 & 0 & 4.195 \\
\hline VIA 19 - Sentido 01 & 133 & 1 & 134 \\
\hline VIA 20 - Sentido 01 & 3.144 & 44 & 3.188 \\
\hline VIA 21 - Sentido 01 & 2.114 & 17 & 2.131 \\
\hline
\end{tabular}


Tabela 21 - Ajuste do número de veículos por tipo e rota para Sentido 02

\begin{tabular}{lccc}
\hline Rota & Carros & Caminhões & TOTAL \\
\hline VIA 01 - Sentido 02 & 1.917 & 16 & 1.933 \\
\hline VIA 02 - Sentido 02 & 1.593 & 9 & 1.602 \\
\hline VIA 03 - Sentido 02 & 1.078 & 4 & 1.082 \\
\hline VIA 04 - Sentido 02 & 4.156 & 36 & 4.192 \\
\hline VIA 05 - Sentido 02 & 1.193 & 0 & 1.193 \\
\hline VIA 06 - Sentido 02 & 2.350 & 0 & 2.350 \\
\hline VIA 07 - Sentido 02 & 1.594 & 9 & 1.603 \\
\hline VIA 08 - Sentido 02 & 343 & 5 & 348 \\
\hline VIA 09 - Sentido 02 & 1.956 & 22 & 1.978 \\
\hline VIA 10 - Sentido 02 & 2.362 & 56 & 2.418 \\
\hline VIA 11 - Sentido 02 & 2.318 & 12 & 2.330 \\
\hline VIA 12 - Sentido 02 & 1.999 & 115 & 2.114 \\
\hline VIA 13 - Sentido 02 & 2.494 & 67 & 2.561 \\
\hline VIA 14 - Sentido 02 & 2.204 & 41 & 2.245 \\
\hline VIA 15 - Sentido 02 & 2.174 & 7 & 2.181 \\
\hline VIA 16 - Sentido 02 & 744 & 413 & 1.157 \\
\hline VIA 17 - Sentido 02 & 3.483 & 0 & 3.483 \\
\hline VIA 18 - Sentido 02 & 169 & 2 & 171 \\
\hline VIA 19 - Sentido 02 & 4.712 & 29 & 4.741 \\
\hline VIA 20 - Sentido 02 & 1.620 & 53 & 1.673 \\
\hline VIA 21 - Sentido 02 & 50 & 24 & 74 \\
\hline
\end{tabular}

\subsection{Resultados do modelo}

Por ter um grande número de volume de tráfego, os resultados dos cenários simulados nesta malha são apresentados de forma consolidada por tipo de veículo, via e sentido. Os resultados levantados são relacionados à velocidade média, tempo médio de viagem, e tempo médio em fila.

\subsubsection{Velocidade Média}

As velocidades médias dos carros e caminhões estão apontadas na Tabela 22 e Tabela 23. 
Tabela 22 - Velocidade média dos carros [ $\mathrm{km} / \mathrm{h}]$

\begin{tabular}{ccccccc}
\hline \multirow{2}{*}{ VIA } & \multicolumn{3}{c}{ SENTIDO 01 } & \multicolumn{3}{c}{ SENTIDO 02 } \\
\cline { 2 - 6 } & Convencional & Parcial & Autônomo & Convencional & Parcial & Autônomo \\
\hline VIA 01 & 7 & 7 & 9 & 8 & 12 & 21 \\
VIA 02 & 13 & 17 & 25 & 22 & 25 & 28 \\
\hline VIA 03 & 8 & 10 & 15 & 3 & 4 & 4 \\
VIA 04 & 31 & 33 & 36 & 15 & 29 & 35 \\
\hline VIA 05 & 5 & 5 & 9 & 17 & 21 & 27 \\
\hline VIA 06 & 1 & 2 & 1 & 50 & 53 & 57 \\
VIA 07 & 3 & 4 & 6 & 8 & 8 & 12 \\
\hline VIA 08 & 10 & 16 & 21 & 18 & 22 & 29 \\
\hline VIA 09 & 33 & 36 & 39 & 15 & 17 & 33 \\
\hline VIA 10 & 14 & 16 & 27 & 12 & 18 & 33 \\
\hline VIA 11 & 14 & 17 & 27 & 19 & 20 & 26 \\
\hline VIA 12 & 27 & 36 & 41 & 21 & 32 & 39 \\
VIA 13 & 37 & 39 & 43 & 31 & 34 & 40 \\
VIA 14 & 22 & 27 & 31 & 19 & 25 & 36 \\
\hline VIA 15 & 2 & 2 & 2 & 17 & 19 & 24 \\
VIA 16 & 80 & 83 & 88 & 81 & 84 & 89 \\
\hline VIA 17 & 81 & 84 & 89 & 81 & 84 & 89 \\
VIA 18 & 16 & 35 & 81 & 78 & 84 & 89 \\
VIA 19 & 71 & 75 & 79 & 73 & 77 & 82 \\
VIA 20 & 23 & 26 & 30 & 33 & 36 & 40 \\
VIA 21 & 5 & 8 & 14 & 21 & 23 & 27 \\
\hline
\end{tabular}


Tabela 23 - Velocidade média caminhões [km/h]

\begin{tabular}{ccccccc}
\hline \multirow{2}{*}{ VIA } & \multicolumn{3}{c}{ SENTIDO 01 } & \multicolumn{3}{c}{ SENTIDO 02 } \\
\cline { 2 - 7 } & Convencional & Parcial & Autônomo & Convencional & Parcial & Autônomo \\
\hline VIA 01 & 6 & 8 & 6 & 8 & 13 & 17 \\
VIA 02 & 13 & 17 & 23 & 22 & 24 & 25 \\
\hline VIA 03 & - & - & - & 7 & 15 & 8 \\
VIA 04 & - & - & - & 12 & 28 & 31 \\
\hline VIA 05 & - & - & - & - & - & - \\
\hline VIA 06 & - & - & - & - & - & - \\
VIA 07 & 3 & 5 & 5 & 8 & 10 & 8 \\
\hline VIA 08 & 10 & 16 & 17 & 20 & 25 & 22 \\
VIA 09 & 34 & 38 & 37 & 14 & 16 & 29 \\
\hline VIA 10 & 14 & 15 & 21 & 12 & 16 & 29 \\
VIA 11 & 13 & 18 & 22 & 18 & 21 & 22 \\
VIA 12 & 21 & 26 & 24 & 16 & 24 & 24 \\
VIA 13 & 34 & 37 & 36 & 30 & 33 & 36 \\
VIA 14 & 17 & 23 & 29 & 19 & 25 & 32 \\
\hline VIA 15 & 7 & 13 & 3 & 16 & 18 & 19 \\
VIA 16 & - & - & - & 56 & 57 & 56 \\
\hline VIA 17 & - & - & - & - & - & - \\
VIA 18 & - & - & - & 57 & 57 & 57 \\
VIA 19 & 57 & 59 & 56 & 57 & 58 & 57 \\
VIA 20 & 22 & 26 & 24 & 34 & 38 & 36 \\
VIA 21 & 6 & 9 & 10 & 19 & 21 & 21 \\
\hline
\end{tabular}

Os espaços sinalizados com - na tabela referem-se às vias que não possuem caminhões.

\subsubsection{Tempo médio de viagem}

A Tabela 24 e a Tabela 25 mostram, respectivamente, os tempos médios das viagens realizadas pelos carros e caminhões de cada via em cada um dos cenários. Foi definido como tempo de viagem o tempo necessário para o veículo completar o trajeto da rota a partir do instante em que é inserido no sistema. 
Tabela 24 - Tempo médio de viagem dos carros por via [s]

\begin{tabular}{lcccccc}
\hline \multirow{2}{*}{ VIA } & \multicolumn{3}{c}{ SENTIDO 01 } & \multicolumn{3}{c}{ SENTIDO 02 } \\
\cline { 2 - 7 } & Convencional & Parcial & Autônomo & Convencional & Parcial & Autônomo \\
\hline VIA 01 & 2.985 & 3.501 & 3.668 & 2.206 & 2.108 & 1.111 \\
\hline VIA 02 & 1.999 & 1.529 & 1.007 & 995 & 971 & 867 \\
\hline VIA 03 & 3.851 & 4.172 & 3.507 & 6.914 & 7.027 & 7.177 \\
\hline VIA 04 & 1.033 & 1.017 & 929 & 2.329 & 1.141 & 928 \\
\hline VIA 05 & 4.046 & 4.290 & 3.764 & 1.454 & 1.306 & 1.010 \\
\hline VIA 06 & 6.215 & 6.256 & 7.462 & 811 & 771 & 713 \\
\hline VIA 07 & 5.946 & 6.150 & 4.624 & 2.390 & 2.774 & 1.988 \\
\hline VIA 08 & 2.953 & 2.534 & 1.852 & 2.013 & 1.617 & 1.203 \\
\hline VIA 09 & 1.564 & 1.436 & 1.310 & 3.838 & 3.047 & 1.559 \\
\hline VIA 10 & 2.805 & 2.581 & 1.572 & 2.852 & 2.567 & 1.209 \\
\hline VIA 11 & 2.783 & 2.434 & 1.535 & 1.190 & 1.190 & 922 \\
\hline VIA 12 & 950 & 750 & 653 & 1.302 & 823 & 675 \\
\hline VIA 13 & 766 & 751 & 674 & 926 & 847 & 714 \\
\hline VIA 14 & 1.755 & 1.681 & 1.411 & 1.978 & 1.591 & 1.088 \\
\hline VIA 15 & 6.586 & 7.055 & 7.640 & 1.074 & 1.015 & 812 \\
\hline VIA 16 & 348 & 338 & 320 & 351 & 341 & 321 \\
\hline VIA 17 & 344 & 337 & 319 & 343 & 336 & 317 \\
\hline VIA 18 & 2.638 & 1.382 & 310 & 434 & 403 & 380 \\
\hline VIA 19 & 421 & 401 & 381 & 484 & 461 & 429 \\
\hline VIA 20 & 139 & 127 & 114 & 329 & 311 & 282 \\
\hline VIA 21 & 4.050 & 3.586 & 2.083 & 671 & 620 & 504 \\
\hline
\end{tabular}


Tabela 25 - Tempo médio de viagem dos caminhões por via [s]

\begin{tabular}{ccccccc}
\hline \multirow{2}{*}{ VIA } & \multicolumn{3}{c}{ SENTIDO 01 } & \multicolumn{3}{c}{ SENTIDO 02 } \\
\cline { 2 - 7 } Convencional & Parcial & Autônomo & Convencional & Parcial & Autônomo \\
\hline VIA 01 & 3.218 & 3.570 & 4.465 & 2.337 & 2.240 & 1.292 \\
VIA 02 & 2.022 & 1.603 & 1.143 & 1.041 & 1.006 & 963 \\
\hline VIA 03 & - & - & - & 6.978 & 5.422 & 7.298 \\
VIA 04 & - & - & - & 2.229 & 1.169 & 1.060 \\
\hline VIA 05 & - & - & - & - & - & - \\
\hline VIA 06 & - & - & - & - & - & - \\
VIA 07 & 6.402 & 6.012 & 6.012 & 2.513 & 2.572 & 2.782 \\
\hline VIA 08 & 2.870 & 2.605 & 2.310 & 1.805 & 1.414 & 1.561 \\
VIA 09 & 1.519 & 1.347 & 1.373 & 4.285 & 3.320 & 1.804 \\
\hline VIA 10 & 3.022 & 2.898 & 2.060 & 2.657 & 2.880 & 1.375 \\
VIA 11 & 3.142 & 3.204 & 1.945 & 1.154 & 1.188 & 1.105 \\
VIA 12 & 1.169 & 1.047 & 1.096 & 1.696 & 1.086 & 1.113 \\
VIA 13 & 760 & 777 & 805 & 950 & 865 & 815 \\
\hline VIA 14 & 1.959 & 2.017 & 1.487 & 2.040 & 1.617 & 1.209 \\
\hline VIA 15 & 5.853 & 3.817 & 7.367 & 1.243 & 1.131 & 991 \\
\hline VIA 16 & - & - & - & 506 & 497 & 507 \\
\hline VIA 17 & - & - & - & - & - & - \\
VIA 18 & - & - & - & 594 & 585 & 593 \\
VIA 19 & 527 & 509 & 534 & 609 & 610 & 623 \\
VIA 20 & 142 & 129 & 141 & 319 & 296 & 316 \\
VIA 21 & 3.629 & 3.115 & 2.941 & 705 & 661 & 662 \\
\hline
\end{tabular}

Os espaços sinalizados com - na tabela são referentes às rotas que não possuem caminhões.

\subsubsection{Tempo em fila}

A Tabela 26 e a Tabela 27 mostram o tempo médio dos veículos em fila para carros e caminhões. Nos cenários, além das filas causadas pelo excesso de veículos nas vias, as filas também podem ser causadas pelas paradas feitas em respeito aos tempos semafóricos. Neste modelo, um veículo foi considerado em fila quando sua velocidade é igual ou menor a $0,1 \mathrm{~m} / \mathrm{s}$. 
Tabela 26 - Tempo médio dos carros em fila [s]

\begin{tabular}{ccccccc}
\hline \multirow{2}{*}{ VIA } & \multicolumn{3}{c}{ SENTIDO 01 } & \multicolumn{3}{c}{ SENTIDO 02 } \\
\cline { 2 - 7 } Convencional & Parcial & Autônomo & Convencional & Parcial & Autônomo \\
\hline VIA 01 & 1.800 & 2.226 & 3.023 & 1.115 & 1.116 & 659 \\
\hline VIA 02 & 715 & 605 & 444 & 261 & 280 & 362 \\
\hline VIA 03 & 1.838 & 1.908 & 2.331 & 5.221 & 5.497 & 6.605 \\
\hline VIA 04 & 185 & 210 & 232 & 487 & 238 & 239 \\
\hline VIA 05 & 2.549 & 2.729 & 3.103 & 562 & 517 & 442 \\
\hline VIA 06 & 5.929 & 5.978 & 7.242 & 0 & 0 & 0 \\
\hline VIA 07 & 4.720 & 4.788 & 3.929 & 1.198 & 1.522 & 1.446 \\
\hline VIA 08 & 1.229 & 904 & 1.015 & 681 & 560 & 484 \\
\hline VIA 09 & 277 & 274 & 275 & 1.972 & 1.351 & 461 \\
\hline VIA 10 & 1.164 & 973 & 598 & 1.262 & 978 & 360 \\
\hline VIA 11 & 1.150 & 883 & 589 & 360 & 416 & 411 \\
\hline VIA 12 & 361 & 315 & 309 & 427 & 321 & 316 \\
\hline VIA 13 & 87 & 95 & 98 & 165 & 163 & 149 \\
\hline VIA 14 & 232 & 268 & 398 & 299 & 250 & 242 \\
\hline VIA 15 & 4.680 & 5.419 & 7.217 & 417 & 398 & 384 \\
\hline VIA 16 & 0 & 0 & 0 & 0 & 0 & 0 \\
\hline VIA 17 & 0 & 0 & 0 & 0 & 0 & 0 \\
\hline VIA 18 & 1.696 & 507 & 0 & 0 & 0 & 0 \\
\hline VIA 19 & 0 & 0 & 0 & 0 & 0 & 0 \\
\hline VIA 20 & 43 & 43 & 47 & 60 & 58 & 56 \\
\hline VIA 21 & 2.294 & 2.107 & 1.656 & 213 & 214 & 177 \\
\hline
\end{tabular}


Tabela 27 - Tempo médio dos caminhões em fila [s]

\begin{tabular}{ccccccc}
\hline \multirow{2}{*}{ VIA } & \multicolumn{3}{c}{ SENTIDO 01 } & \multicolumn{3}{c}{ SENTIDO 02 } \\
\cline { 2 - 8 } & Convencional & Parcial & Autônomo & Convencional & Parcial & Autônomo \\
\hline VIA 01 & 1.946 & 2.156 & 3.101 & 1.136 & 1.241 & 625 \\
\hline VIA 02 & 687 & 639 & 375 & 264 & 295 & 276 \\
\hline VIA 03 & - & - & - & 5.015 & 4.053 & 6.032 \\
\hline VIA 04 & - & - & - & 410 & 243 & 217 \\
\hline VIA 05 & - & - & - & - & - & - \\
\hline VIA 06 & - & - & - & - & - & - \\
\hline VIA 07 & 5.065 & 4.549 & 4.515 & 1.275 & 1.386 & 1.616 \\
\hline VIA 08 & 1.107 & 891 & 1.084 & 577 & 439 & 544 \\
\hline VIA 09 & 233 & 266 & 163 & 2.297 & 1.505 & 387 \\
\hline VIA 10 & 1.325 & 1.240 & 661 & 1.083 & 1.129 & 295 \\
\hline VIA 11 & 1.334 & 1.763 & 656 & 331 & 412 & 417 \\
\hline VIA 12 & 436 & 431 & 408 & 517 & 411 & 425 \\
\hline VIA 13 & 83 & 98 & 110 & 173 & 168 & 151 \\
\hline VIA 14 & 275 & 295 & 312 & 293 & 252 & 213 \\
\hline VIA 15 & 4.057 & 2.654 & 6.335 & 549 & 475 & 356 \\
\hline VIA 16 & - & - & - & 0 & 0 & 0 \\
\hline VIA 17 & - & - & - & - & - & - \\
\hline VIA 18 & - & - & - & 0 & 0 & 0 \\
\hline VIA 19 & 0 & 0 & 1 & 0 & 0 & 0 \\
\hline VIA 20 & 42 & 41 & 47 & 50 & 40 & 49 \\
\hline VIA 21 & 1.984 & 1.835 & 2.102 & 233 & 232 & 225 \\
\hline
\end{tabular}

Os valores em branco na tabela referem-se às rotas que não possuem caminhões. Já os valores nulos representam que os caminhões existentes no cenário em média não estiveram parados em filas.

\section{AVALIAÇÃo dos RESUltados do MODELO DE APROXIMAÇÃO DA REALIDADE}

Os valores de velocidade média, tempo médio de viagem e tempo em fila, obtidos nos cenários Convencional, Parcial e Autônomo foram comparados 
neste capitulo seguindo três classificações das vias com relação aos seguintes aspectos:

- Volume de veículos;

- Extensão da via;

- Número de semáforos

Além destas comparações, ao final desta seção detalham-se os comportamentos dos veículos convencionais e autônomos no cenário Parcial.

\subsection{Volume de veículos}

As vias foram segmentadas em 13 faixas de acordo com o volume de veículos (carros e caminhões). A Figura 30 mostra o número de rotas (via/sentido) em cada uma das faixas.

Figura 30 - Número de rotas por faixa de volume de veículos

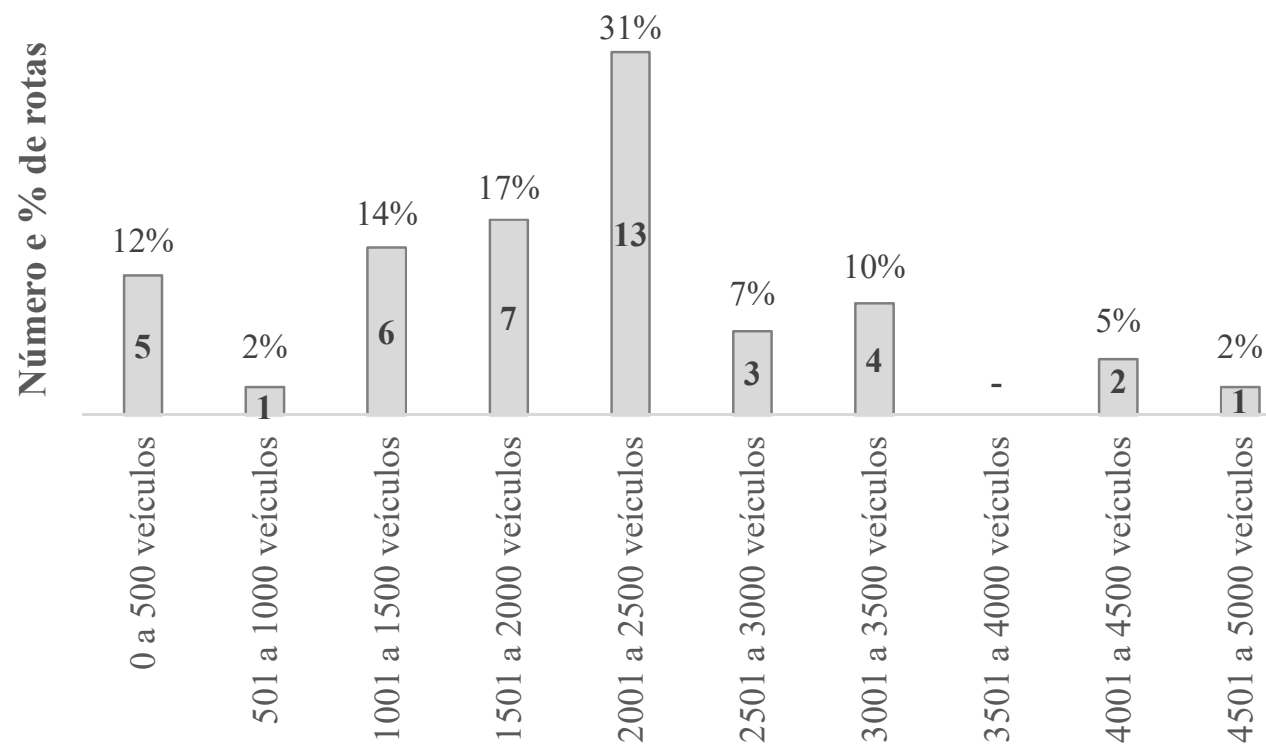

Faixa de volume de veículos

E a Tabela 28 detalha a classificação de cada uma das rotas. 
Tabela 28 - Classificação das rotas por volume de veículos

\begin{tabular}{|c|c|c|c|}
\hline Rota & Faixa de volume & Rota & Faixa de volume \\
\hline VIA 01 - Sentido 01 & 1501 a 2000 & VIA 01 - Sentido 02 & 1501 a 2000 \\
\hline VIA 02 - Sentido 01 & 1501 a 2000 & VIA 02 - Sentido 02 & 1501 a 2000 \\
\hline VIA 03 - Sentido 01 & 1501 a 2000 & VIA 03 - Sentido 02 & 1001 a 1500 \\
\hline VIA 04 - Sentido 01 & 2001 a 2500 & VIA 04 - Sentido 02 & 4001 a 4500 \\
\hline VIA 05 - Sentido 01 & 2501 a 3000 & VIA 05 - Sentido 02 & 1001 a 1500 \\
\hline VIA 06 - Sentido 01 & 2501 a 3000 & VIA 06 - Sentido 02 & 2001 a 2500 \\
\hline VIA 07 - Sentido 01 & 501 a 1000 & VIA 07 - Sentido 02 & 1501 a 2000 \\
\hline VIA 08 - Sentido 01 & 1001 a 1500 & VIA 08 - Sentido 02 & 0 a 500 \\
\hline VIA 09 - Sentido 01 & 0 a 500 & VIA 09 - Sentido 02 & 1501 a 2000 \\
\hline VIA 10 - Sentido 01 & 2001 a 2500 & VIA 10 - Sentido 02 & 2001 a 2500 \\
\hline VIA 11 - Sentido 01 & 1001 a 1500 & VIA 11 - Sentido 02 & 2001 a 2500 \\
\hline VIA 12 - Sentido 01 & 2001 a 2500 & VIA 12 - Sentido 02 & 2001 a 2500 \\
\hline VIA 13 - Sentido 01 & 2001 a 2500 & VIA 13 - Sentido 02 & 2501 a 3000 \\
\hline VIA 14 - Sentido 01 & 2001 a 2500 & VIA 14 - Sentido 02 & 2001 a 2500 \\
\hline VIA 15 - Sentido 01 & 1001 a 1500 & VIA 15 - Sentido 02 & 2001 a 2500 \\
\hline VIA 16 - Sentido 01 & 3001 a 3500 & VIA 16 - Sentido 02 & 1001 a 1500 \\
\hline VIA 17 - Sentido 01 & 3001 a 3500 & VIA 17 - Sentido 02 & 3001 a 3500 \\
\hline VIA 18 - Sentido 01 & 4001 a 4500 & VIA 18 - Sentido 02 & 0 a 500 \\
\hline VIA 19 - Sentido 01 & 0 a 500 & VIA 19 - Sentido 02 & 4501 a 5000 \\
\hline VIA 20 - Sentido 01 & 3001 a 3500 & VIA 20 - Sentido 02 & 1501 a 2000 \\
\hline VIA 21 - Sentido 01 & 2001 a 2500 & VIA 21 - Sentido 02 & 0 a 500 \\
\hline
\end{tabular}

As rotas que possuem entre 4.001 a 4.500 veículos apresentam as maiores melhorias nas velocidades médias com a inclusão crescente dos veículos autônomos, como mostra a Tabela 29 na qual a escala de verde ressalta maior melhoria. Observa-se que em todas as faixas de volume de veículos a inclusão dos veículos autônomos resultou em melhorias na velocidade média. 
Tabela 29 - Comparação percentual das diferenças de velocidade média por faixa de volume de veículos

\begin{tabular}{ccc}
\hline Número de veículos & $\begin{array}{c}\text { PARCIAL vs } \\
\text { CONVENCIONAL }\end{array}$ & $\begin{array}{c}\text { AUTONOMO vs } \\
\text { CONVENCIONAL }\end{array}$ \\
\hline 0 a 500 veículos & $10 \%$ & $25 \%$ \\
501 a 1000 veículos & $31 \%$ & $122 \%$ \\
1001 a 1500 veículos & $19 \%$ & $46 \%$ \\
1501 a 2000 veículos & $18 \%$ & $70 \%$ \\
2001 a 2500 veículos & $25 \%$ & $70 \%$ \\
2501 a 3000 veículos & $16 \%$ & $33 \%$ \\
3001 a 3500 veículos & $7 \%$ & $15 \%$ \\
3501 a 4000 veículos & - & - \\
4001 a 4500 veículos & $103 \%$ & $265 \%$ \\
4501 a 5000 veículos & $5 \%$ & $13 \%$
\end{tabular}

O mesmo padrão é observado quando é feita a comparação entre tempo médio de viagem. Na Tabela 30, a escala em tons de verde destaca as maiores reduções nos tempos de viagem.

Tabela 30 - Comparação percentual das diferenças de tempo médio de viagem por faixa de volume de veículos

\begin{tabular}{ccc}
\hline Número de veículos & $\begin{array}{c}\text { PARCIAL vs } \\
\text { CONVECIONAL }\end{array}$ & $\begin{array}{c}\text { AUTONOMO vs } \\
\text { CONVENCIONAL }\end{array}$ \\
\hline 0 a 500 veículos & $-9 \%$ & $-19 \%$ \\
501 a 1000 veículos & $3 \%$ & $-22 \%$ \\
1001 a 1500 veículos & $-5 \%$ & $-16 \%$ \\
1501 a 2000 veículos & $1 \%$ & $-20 \%$ \\
2001 a 2500 veículos & $-11 \%$ & $-32 \%$ \\
2501 a 3000 veículos & $-1 \%$ & $-3 \%$ \\
3001 a 3500 veículos & $-4 \%$ & $-10 \%$ \\
3501 a 4000 veículos & - & - \\
4001 a 4500 veículos & $-49 \%$ & $-74 \%$ \\
4501 a 5000 veículos & $-5 \%$ & $-11 \%$
\end{tabular}

Quando o foco é o tempo médio em fila, destacam-se como melhores ao acréscimo de veículos autônomos as faixas de 4.001 a 5.000 veículos. As faixas de 3.001 a 3.500 e de 0 a 500 veículos também apresentam bons 
resultados na redução do tempo médio em fila, como mostra a Tabela 31, que tem os tons de verde destacando as maiores reduções.

Tabela 31 - Comparação percentual das diferenças de tempo médio em fila por faixa de volume de veículos

\begin{tabular}{ccc}
\hline Número de veículos & $\begin{array}{c}\text { PARCIAL vS } \\
\text { CONVENCIONAL }\end{array}$ & $\begin{array}{c}\text { AUTONOMO vs } \\
\text { CONVENCIONAL }\end{array}$ \\
\hline 0 a 500 veículos & $-25 \%$ & $-43 \%$ \\
501 a 1000 veículos & $1 \%$ & $-17 \%$ \\
1001 a 1500 veículos & $-17 \%$ & $-8 \%$ \\
1501 a 2000 veículos & $4 \%$ & $4 \%$ \\
2001 a 2500 veículos & $-9 \%$ & $-18 \%$ \\
2501 a 3000 veículos & $2 \%$ & $11 \%$ \\
3001 a 3500 veículos & $-40 \%$ & $-72 \%$ \\
3501 a 4000 veículos & - & - \\
4001 a 4500 veículos & $-61 \%$ & $-75 \%$ \\
4501 a 5000 veículos & $-55 \%$ & $-100 \%$
\end{tabular}

\subsection{Extensão das vias}

A segunda classificação das rotas foi feita com relação às suas extensões. A Figura 31 mostra a distribuição das rotas nas faixas de quilometragem e a Tabela 32 detalha as classificações de cada rota. 
Figura 31 - Número de rotas por faixa de quilometragem

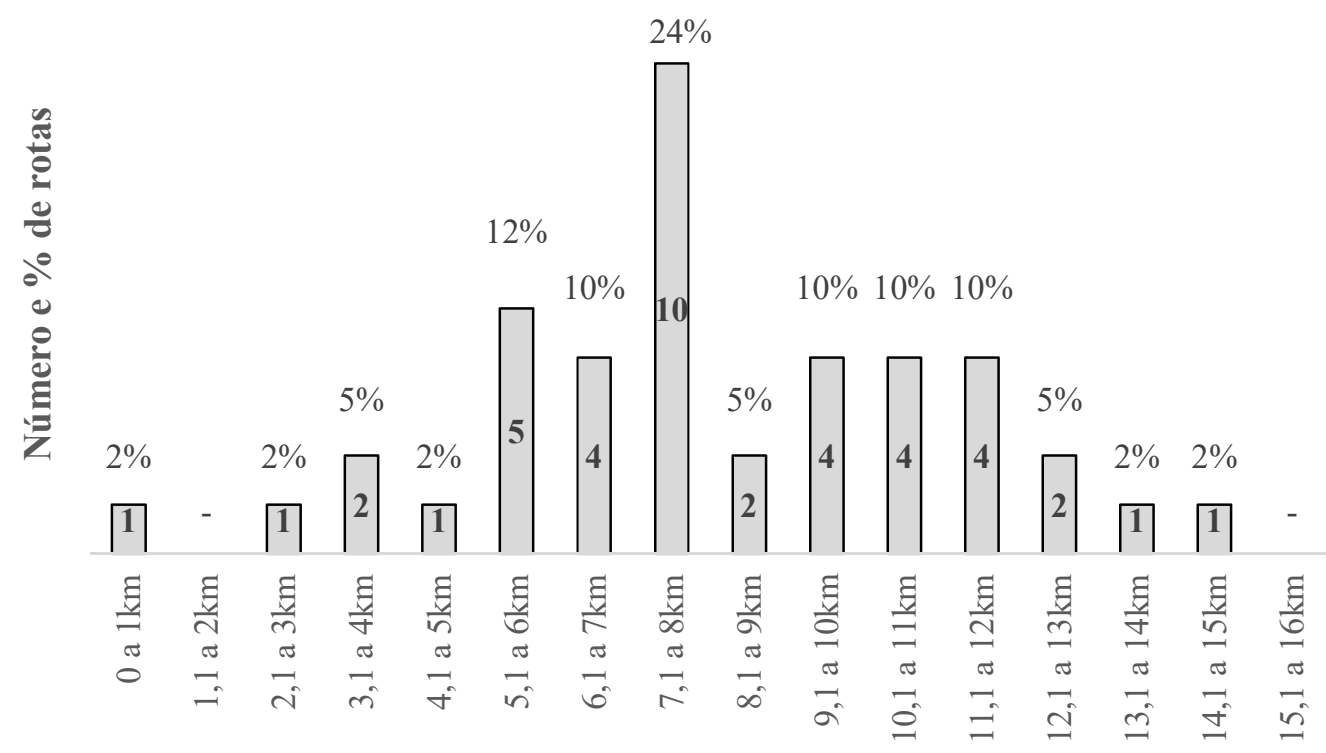

Extensão da rota

Tabela 32 - Classificação das rotas por faixa de quilometragem

\begin{tabular}{|c|c|c|c|}
\hline Rota & Faixa de km & Rota & Faixa de km \\
\hline VIA 01 - Sentido 01 & 4,1 a $5 \mathrm{~km}$ & VIA 01 - Sentido 02 & 5,1 a $6 \mathrm{~km}$ \\
\hline VIA 02 - Sentido 01 & 6,1 a $7 \mathrm{~km}$ & VIA 02 - Sentido 02 & 6,1 a $7 \mathrm{~km}$ \\
\hline VIA 03 - Sentido 01 & 12,1 a $13 \mathrm{~km}$ & VIA 03 - Sentido 02 & 12,1 a $13 \mathrm{~km}$ \\
\hline VIA 04 - Sentido 01 & 9,1 a $10 \mathrm{~km}$ & VIA 04 - Sentido 02 & 8,1 a $9 k m$ \\
\hline VIA 05 - Sentido 01 & 7,1 a $8 \mathrm{~km}$ & VIA 05 - Sentido 02 & 7,1 a $8 \mathrm{~km}$ \\
\hline VIA 06 - Sentido 01 & 11,1 a $12 \mathrm{~km}$ & VIA 06 - Sentido 02 & 11,1 a $12 \mathrm{~km}$ \\
\hline VIA 07 - Sentido 01 & 5,1 a $6 \mathrm{~km}$ & VIA 07 - Sentido 02 & 5,1 a $6 \mathrm{~km}$ \\
\hline VIA 08 - Sentido 01 & 10,1 a $11 \mathrm{~km}$ & VIA 08 - Sentido 02 & 9,1 a $10 \mathrm{~km}$ \\
\hline VIA 09 - Sentido 01 & 14,1 a $15 \mathrm{~km}$ & VIA 09 - Sentido 02 & 13,1 a $14 \mathrm{~km}$ \\
\hline VIA 10 - Sentido 01 & 11,1 a $12 \mathrm{~km}$ & VIA 10 - Sentido 02 & 10,1 a $11 \mathrm{~km}$ \\
\hline VIA 11 - Sentido 01 & 10,1 a $11 \mathrm{~km}$ & VIA 11 - Sentido 02 & 6,1 a $7 \mathrm{~km}$ \\
\hline VIA 12 - Sentido 01 & 7,1 a $8 \mathrm{~km}$ & VIA 12 - Sentido 02 & 7,1 a $8 \mathrm{~km}$ \\
\hline VIA 13 - Sentido 01 & 7,1 a $8 \mathrm{~km}$ & VIA 13 - Sentido 02 & $7,1 \mathrm{a} 8 \mathrm{~km}$ \\
\hline VIA 14 - Sentido 01 & 11,1 a $12 \mathrm{~km}$ & VIA 14 - Sentido 02 & 10,1 a $11 \mathrm{~km}$ \\
\hline VIA 15 - Sentido 01 & 5,1 a $6 \mathrm{~km}$ & VIA 15 - Sentido 02 & 5,1 a $6 \mathrm{~km}$ \\
\hline VIA 16 - Sentido 01 & 7,1 a $8 \mathrm{~km}$ & VIA 16 - Sentido 02 & 7,1 a $8 \mathrm{~km}$ \\
\hline VIA 17 - Sentido 01 & 7,1 a $8 \mathrm{~km}$ & VIA 17 - Sentido 02 & $7,1 \mathrm{a} 8 \mathrm{~km}$ \\
\hline VIA 18 - Sentido 01 & 6,1 a $7 \mathrm{~km}$ & VIA 18 - Sentido 02 & 9,1 a $10 \mathrm{~km}$ \\
\hline VIA 19 - Sentido 01 & 8,1 a $9 \mathrm{~km}$ & VIA 19 - Sentido 02 & 9,1 a $10 \mathrm{~km}$ \\
\hline VIA 20 - Sentido 01 & 0 a $1 \mathrm{~km}$ & VIA 20 - Sentido 02 & 2,1 a $3 \mathrm{~km}$ \\
\hline VIA 21 - Sentido 01 & $3,1 \mathrm{a} 4 \mathrm{~km}$ & VIA 21 - Sentido 02 & 3,1 a $4 \mathrm{~km}$ \\
\hline
\end{tabular}


Analisando as melhorias nas velocidades médias com relação à classificação das quilometragens, nota-se que as rotas de 6,1 a $7 \mathrm{~km}$ são as mais beneficiadas pelo acréscimo de veículos autônomos e que todas as rotas apresentam melhorias, conforme mostra a Tabela 33.

Tabela 33 - Comparação percentual das diferenças de velocidade média por faixa quilometragem

\begin{tabular}{ccc}
\hline Faixa de $\mathbf{k m}$ & $\begin{array}{c}\text { PARCIAL vs } \\
\text { CONVENCIONAL }\end{array}$ & $\begin{array}{c}\text { AUTONOMO vs } \\
\text { CONVENCIONAL }\end{array}$ \\
\hline 0 a $1 \mathrm{~km}$ & $15 \%$ & $32 \%$ \\
0,1 a $2 \mathrm{~km}$ & - & - \\
2,1 a $3 \mathrm{~km}$ & $10 \%$ & $21 \%$ \\
3,1 a $4 \mathrm{~km}$ & $29 \%$ & $96 \%$ \\
4,1 a $5 \mathrm{~km}$ & $1 \%$ & $31 \%$ \\
5,1 a $6 \mathrm{~km}$ & $20 \%$ & $74 \%$ \\
6,1 a $7 \mathrm{~km}$ & $41 \%$ & $137 \%$ \\
7,1 a $8 \mathrm{~km}$ & $14 \%$ & $34 \%$ \\
8,1 a $9 \mathrm{~km}$ & $50 \%$ & $74 \%$ \\
9,1 a $10 \mathrm{~km}$ & $10 \%$ & $24 \%$ \\
10,1 a $11 \mathrm{~km}$ & $38 \%$ & $116 \%$ \\
11,1 a $12 \mathrm{~km}$ & $19 \%$ & $35 \%$ \\
$12,1 \mathrm{a} 13 \mathrm{~km}$ & $20 \%$ & $49 \%$ \\
13,1 a $14 \mathrm{~km}$ & $18 \%$ & $121 \%$ \\
14,1 a $15 \mathrm{~km}$ & $10 \%$ & $19 \%$
\end{tabular}

Quando são comparados os tempos médios de viagem, o mesmo padrão observado na velocidade média ocorre, conforme mostra a Tabela 34 . Através desta análise é possível notar que em todas as faixas de quilometragem o cenário Autônomo apresenta melhoria em relação cenário Convencional. 
Tabela 34 - Comparação percentual das diferenças de tempo médio de viagem por faixa quilometragem

\begin{tabular}{ccc}
\hline Faixa de $\mathbf{k m}$ & $\begin{array}{c}\text { PARCIAL vS } \\
\text { CONVENCIONAL }\end{array}$ & $\begin{array}{c}\text { AUTONOMO vS } \\
\text { CONVENCIONAL }\end{array}$ \\
\hline 0 a $1 \mathrm{~km}$ & $-8 \%$ & $-17 \%$ \\
0,1 a $2 \mathrm{~km}$ & - & - \\
2,1 a $3 \mathrm{~km}$ & $-6 \%$ & $-14 \%$ \\
3,1 a $4 \mathrm{~km}$ & $-9 \%$ & $-33 \%$ \\
4,1 a $5 \mathrm{~km}$ & $6 \%$ & $-13 \%$ \\
5,1 a $6 \mathrm{~km}$ & $5 \%$ & $-12 \%$ \\
6,1 a $7 \mathrm{~km}$ & $-18 \%$ & $-43 \%$ \\
7,1 a $8 \mathrm{~km}$ & $-8 \%$ & $-18 \%$ \\
8,1 a $9 \mathrm{~km}$ & $-28 \%$ & $-35 \%$ \\
9,1 a $10 \mathrm{~km}$ & $-8 \%$ & $-18 \%$ \\
10,1 a $11 \mathrm{~km}$ & $-14 \%$ & $-46 \%$ \\
11,1 a $12 \mathrm{~km}$ & $-4 \%$ & $-14 \%$ \\
12,1 a $13 \mathrm{~km}$ & $5 \%$ & $-3 \%$ \\
13,1 a $14 \mathrm{~km}$ & $-21 \%$ & $-59 \%$ \\
14,1 a $15 \mathrm{~km}$ & $-8 \%$ & $-16 \%$
\end{tabular}

$\mathrm{Na}$ Tabela 35, na qual os tons de verde indicam as maiores diminuições nos tempos médios em fila, é possível perceber uma redução gradual entre as faixas de 5,1 a $13 \mathrm{~km}$, sendo a faixa de 13,1 a $14 \mathrm{~km}$, a com maior redução. Além disso, observa-se que com exceção das faixas 0 a 1km, 4,1 a $6 \mathrm{~km}$ e 12,1 a $13 \mathrm{~km}$, todas apresentaram valores percentuais negativos, o que indica melhoria nos tempos médios em fila. 
Tabela 35 - Diferença percentual do tempo médio em fila por faixa de volume

\begin{tabular}{ccc}
\hline Faixa de $\mathbf{k m}$ & $\begin{array}{c}\text { PARCIAL vs } \\
\text { CONVENCIONAL }\end{array}$ & $\begin{array}{c}\text { AUTONOMO vs } \\
\text { CONVENCIONAL }\end{array}$ \\
\hline 0 a $1 \mathrm{~km}$ & $1 \%$ & $12 \%$ \\
0,1 a $2 \mathrm{~km}$ & - & - \\
2,1 a $3 \mathrm{~km}$ & $-3 \%$ & $-7 \%$ \\
3,1 a $4 \mathrm{~km}$ & $-4 \%$ & $-20 \%$ \\
4,1 a $5 \mathrm{~km}$ & $24 \%$ & $68 \%$ \\
5,1 a $6 \mathrm{~km}$ & $8 \%$ & $2 \%$ \\
6,1 a $7 \mathrm{~km}$ & $-16 \%$ & $-21 \%$ \\
7,1 a $8 \mathrm{~km}$ & $-26 \%$ & $-38 \%$ \\
8,1 a $9 \mathrm{~km}$ & $-54 \%$ & $-61 \%$ \\
9,1 a $10 \mathrm{~km}$ & $-27 \%$ & $-51 \%$ \\
10,1 a $11 \mathrm{~km}$ & $-22 \%$ & $-39 \%$ \\
11,1 a $12 \mathrm{~km}$ & $-14 \%$ & $-14 \%$ \\
12,1 a $13 \mathrm{~km}$ & $4 \%$ & $27 \%$ \\
13,1 a $14 \mathrm{~km}$ & $-32 \%$ & $-77 \%$ \\
14,1 a $15 \mathrm{~km}$ & $-1 \%$ & $-1 \%$
\end{tabular}

\subsection{Número de semáforos}

As rotas foram classificadas de acordo com o número de semáforos que existem. A Figura 32 mostra a quantidade de rotas por faixa de número de semáforos e a Tabela 36 detalha a classificação de cada uma das rotas. 
Figura 32 - Número de rotas por número de semáforos

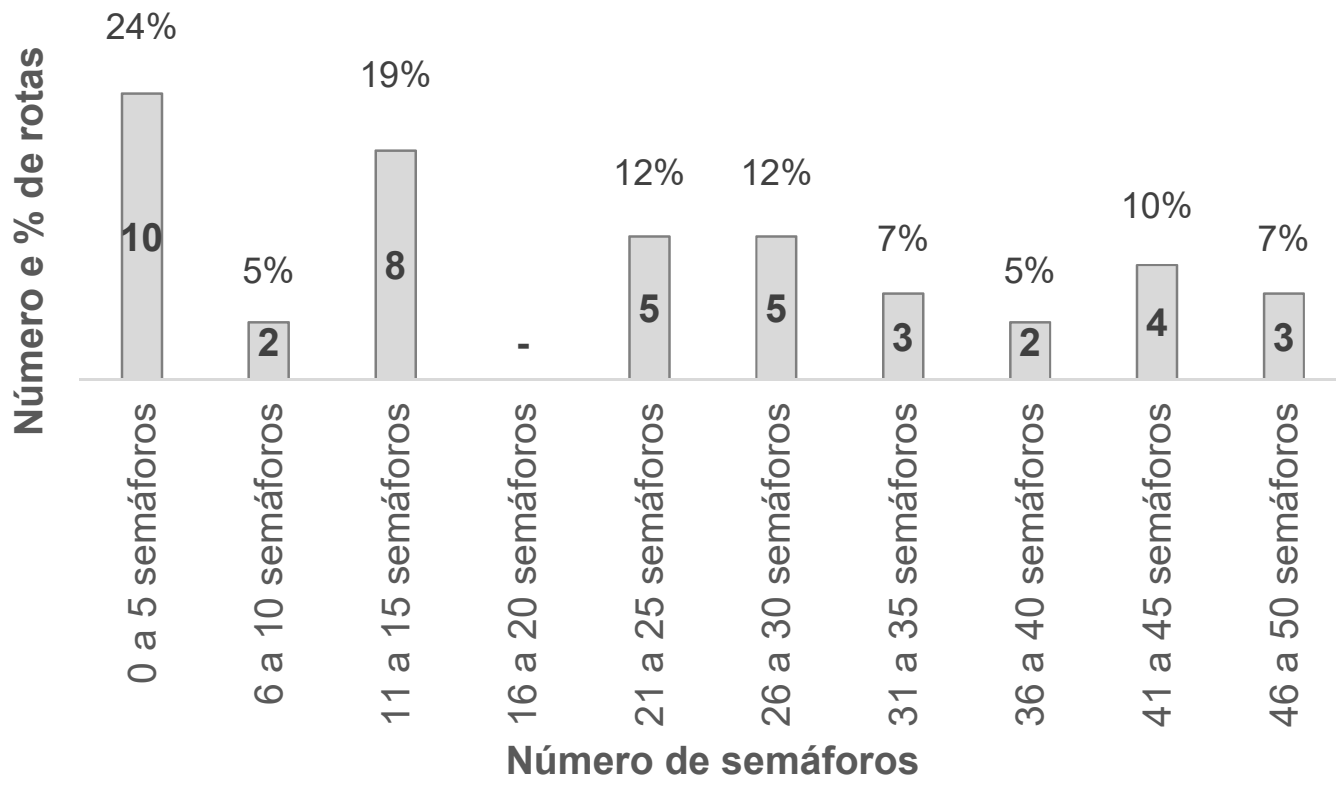

Tabela 36 - Classificação das rotas por número de semáforos

\begin{tabular}{|c|c|c|c|}
\hline Rota & $\begin{array}{l}\text { Número } \\
\text { Semáforos }\end{array}$ & Rota & $\begin{array}{l}\text { Número de } \\
\text { Semáforos }\end{array}$ \\
\hline VIA 01 - Sentido 01 & 21 a 25 semáforos & VIA 01 - Sentido 02 & 31 a 35 semáforos \\
\hline VIA 01 - Sentido 01 & 21 a 25 semáforos & VIA 02 - Sentido 02 & 26 a 30 semáforos \\
\hline VIA 03 - Sentido 01 & 41 a 45 semáforos & VIA 03 - Sentido 02 & 46 a 50 semáforos \\
\hline VIA 04 - Sentido 01 & 11 a 15 semáforos & VIA 04 - Sentido 02 & 11 a 15 semáforos \\
\hline VIA 05 - Sentido 01 & 26 a 30 semáforos & VIA 05 - Sentido 02 & 31 a 35 semáforos \\
\hline VIA 06 - Sentido 01 & 0 a 5 semáforos & VIA 06 - Sentido 02 & 0 a 5 semáforos \\
\hline VIA 07 - Sentido 01 & 31 a 35 semáforos & VIA 07 - Sentido 02 & 36 a 40 semáforos \\
\hline VIA 08 - Sentido 01 & 36 a 40 semáforos & VIA 08 - Sentido 02 & 41 a 45 semáforos \\
\hline VIA 09 - Sentido 01 & 26 a 30 semáforos & VIA 09 - Sentido 02 & 21 a 25 semáforos \\
\hline VIA 10 - Sentido 01 & 21 a 25 semáforos & VIA 10 - Sentido 02 & 21 a 25 semáforos \\
\hline VIA 11 - Sentido 01 & 41 a 45 semáforos & VIA 11 - Sentido 02 & 41 a 45 semáforos \\
\hline VIA 12 - Sentido 01 & 46 a 50 semáforos & VIA 12 - Sentido 02 & 46 a 50 semáforos \\
\hline VIA 13 - Sentido 01 & 11 a 15 semáforos & VIA 13 - Sentido 02 & 11 a 15 semáforos \\
\hline VIA 14 - Sentido 01 & 6 a 10 semáforos & VIA 14 - Sentido 02 & 6 a 10 semáforos \\
\hline VIA 15 - Sentido 01 & 26 a 30 semáforos & VIA 15 - Sentido 02 & 21 a 25 semáforos \\
\hline VIA 16 - Sentido 01 & 0 a 5 semáforos & VIA 16 - Sentido 02 & 0 a 5 semáforos \\
\hline VIA 17 - Sentido 01 & 0 a 5 semáforos & VIA 17 - Sentido 02 & 0 a 5 semáforos \\
\hline VIA 18 - Sentido 01 & 0 a 5 semáforos & VIA 18 - Sentido 02 & 0 a 5 semáforos \\
\hline VIA 19 - Sentido 01 & 0 a 5 semáforos & VIA 19 - Sentido 02 & 0 a 5 semáforos \\
\hline VIA 20 - Sentido 01 & 11 a 15 semáforos & VIA 20 - Sentido 02 & 11 a 15 semáforos \\
\hline VIA 21 - Sentido 01 & 11 a 15 semáforos & VIA 21 - Sentido 02 & 11 a 15 semáforos \\
\hline
\end{tabular}


Todas as rotas apresentam aumentos nas velocidades médias dos veículos e as rotas que possuem de 31 a 35 semáforos, estas melhorias nas velocidades médias são mais expressivas, conforme mostra a Tabela 37, na qual a escala de verde indica maiores melhorias

Tabela 37 - Comparação percentual das diferenças de velocidade média por faixa de número de semáforos

\begin{tabular}{ccc}
\hline $\begin{array}{c}\text { Número de } \\
\text { Semáforos }\end{array}$ & $\begin{array}{c}\text { PARCIAL vs } \\
\text { CONVENCIONAL }\end{array}$ & $\begin{array}{c}\text { AUTÔNOMO vs } \\
\text { CONVENCIONAL }\end{array}$ \\
\hline 0 a 5 semáforos & $19 \%$ & $48 \%$ \\
6 a 10 semáforos & $25 \%$ & $64 \%$ \\
11 a 15 semáforos & $25 \%$ & $55 \%$ \\
16 a 20 semáforos & - & - \\
21 a 25 semáforos & $20 \%$ & $91 \%$ \\
26 a 30 semáforos & $12 \%$ & $42 \%$ \\
31 a 35 semáforos & $32 \%$ & $108 \%$ \\
36 a 40 semáforos & $33 \%$ & $84 \%$ \\
41 a 45 semáforos & $19 \%$ & $68 \%$ \\
46 a 50 semáforos & $32 \%$ & $49 \%$
\end{tabular}

Apesar da notável melhoria nos tempos médios de viagem em todos as faixas de número de semáforos, como mostra a Tabela 38, não é possível associar este parâmetro com o número de semáforos. O número total de semáforos na via e a variação do tempo médio de viagem não apresentam uma relação direta, isto é, não é observada uma correspondência entre o maior ou menor número de semáforos e a maior ou menor melhoria no tempo de viagem. 
Tabela 38 - Comparação percentual das diferenças de tempo médio de viagem por faixa de número de semáforos

\begin{tabular}{lcc}
\hline \multicolumn{1}{c}{$\begin{array}{c}\text { Número de } \\
\text { Semáforos }\end{array}$} & $\begin{array}{c}\text { PARCIAL vs } \\
\text { CONVENCIONAL }\end{array}$ & $\begin{array}{c}\text { AUTONOMO vs } \\
\text { CONVENCIONAL }\end{array}$ \\
\hline 0 a 5 semáforos & $-8 \%$ & $-14 \%$ \\
6 a 10 semáforos & $-12 \%$ & $-32 \%$ \\
11 a 15 semáforos & $-12 \%$ & $-25 \%$ \\
16 a 20 semáforos & - & - \\
21 a 25 semáforos & $-5 \%$ & $-32 \%$ \\
26 a 30 semáforos & $-4 \%$ & $-14 \%$ \\
31 a 35 semáforos & $-4 \%$ & $-34 \%$ \\
36 a 40 semáforos & $1 \%$ & $-27 \%$ \\
41 a 45 semáforos & $-6 \%$ & $-29 \%$ \\
46 a 50 semáforos & $-19 \%$ & $-25 \%$
\end{tabular}

Porém, quando o foco é o tempo médio em fila as rotas mais beneficiadas com o acréscimo do número de veículos autônomos, são as que possuem até 5 semáforos. A Tabela 39 detalha as reduções nos tempos médios em fila. A escala em verde indica as maiores reduções de tempo, ou seja, melhores resultados.

Tabela 39 - Comparação percentual das diferenças de tempo médio em fila por faixa de número de semáforos

\begin{tabular}{lcc}
\hline \multicolumn{1}{c}{$\begin{array}{c}\text { Número de } \\
\text { Semáforos }\end{array}$} & $\begin{array}{c}\text { PARCIAL vs } \\
\text { CONVENCIONAL }\end{array}$ & $\begin{array}{c}\text { AUTONOMO vs } \\
\text { CONVENCIONAL }\end{array}$ \\
\hline 0 a 5 semáforos & $-51 \%$ & $-79 \%$ \\
6 a 10 semáforos & $-1 \%$ & $25 \%$ \\
11 a 15 semáforos & $-5 \%$ & $-7 \%$ \\
16 a 20 semáforos & - & - \\
21 a 25 semáforos & $-12 \%$ & $-32 \%$ \\
26 a 30 semáforos & $5 \%$ & $21 \%$ \\
31 a 35 semáforos & $-8 \%$ & $-33 \%$ \\
36 a 40 semáforos & $-13 \%$ & $-17 \%$ \\
41 a 45 semáforos & $0 \%$ & $-11 \%$ \\
46 a 50 semáforos & $-7 \%$ & $3 \%$
\end{tabular}


Com exceção das rotas com mais de 46 semáforos, todas as rotas apresentam reduções nos tempos médios em fila.

\subsection{Análise detalhada entre os veículos do cenário Parcial}

Ao aumentar o nível de detalhe na análise do Cenário Parcial quando comparando com o cenário convencional, percebe-se que as grandes melhorias nas velocidades médias acontecem para os veículos autônomos. Estes, em média, tiveram uma melhoria de $27 \%$ na velocidade média nas rotas de Sentido 01 e $26 \%$ nas rotas de Sentido 02. Já os veículos convencionais foram beneficiados com a melhoria de apenas $20 \%$ nas rotas de Sentido 01 e $16 \%$ nas rotas de Sentido 02 , como mostra a Tabela 40 e a Tabela 41 . A escala em verde destaca o maior aumento percentual da velocidade média entre os veículos convencionais e autônomos na mesma rota. 
Tabela 40 - Aumento da velocidade média no Sentido 1 de cada via

\begin{tabular}{lcc}
\hline \multicolumn{1}{c}{ ROTA } & $\begin{array}{c}\text { Veículos } \\
\text { Convencionais }\end{array}$ & $\begin{array}{c}\text { Veículos } \\
\text { Autônomos }\end{array}$ \\
\hline VIA 01 - Sentido 01 & $-2 \%$ & $5 \%$ \\
\hline VIA 02 - Sentido 01 & $26 \%$ & $29 \%$ \\
\hline VIA 03 - Sentido 01 & $26 \%$ & $35 \%$ \\
\hline VIA 04 - Sentido 01 & $0 \%$ & $12 \%$ \\
\hline VIA 05 - Sentido 01 & $2 \%$ & $4 \%$ \\
\hline VIA 06 - Sentido 01 & $26 \%$ & $45 \%$ \\
\hline VIA 07 - Sentido 01 & $23 \%$ & $39 \%$ \\
\hline VIA 08 - Sentido 01 & $53 \%$ & $62 \%$ \\
\hline VIA 09 - Sentido 01 & $1 \%$ & $18 \%$ \\
\hline VIA 10 - Sentido 01 & $9 \%$ & $21 \%$ \\
\hline VIA 11 - Sentido 01 & $12 \%$ & $22 \%$ \\
\hline VIA 12 - Sentido 01 & $28 \%$ & $40 \%$ \\
\hline VIA 13 - Sentido 01 & $-2 \%$ & $10 \%$ \\
\hline VIA 14 - Sentido 01 & $21 \%$ & $22 \%$ \\
\hline VIA 15 - Sentido 01 & $6 \%$ & $2 \%$ \\
\hline VIA 16 - Sentido 01 & $0 \%$ & $8 \%$ \\
\hline VIA 17 - Sentido 01 & $0 \%$ & $8 \%$ \\
\hline VIA 18 - Sentido 01 & $121 \%$ & $102 \%$ \\
\hline VIA 19 - Sentido 01 & $0 \%$ & $10 \%$ \\
\hline VIA 20 - Sentido 01 & $9 \%$ & $21 \%$ \\
\hline VIA 21 - Sentido 01 & $50 \%$ & $49 \%$ \\
\hline MÉDIA TOTAL & $\mathbf{2 0 \%}$ & $\mathbf{2 7 \%}$ \\
\hline
\end{tabular}


Tabela 41 - Aumento da velocidade média no Sentido 2 de cada via

\begin{tabular}{|ccc}
\hline ROTA & $\begin{array}{c}\text { Veículos } \\
\text { Convencionais }\end{array}$ & $\begin{array}{c}\text { Veículos } \\
\text { Autônomos }\end{array}$ \\
\hline VIA 01 - Sentido 02 & $37 \%$ & $48 \%$ \\
\hline VIA 02 - Sentido 02 & $10 \%$ & $16 \%$ \\
\hline VIA 03 - Sentido 02 & $1 \%$ & $18 \%$ \\
\hline VIA 04 - Sentido 02 & $86 \%$ & $102 \%$ \\
\hline VIA 05 - Sentido 02 & $18 \%$ & $26 \%$ \\
\hline VIA 06 - Sentido 02 & $0 \%$ & $11 \%$ \\
\hline VIA 07 - Sentido 02 & $7 \%$ & $9 \%$ \\
\hline VIA 08 - Sentido 02 & $16 \%$ & $26 \%$ \\
\hline VIA 09 - Sentido 02 & $13 \%$ & $24 \%$ \\
\hline VIA 10 - Sentido 02 & $41 \%$ & $57 \%$ \\
\hline VIA 11 - Sentido 02 & $6 \%$ & $12 \%$ \\
\hline VIA 12 - Sentido 02 & $45 \%$ & $59 \%$ \\
\hline VIA 13 - Sentido 02 & $7 \%$ & $12 \%$ \\
\hline VIA 14 - Sentido 02 & $26 \%$ & $32 \%$ \\
\hline VIA 15 - Sentido 02 & $10 \%$ & $23 \%$ \\
\hline VIA 16 - Sentido 02 & $-1 \%$ & $6 \%$ \\
\hline VIA 17 - Sentido 02 & $0 \%$ & $8 \%$ \\
\hline VIA 18 - Sentido 02 & $3 \%$ & $12 \%$ \\
\hline VIA 19 - Sentido 02 & $1 \%$ & $9 \%$ \\
\hline VIA 20 - Sentido 02 & $1 \%$ & $18 \%$ \\
\hline VIA 21 - Sentido 02 & $1 \%$ & $16 \%$ \\
\hline MÉDIA TOTAL & $\mathbf{1 6 \%}$ & $\mathbf{2 6 \%}$ \\
\hline
\end{tabular}

O padrão de melhoria para os veículos autônomos também se repete quando o tempo médio de viagem é observado, como mostra a Tabela 42 e a Tabela 43. Em média, os veículos autônomos reduziram seus tempos médios de viagem em 9\% nas rotas de Sentido 01 e em 13\% nas rotas de Sentido 02. Os veículos convencionais em média reduziram seus tempos de viagem em $4 \%$ nas rotas de Sentido 01 e em $6 \%$ nas rotas de Sentido 02 . 
Tabela 42 - Redução do tempo médio de viagem no Sentido 1 de cada

\begin{tabular}{ccc}
\multicolumn{1}{c}{ ROTA } & $\begin{array}{c}\text { Veículos } \\
\text { Convencionais }\end{array}$ & $\begin{array}{c}\text { Veículos } \\
\text { Autônomos }\end{array}$ \\
\hline VIA 01 - Sentido 01 & $19 \%$ & $15 \%$ \\
\hline VIA 02 - Sentido 01 & $-23 \%$ & $-24 \%$ \\
\hline VIA 03 - Sentido 01 & $10 \%$ & $7 \%$ \\
\hline VIA 04 - Sentido 01 & $4 \%$ & $-7 \%$ \\
\hline VIA 05 - Sentido 01 & $6 \%$ & $6 \%$ \\
\hline VIA 06 - Sentido 01 & $1 \%$ & $0 \%$ \\
\hline VIA 07 - Sentido 01 & $5 \%$ & $2 \%$ \\
\hline VIA 08 - Sentido 01 & $-12 \%$ & $-16 \%$ \\
\hline VIA 09 - Sentido 01 & $-1 \%$ & $-16 \%$ \\
\hline VIA 10 - Sentido 01 & $-3 \%$ & $-13 \%$ \\
\hline VIA 11 - Sentido 01 & $-9 \%$ & $-16 \%$ \\
\hline VIA 12 - Sentido 01 & $-17 \%$ & $-25 \%$ \\
\hline VIA 13 - Sentido 01 & $4 \%$ & $-8 \%$ \\
\hline VIA 14 - Sentido 01 & $-4 \%$ & $-4 \%$ \\
\hline VIA 15 - Sentido 01 & $6 \%$ & $8 \%$ \\
\hline VIA 16 - Sentido 01 & $1 \%$ & $-6 \%$ \\
\hline VIA 17 - Sentido 01 & $1 \%$ & $-5 \%$ \\
\hline VIA 18 - Sentido 01 & $-50 \%$ & $-45 \%$ \\
\hline VIA 19 - Sentido 01 & $0 \%$ & $-9 \%$ \\
\hline VIA 20 - Sentido 01 & $-4 \%$ & $-13 \%$ \\
\hline VIA 21 - Sentido 01 & $-13 \%$ & $-10 \%$ \\
\hline MÉDIA TOTAL & $-4 \%$ & $-9 \%$ \\
\hline
\end{tabular}


Tabela 43 - Redução do tempo médio de viagem no Sentido 2 de cada via

\begin{tabular}{ccc}
\hline \multicolumn{1}{c}{ ROTA } & $\begin{array}{c}\text { Veículos } \\
\text { Convencionais }\end{array}$ & $\begin{array}{c}\text { Veículos } \\
\text { Autônomos }\end{array}$ \\
\hline VIA 01 - Sentido 02 & $-1 \%$ & $-8 \%$ \\
\hline VIA 02 - Sentido 02 & $0 \%$ & $-5 \%$ \\
\hline VIA 03 - Sentido 02 & $3 \%$ & $0 \%$ \\
\hline VIA 04 - Sentido 02 & $-49 \%$ & $-53 \%$ \\
\hline VIA 05 - Sentido 02 & $-7 \%$ & $-13 \%$ \\
\hline VIA 06 - Sentido 02 & $0 \%$ & $-10 \%$ \\
\hline VIA 07 - Sentido 02 & $17 \%$ & $14 \%$ \\
\hline VIA 08 - Sentido 02 & $-17 \%$ & $-22 \%$ \\
\hline VIA 09 - Sentido 02 & $-17 \%$ & $-24 \%$ \\
\hline VIA 10 - Sentido 02 & $-5 \%$ & $-14 \%$ \\
\hline VIA 11 - Sentido 02 & $3 \%$ & $-3 \%$ \\
\hline VIA 12 - Sentido 02 & $-34 \%$ & $-40 \%$ \\
\hline VIA 13 - Sentido 02 & $-6 \%$ & $-11 \%$ \\
\hline VIA 14 - Sentido 02 & $-18 \%$ & $-22 \%$ \\
\hline VIA 15 - Sentido 02 & $0 \%$ & $-11 \%$ \\
\hline VIA 16 - Sentido 02 & $0 \%$ & $-5 \%$ \\
\hline VIA 17 - Sentido 02 & $1 \%$ & $-5 \%$ \\
\hline VIA 18 - Sentido 02 & $-3 \%$ & $-11 \%$ \\
\hline VIA 19 - Sentido 02 & $-1 \%$ & $-8 \%$ \\
\hline VIA 20 - Sentido 02 & $1 \%$ & $-12 \%$ \\
\hline VIA 21 - Sentido 02 & $-1 \%$ & $-13 \%$ \\
\hline MÉDIA TOTAL & $-6 \%$ & $-13 \%$ \\
\hline
\end{tabular}

\section{CONCLUSÃo}

Neste trabalho, foram simulados dois modelos de tráfego em duas malhas logísticas diferentes. O modelo inicial foi construído com uma malha fictícia, circular com pistas simples para circulação dos veículos. A análise dos resultados mostra que os parâmetros configurados para distinguir os veículos convencionais dos veículos autônomos, de fato, geram comportamentos diferentes nos veículos o que reforçaram o tipo de configuração adotado. Além disso, é possível verificar que os fatores de velocidade média, distância 
percorrida e tempo total em fila não melhoram uniformemente de acordo com o acréscimo da proporção de veículos autônomos no sistema.

O segundo passo do trabalho foi utilizar um modelo mais próximo da realidade. As vias modeladas correspondem a algumas vias da região metropolitana da cidade de São Paulo. Com base em dados de volumes de tráfego da Companhia de Engenharia de Tráfego, disponibilizou-se um montante de veículos a percorrerem as vias. Nos três cenários simulados Convencional, Parcial e Autônomo, nem todos os veículos puderam entrar no sistema, devido à simplificação do modelo em que cada veículo deve, obrigatoriamente, entrar e sair do sistema apenas pelas extremidades das vias. Assim, fez-se necessário reconfigurar o modelo para possuir o número total de veículos que o cenário Convencional foi capaz de absorver. Assim, as simulações foram feitas com 3 horas de duração e os resultados de velocidade média, tempo médio de viagem e tempo em fila foram analisados sob os aspectos de volume de veículos, extensão das vias e número de semáforos.

A análise com o número de veículos mostra que nas rotas com um baixo número de veículos não se observa uma grande melhoria na velocidade média, tempo médio de viagem e tempo em fila. Estes resultados melhoram com o aumento gradual do número de veículos. Pode-se concluir que em uma via com menor volume, os veículos possuem mais espaço livre para trafegar, então o movimento de um veículo não é totalmente dependente dos veículos ao seu redor. Já numa via com muito veículos todos os veículos interferem no movimento de todos. Um veículo não pode atingir sua velocidade máxima e torna-la constante, pois existem outros veículos compartilhando a mesma via. Se um veículo reduz sua velocidade por algum motivo, os veículos que estão 
atrás dele são influenciados e obrigados a reduzirem suas velocidades também.

Como os veículos autônomos possuem características aprimoradas de velocidade e distância do veículo a frente, quando existe um grande número de veículos trefegando na via os benefícios da inserção de veículos autônomos no sistema gera melhorias mais representativas na velocidade média, tempo de viagem e tempo em fila.

A análise individual da extensão das vias não é suficiente para observar um padrão nas taxas de melhoria. Observa-se apenas que o tempo médio em fila tem seus valores menos representativos na menor e maior faixa de quilometragem.

Classificando as vias pelo número de semáforos o tempo médio em fila tem suas melhores taxas de melhorias nas rotas que possuem até 5 semáforos. Como premissa deste estudo, todos os veículos devem respeitar os tempos semafóricos de trafego e parada. Assim, quando não existem semáforos na via, os veículos não são forçados a pararem a não ser que seja para evitar colisões com o veículo a frente. Quando existe um grande número de semáforos, os veículos não possuem total liberdade para trafegarem nas vias sem serem forçados a reduzir sua velocidade. Assim, pode-se esperar que o tráfego nas vias de trânsito rápido, sem semáforos ou cruzamentos, serão mais beneficiados com a inclusão dos veículos autônomos.

Considerando as análises apresentadas conclui-se então que apesar das taxas de melhorias das velocidades médias, tempo médio de viagem e tempo em fila serem diferentes quando analisadas sob as classificações de 
faixas definidas de volume de veículos, extensão das vias e número de semáforos, é incontestável que os cenários Parcial e Autônomo apresentam melhorias significativas quando comparados ao cenário Convencional.

Além destas análises comparativas entre os três cenários, através da comparação entre os veículos autônomos e convencionais do cenário Parcial (veículos convencionais e autônomos) e Convencional (apenas veículos convencionais), nota-se que os veículos autônomos possuem maiores velocidades médias e menores tempos de viagem e em filas. Ou seja, quando os veículos autônomos começarem a surgir nas vias, os motoristas de veículos convencionais não terão a mesma percepção de melhoria de velocidade, tempo de fila e tempo de viagem, como os usuários dos veículos autônomos que serão os mais beneficiados no período de transição entre o uso de veículos convencionais e autônomos. Apesar disso, a analise total do cenário Parcial (considerando os veículos autônomos e convencionais) apresenta melhorias em relação ao cenário Convencional.

Pode-se concluir em resumo que independente da proporção de veículos autônomos inseridos no sistema (cenário parcialmente autônomo ou totalmente autônomo), os resultados obtidos se apresentam vantajosos com relação às maiores velocidades médias, menores tempos de viagem e menores tempos em fila, mesmo que estas melhorias sejam observadas de forma uniforme no tráfego, ou seja, algumas rotas, dependendo da sua extensão, volume de veículos e número de semáforos podem sofrer poucas melhorias com a operação de veículos autônomos. 


\section{PESQUISAS FUTURAS}

Conforme mencionado anteriormente, uma das vantagens de trabalhar com simuladores é a relativa facilidade em criar cenários (“E se?”). Assim, como possibilidade de futuras pesquisas, é interessante modificar a forma como os veículos entram e deixam o sistema modelado para aproximar ainda mais o modelo de simulação com o ambiente real.

Outro aspecto que pode trazer resultados relevantes é a alteração dos parâmetros definidos para cada tipo de veículo (velocidade máxima, aceleração, distância entre veículos e imperfeição do motorista). No modelo de simulação deste trabalho, foi considerado que não existe a possibilidade de colisões e que o veículo comandado por motoristas mantém a distância do veículo a frente, maior que os veículos convencionais. É interessante investigar o desempenho do sistema quando alguns veículos convencionais alterarem esta distância, simulando o comportamento agressivo e imprudente de alguns motoristas.

Sobre a caracterização das vias, neste trabalho foi considerado que todas as vias são livres. Não foram simulados casos como veículos parados na pista por falha mecânica ou outros problemas, e veículos estacionados nas vias, obstruindo então um ponto de passagem. Para aproximar ainda mais o modelo da realidade, seria interessante investigar como os dois tipos de veículos se comportariam nestas situações.

Outro ponto que não foi abordado nesta pesquisa é a presença de pedestres nas travessias das vias. É muito pertinente investigar como os 
veículos autônomos se comportarão com relação aos pedestres que atravessem as vias fora dos lugares sinalizados. 


\section{REFERÊNCIAS BIBLIOGRÁFICAS}

AZMAT, M. Future Scenario: self-driving cars - the future has already begun. Conference paper, DOI:10.13140/RG.2.1.3143.6965. Maio, 2015.

BOSE, A.; IOANNOU, P. A. Analysis of traffic flow with mixed manual and semiautomated vehicles. IEEE Transactions on Intelligent Transportation Systems, v. 4, n. 4, p. 173-188, 2003.

CADILLAC. Cadillac to expand Super Cruise across entire lineup. Nova Iorque, 2018. Disponível em < https://media.cadillac.com/media/us/en/cadillac/home.detail.html/content/Pages/ news/us/en/2018/jun/0606-its-cadillac.html>. Acesso em 07 de fevereiro de 2019.

CARVALHO, L. S. Modelagem e simulação: ponderosa ferramenta para otimização de operações logísticas. Salvador, 2003.

CET, 2017. Pesquisa de monitoração da mobilidade: Mobilidade no Sitema Viário Principal. Volume e Velocidade 2016. Companhia de Enegenharia de Tráfego, CET. Junho, 2017

CHEN, T. D.; KOCKELMAN, K. M.; HANNA, J. P. Operations of a shared, autonomous, electric vehicle fleet: Implications of vehicle \& charging infrastructure decisions. Transportation Research Part A: Policy and Practice, v. 94, p. 243-254, 2016.

CHWIF, L.; MEDINA, A. C. Modelagem e simulação de eventos discretos. 3a edição. São Paulo, 2010.

Comissão Europeia. Internet of things: Connected Cars. Case Study 43. Business Inovation. União Europeia, 2015.

DANIEL, A. et al. Cooperative Intelligence of Vehicles for Intelligent Transportation Systems (ITS). 2015.

Departamento Nacional de Infra-Estrutura de Transportes - DNIT. Manual de projeto de intersecções. Instituto de Pesquisas Rodoviárias. $2^{a}$ edição. Rio de Janeiro, 2005.

FERNANDES, V. A, et al. Resiliência da mobilidade urbana: Uma proposta conceitual. XXIX Congresso Nacional de Pesquisa em Transporte da ANPET. p2759-2770. Ouro Preto, 2015.

FREITAS FILHO, P. J. Introdução à modelagem e sistemas de simulação. $2^{a}$ edição. Florianópolis, Santa Catarina. Visual Books, 2008.

GAVIRA, M. O. Simulação computacional como uma ferramenta de aquisição de conhecimento. Tese de Doutorado. Escola de Engenharia de São Carlos da Universidade Federal de São Paulo. Universidade de São Paulo, São Carlos. 2003. 
HALLMANN, H. V. Comparação entre softwares simuladores de trânsito. 2011. 104 p. TCC (Graduação) - Curso de Ciência da Computação, Instituto de Informática, Universidade Federal do Rio Grande do Sul, Porto Alegre, 2011.

HARDING, A. Rio Tinto adota caminhões sem motorista e reduz custos na Austrália. Folha de São Paulo, 24 de outubro de 2015. Disponível em< http://www1.folha.uol.com.br/mercado/2015/10/1697985-rio-tinto-adotacaminhoes-sem-motorista-e-reduz-custos-na-australia.shtml>. Acesso em 13 de junho de 2016.

KELTON, W. D. Simulation with Arena. 2nd Edition. McGraw-hill, 2002.

KHAN, A. M, et al, Automation in driving for enhancing resiliency in transportation system. Resilient Infrastructure. Londres, 2016.

KRAUSS, S. Microscopic modeling of trafic flow: Investigation of collision free vehicle dynamics. Tese de Doutorado. Londres. 1998.

LEKSONO, C. Y, ADRIYANA, T (2012) Roundabout microsimulation using SUMO: A case study in Idrottsparken Roundabout Norrkoping Sweden. Universidade de Linkoping. Departamento de Ciência e Tecnologia.

LOBÃO, E. C.; PORTO, A. J. V. Evolução das técnicas de simulação. Production, v. 9, n. 1, p. 13-21, 1999.

MARTINS, R. É justo aumentar o preço das tarifas de transporte público? Revista Exame. Agosto, 2017. Disponível em < https://exame.abril.com.br/brasil/e-justo-aumentar-o-preco-das-tarifas-detransporte-publico/>. Acesso em 08 de janeiro de 2019

MAURER, M. et al. Autonomous driving: technical, legal and social aspects. Springer Publishing Company, Incorporated, 2016.

MCGEHEE, D. V. et al. Review of Automated Vehicle Technology: Policy and Implementation Implications. 2016.

MILLER-HOOKS, E.; ZHANG, X.; FATURECHI, R. Measuring and maximizing resilience of freight transportation networks. Computers \& Operations Research, v. 39, n. 7, p. 1633-1643, 2012.

NAÇÕES UNIDAS. World's population increasingly urban with more than half living in urban areas. Nova lorque, 2014. Disponível em < http://www.un.org/en/development/desa/news/population/world-urbanizationprospects-2014.html>. Acesso em 19 de setembro de 2017.

NHTSA Natioal Higway Traffic Safety Adminsitration. U.S. Department of transportation releases policy on automated vehicle development. Disponível em:

<http://www.nhtsa.gov/About+NHTSA/Press+Releases/U.S.+Department+of+Tr ansportation+Releases+Policy+on+Automated+Vehicle+Development>. Acesso em 05 de junho de 2016.

PANTER, D. Bus operations in the autonomous world. 2018. Disponível em < https://www.trapezegroup.com.au/ee_assets/d/Trapeze-Whitepaper-Bus- 
Operations-in-the-Autonomous-World-2018.pdf>. Acesso em 08 de janeiro de 2019.

PARAVISI, M.; MUSSE, S. R.; BICHO, A. L. Modelagem e simulação do tráfego de veículos e controle semafórico em um ambiente virtual. Vetor, Rio Grande, v16, n.2, p. 16-37, 2006.

PETTERSSON, I.; KARLSSON, I. C. M.. Setting the stage for autonomous cars: a pilot study of future autonomous driving experiences. IET intelligent transport systems, v. 9, n. 7, p. 694-701, 2015.

RENAULT, Autonomous Driving: Renault NEXT TWO, for an affordable, hyperconnected mobile lifestyle. Fevereiro, 2014. Disponível em: $<$ media.renault.com/download/media/specialfile/54698_1_5.aspx>. Acesso em 02 de julho de 2016.

SAE, Society of Automotive Engineers. Automated driving: levels os driving automation are defined in new SAE international standard. J3016. Novembro, 2017. Avaiable at < https://web.archive.org/web/20161120142825/http://www.sae.org/misc/pdfs/aut omated_driving.pdf>.

SANTOS, P. N. M.; CAMARGO JUNIOR, J. B.; VISMARI, L. F. Uma proposta de análise do impacto dos veículos autônomos sobre aspectos logísticos do sistema viário atual. In: Congresso de Pesquisa e Ensino em Transporte da ANPET, 32., 2018, Gramado. Anais... Gramado, 2018. p. 3450-3461.

SANTOS, R. S.; PAQUEROTE, W. A.; SOARES, W. K S. Simulação de trânsito e semáforos: um estudo de caso em um trecho do entorno do campus da UFRN. XLVII Simpósio Brasileiro de Pesquisa Operacional. Porto de Galinhas, Pernambuco. 2015. Disponível em <http://cdsid.org.br/sbpo2015/wpcontent/uploads/2015/08/142661.pdf>. Acesso em 10 de novembro de 2016.

SCANIA, Autonomous transport solutions open up a world of opportunities. Maio, 2016. Disponível em: <https://www.scania.com/group/en/autonomoustransport-solutions-open-up-a-world-of-opportunities/>. Acesso em 13 de julho de 2016.

SCHANK J. et al. Preparing a nation for autonomous vehicles: Opportunitties, barriers and policy recommendations. ENO Center for Transportation. Washington, DC 2012.

SCHOETTLE, B.; SIVAK, M. Potential impact of self-driving vehicles on household vehicle demand and usage. 2015.

SUMO. SUMO Main page. Disponível em: < http://sumo.dlr.de/wiki/Simulation_of_Urban_MObility_-_Wiki>. Acesso em 17 de março de 2017.

SUMO. User documentation. German Aerospace Center, Institute of Transportation Systems. Janeiro, 2019. Disponível em < http://sumo.sourceforge.net/userdoc/Sumo_at_a_Glance.html >. Acesso em 07 de fevereiro de 2019. 
SILVA, P. C. M. Teoria do fluxo de tráfego. Apostila, Universidade de Brasília, Brasília, Brasil, 2001.

SIVAK, M.; SCHOETTLE, B. Road safety with self-driving vehicles: General limitations and road sharing with conventional vehicles. University of Michigan. Transportation Research Institute. 2015.

SOUSA, L. A. P, Taxas de desaceleração e tempos de percepção e reação dos motoristas em intersecções semaforizadas. Dissertação de Mestrado. Programa de Engenharia de Transportes. Programa de Pós-Graduação de Engenharia de Transportes da Universidade Federal do Rio de Janeiro. Rio de Janeiro, 2011.

SURDEN, H. WILLIAMS, M. A. How self-driving cars work. Junho, 2016. Disponível em: <http://papers.ssrn.com/sol3/Papers.cfm?abstract_id=2747491>. Acesso em 07 de junho de 2016.

TOYOTA, New Toyota test vehicle paves the way for commercialization of automated highway driving technologies. Outubro, 2015. Disponível em $<$ http://newsroom.toyota.co.jp/en/detail/9753831>. Acesso em 13 de julho de 2016.

VARAIYA, P. Smart cars on smart roads: problems of control. IEEE Transactions on automatic control, v. 38, n. 2, p. 195-207, 1993.

TRAPEZE GROUP, Milestone: Autonomous Bus Integrated with Schaffhausen's Control System. 2018. <https://www.trapezegroup.com.au/resources/article-milestone-autonomousbus-integrated-with-schaffhausens-control-syst>. Acesso em 08 de janeiro de 2019.

WAGNER, P. Traffic control and traffic management in a transportation system with autonomous vehicles. In: Autonomous Driving. Springer Berlin Heidelberg, 2016. p. 301-316. 